\title{
WestVirginiaUniversity
}

THE RESEARCH REPOSITORY @ WVU

Graduate Theses, Dissertations, and Problem Reports

2017

\section{Radial Growth Patterns in Trees Surviving Canopy Gap Disturbances}

Ruth A. Stetler

Follow this and additional works at: https://researchrepository.wvu.edu/etd

\section{Recommended Citation}

Stetler, Ruth A., "Radial Growth Patterns in Trees Surviving Canopy Gap Disturbances" (2017). Graduate Theses, Dissertations, and Problem Reports. 6724.

https://researchrepository.wvu.edu/etd/6724

This Thesis is protected by copyright and/or related rights. It has been brought to you by the The Research Repository @ WVU with permission from the rights-holder(s). You are free to use this Thesis in any way that is permitted by the copyright and related rights legislation that applies to your use. For other uses you must obtain permission from the rights-holder(s) directly, unless additional rights are indicated by a Creative Commons license in the record and/ or on the work itself. This Thesis has been accepted for inclusion in WVU Graduate Theses, Dissertations, and Problem Reports collection by an authorized administrator of The Research Repository @ WVU. For more information, please contact researchrepository@mail.wvu.edu. 


\title{
Radial Growth Patterns in Trees Surviving Canopy Gap Disturbances
}

\author{
Ruth A. Stetler \\ Thesis submitted to \\ The Eberly College of Arts and Sciences \\ at West Virginia University
}

In partial fulfillment of the requirements of the degree of

Master of Arts in

Geography

Amy Hessl, Ph.D., Chair

Thomas Saladyga, Ph.D.

Brenden McNeil, Ph.D.

Department of Geology and Geography

Morgantown, West Virginia

2017

Keywords: tree-ring research, disturbance ecology, eastern North America, paleoecology, TRADER Copyright 2017 Ruth Stetler 


\begin{abstract}
Radial Growth Patterns in Trees Surviving Canopy Gap Disturbances

Ruth Stetler
\end{abstract}

Forest disturbance regimes in eastern North America have long been conceptualized as localized gap disturbances, but recent studies suggest that more widespread, infrequent disturbance events may also be important. However, uncertainties in tree-ring methods used to detect disturbance, and in the factors that drive growth release of trees, limit the conclusions that can be drawn from regional disturbance analyses. I designed a study to further elucidate forest disturbance dynamics in eastern North America by using two approaches: 1) a case study examining the sensitivity of the radial growth averaging method of detecting disturbance and the factors influencing detection of a known disturbance event, and 2) a regional-scale study using publicly available tree-ring data to explore disturbance regimes of eastern North America and the possibility of spatial and temporal synchrony in disturbance across the region. The case study revealed strong variation in the number and timing of disturbances detected with different thresholds and window criteria required by radial growth averaging. A threshold of $50 \%$ growth change, with symmetrical 15 year windows is suggested for future tree-ring reconstructions of disturbance history. Furthermore, intermediate and suppressed individuals may be more likely to respond strongly to canopy disturbance than overstory trees. Regional disturbance analysis suggested periods of elevated disturbance across eastern North America, including 1690-1710, 1774-1780, 1880-1900, and 1920-1936. Anthropogenic influence in the region was highlighted in the past 140 years, likely caused by widespread logging, damage from introduced pathogenic organisms, and finally forest protection efforts post-1930. These findings suggest the importance of further study regarding the interaction between anthropogenic disturbance and disturbance events driven by stochastic climate anomalies. 


\section{ACKNOWLEDGEMENTS}

I would like to thank my committee members for their support. Thank you for good advice and ample inspiration, as well as for patiently steering me away from the instinct to go down every rabbit hole I came across. Thanks to Amy Hessl, my advisor, for holding me to the highest academic standard, pushing me to expand my coding and analytical abilities, while also teaching me that 'everyone's data has problems.' I don't think I could even begin to express how much I have learned from being a part of your lab. To Tom Saladyga, thank you for lending me your ninja chainsaw skills in the field and for much-needed encouragement regarding my future job prospects. To Brenden McNeil, thanks for trusting me with your photo equipment and analysis software so I could travel down several particularly interesting rabbit holes. I only wish I had more time to explore them.

Much of this project would not have been possible without the help I received in the field and in the lab. High fives to Alex Dye and Matthew Hoffman for sweating in the field with me, without you my fieldwork would certainly have taken ages! For their careful work on my samples, thanks to Taryn Pifer and Morgan Leef. To lab mates Shawn Cockrell, Kristen de Graauw, Alex Dye, and Jennie Zhu: thanks for keeping me company in the lab, collaborating on this ongoing monstrous 'fuzzy boots' regional disturbance project, and for patiently answering nearly a thousand questions about trees, crossdating, $R$, academia, life, etc.

I would like to thank the various people who listened and responded to my many calls and emails while I was looking for potential study sites. Thank you for your cooperation, and for your interest in sharing your knowledge and property for the sake of science and forest ecology! Special thanks to Sam Cowell at Carnifex Ferry Battlefield State Park, for unending patience and hospitality during my many visits to Summersville, WV. Also, for enthusiastically sharing National Park Service data, personal experience, and expertise regarding my study sites, thanks to John Perez and Layne Strickler. May your passion for forests never cease inspiring others as it did me.

Last but not least, I offer my gratitude to the diverse group of people who made up my support system during the last two years. Thanks to my family and my partner in life as well as all things science and adventure, Matt. You never once gave up on me. Thanks to my roommates, office and lab mates, who offered support and friendship. Finally, to the incredible staff and members of the graduate student group over at the WVU Carruth Center, with the utmost sincerity, I thank you for being an understanding and compassionate presence throughout the most challenging moments of my degree. I cannot imagine getting through the last two years without you all. 


\section{Table of Contents}

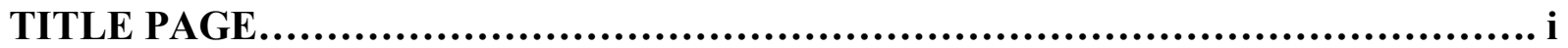

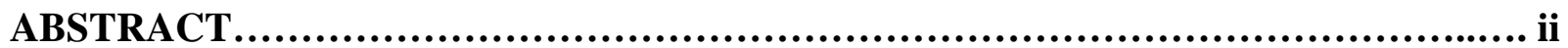

ACKNOWLEDGEMENTS................................................................ iii

Table of Contents..................................................................... iv

List of Tables............................................................................ vi

List of Figures................................................................... vii

\section{CHAPTER 1. Assessing the Sensitivity of Eastern Broadleaf Forests to Past Disturbance}

\section{Events}

Introduction.............................................................................. 1

Methods and Analysis................................................................ 5

Study Area

Dendroecological Sampling Design

Light Availability Sampling Design

Sample Preparation and Data Analysis

Results............................................................................... 14

Sensitivity Analysis of Radial Growth Averaging Method

Radial Growth Response to 2012 Derecho

Response to Light Availability

Discussion.

Sensitivity of Growth Release Criteria

Radial Growth Response to 2012 Derecho

Conclusions

Figures and Tables................................................................... 26

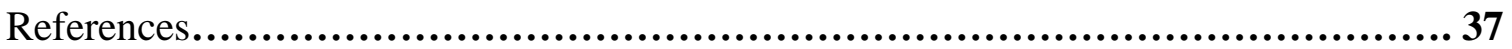

Supplemental Materials

A. Examples of Light Data Results.........................................43

B. Plots of Series and Chronologies......................................... 44

C. Summary of Outer Ring Dates of Gapmakers.............................. 52 


\section{CHAPTER 2. Exploring Mesoscale Disturbance in Eastern North American Forests}

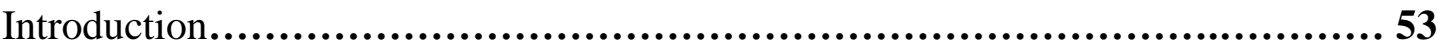

Methods and Analysis................................................................55

Tree Ring Data Retrieval from the ITRDB

Site Level Disturbance Analysis

Assessment of Regional Synchrony

Results.............................................................................61 61

Disturbance Regimes of Eastern North American Forests

Spatial and Temporal Synchrony

Discussion...........................................................................63

Comparing Disturbance Regimes of Eastern North American Forests

Evidence of Spatial and Temporal Synchrony

Conclusions.......................................................................... 70

Figures and Tables................................................................... 72

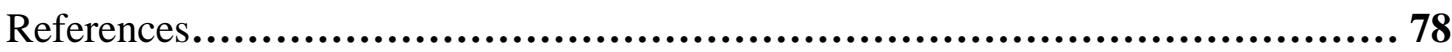

Supplemental Materials

A. ITRDB Citations................................................... 82

B. Example Ring Width File in Tucson Decadal Format.................. 93

C. Additional Temporal Synchrony Analysis Graphs...................... 98

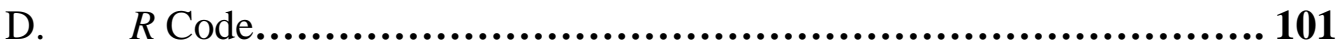




\section{List of Tables}

Table 1: Summary of study site and tree ring chronologies......................... 28

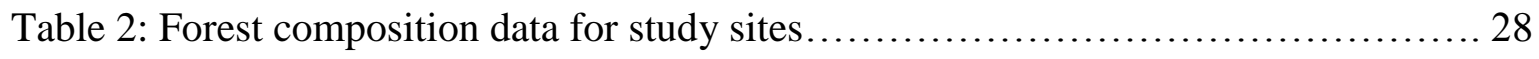

Table 3: Summary of results from three methods used to detect the 2012 derecho....... 30

Table 4: Summary of relationship between light values and growth change............. 33

Table 5: Summary of results from disturbance analysis by ecoregion.................. 73 


\section{List of Figures}

Figure 1: 2012 derecho radar reflectivity imagery.......................................26

Figure 2: Map of study locations within West Virginia................................... 26

Figure 3: Map of study plot locations............................................... 27

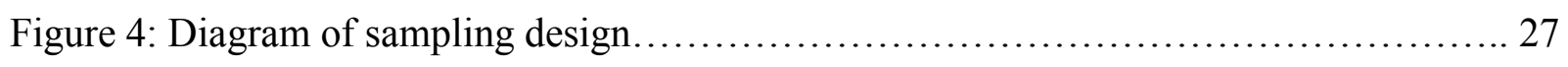

Figure 5: Release years resulting from changing the criteria applied to RGA.................. 29

Figure 6: Rate and total disturbances detected by RGA under different criteria............... 30

Figure 7: Results of RGA methods used to detect the 2012 derecho.......................... 31

Figure 8: Results of CID method used to detect the 2012 derecho ......................... 31

Figure 9: Relationship between SD values and LAI versus Openness..................... 32

Figure 10: Relationship between light/tree diameter and 2012 growth change............... 34

Figure 11: Relationship between SD values 2012 growth change........................ 35

Figure 12: Relationship between LAI and 2012 growth change .......................... 35

Figure 13: Relationship between downed tree diameter and 2012 growth change........... 36

Figure 14: Relationship between cored tree diameter and 2012 growth change................ 36

Figure 15: Map of ITRDB study site locations and distribution of species represented....... 72

Figure 16: Distribution of rates of disturbance by ecoregion........................... 73

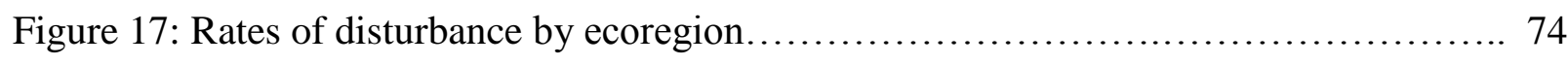

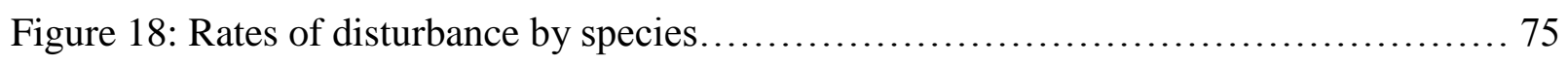

Figure 19: Results of moving count analyses........................................ 76

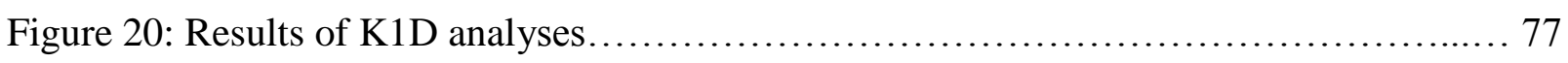




\section{Chapter 1. Assessing the Sensitivity of Eastern Broadleaf Forests to Past Disturbance Events}

\section{Introduction}

Disturbance to the forest canopy plays an important role in shaping temperate forest ecosystems by altering community structure, composition and access to light over time (Krebs, 2009; Papaik et al., 2006; Turner, 2010). Much of the mixed mesophytic forest region of eastern North America is currently even-aged after widespread logging and associated disturbances between 1880-1920. However, some suggest that these stands were historically dominated by fine-scale, gap-phase dynamics, in which baseline mortality and smaller canopy disturbances from windthrow, insect, fire, or ice damage promote the development of uneven aged stands as patches of mature trees give way to younger cohorts (Hicks, 1998; Oliver and Larson, 1996). Spatial variability in the frequency and intensity of disturbance, coupled with diverging plant response strategies, leads to heterogeneity in the landscape and in understory light environment and forest structure, thereby increasing biodiversity and persistence of native plant and animal species (Hanson and Lorimer, 2007; Lorimer, 2001; Turner, 1989). However, with shifting climate and land-use practices, establishing the characteristics of disturbance regimes that drive forest composition is complex, and a better understanding of underlying variables influencing tree response to disturbance is necessary.

Trees surviving disturbance are often suppressed, scarred, or released by the event, creating a record of past disturbance events within their annual growth rings. This record provides a means of estimating the frequency of past forest disturbances. Most studies examining the dynamics of canopy gaps infer that an abrupt increase in ring widths, or a step change in 
radial growth, is caused by a local canopy disturbance event (McEwan et al., 2014; Pederson et al., 2014; Rodgers et al., 2006). This sudden increase in growth can indicate canopy ascension of suppressed trees or decreased competition for resources. Studies of radial growth response to mechanical thinning 'disturbances' indicate that percent canopy removed is positively correlated with the magnitude of percent growth change, and that this response can occur over a period of 10 years, but may vary by species (Anning, 2013; Rentch et al., 2002). However, the increased growth rate observed by dendrochronology is that of secondary growth via radial growth rings; therefore, the relationship between disturbance severity and increased growth is not direct (Lorimer and Frelich, 1989). Newly accessed resources may be allocated first to increasing tree height or crown size. For this reason, methods for identifying release events usually prescribe a threshold percentage of growth increase that is great enough to prevent false identifications, but sensitive enough to detect smaller releases.

There is no single quantitative method nor threshold growth increase used to identify years of disturbance. Lorimer and Frelich (1989) suggest 50-100\% growth increases as a basic threshold. Nowacki and Abrams (1997) subsequently determined this range was not sensitive enough for certain closed canopy old growth stands, and instead suggested a formula for determining a threshold which takes into account the change in average growth between two time periods. This radial growth averaging (RGA) technique reduced the number of false positives detected while using a more liberal threshold of 25-50\% (Nowacki and Abrams, 1997). Black and Abrams (2003) further developed RGA through the boundary line method, which prevents false event detection by accounting for the effect of past growth rate on rate of release, but requires extensive prior measurement and calculation to identify an appropriate equation for the boundary line (Black and Abrams, 2003). More recently, Druckenbrod et al. (2013) 
introduced the curve intervention detection (CID) strategy for detecting releases, which uses autoregressive modeling instead of a moving average to isolate release-associated step changes within each time series from climatic and growth related trends. However, challenges remain, as certain climate analyses suggest that using a moving average can introduce false periodicity into a time series, and most of these methods involve at least one moving average calculation (Bartlein, 2013). I developed the present study to further our understanding of the merits and shortcomings of several of these disturbance detection methods.

Among the primary causes of both fine-scale and catastrophic canopy disturbance is damage from wind events (Everham and Brokaw, 1996). Severe wind events are common in eastern forests (Lorimer, 2001), and evidence from sediment cores suggests that wind disturbance may have contributed significantly to the historical development of mesic hardwood forests (Delcourt and Delcourt, 1996; Clark et al., 1996). 'Straight-line' wind storms associated with severe thunderstorms are one source of wind disturbance which can affect areas smaller than four square kilometers to upwards of several hundred square kilometers (Peterson, 2000). These larger events, termed derechos, are caused by clusters of downbursts that form within a convective storm system. Derechos characteristically travel a linear path, often traversing up to four hundred kilometers over the course of several hours (Walker and Mote, 2005). In the eastern United States, an average of one derecho per year was recorded between 1986-2003, resulting in property damage estimates comparable to those generated by rotational wind storms such as hurricanes or tornadoes (Walker and Mote, 2005).

Ecological response and recovery from wind disturbance is species specific, often related to shade tolerance, and can vary throughout the life of the tree (Papaik et al., 2006; Kobe et al., 1995). Runkle (1998) found that young shade tolerant species like red maple (Acer rubrum L.) 
and American beech (Fagus grandifolia Ehrh.) tend to grow rapidly in gap-created environments. Larger canopy gaps (at least $400-1000 \mathrm{~m}^{2}$ ) are necessary for regeneration of more shade intolerant species (Muscolo et al., 2014). However, in regards to juvenile individuals (less than $10 \mathrm{~cm}$ in diameter), Kobe et al. (1995) found that shade tolerance was inversely correlated with growth rate in high-light conditions, in that shade intolerant saplings grew faster than shade tolerant saplings when in high-light conditions. However, these shade intolerant individuals exhibited comparatively poor low-light survivorship, indicating a tradeoff between growth rate in high-light and ability to survive in low-light (Kobe et al., 1995). Compared to managed stands after an uneven-aged harvest, stands affected by wind damage exhibit more solar radiation at the forest floor, as well as more variability in gap size and light availability (Hanson and Lorimer, 2007). Given that many consider light to be one of the most limiting resources in eastern hardwood forests, canopy disturbances have large impacts on subsequent forest composition and structure (Oliver and Larson, 1996). One way to further our understanding of these implications is to relate radial growth patterns in surviving trees to quantitative measurements of their light environment following disturbance.

On June 29, 2012, a derecho struck states across the Ohio Valley and Mid-Atlantic regions (Figure 1). West Virginia was one of the more severely impacted states, with recorded wind speeds up to $78 \mathrm{mph}$ in Charleston, and an estimated 643,284 electric customers subsequently affected by power outages (Furgione, 2013). Mesic hardwood stands near the Gauley River National Recreation Area, including old growth stands in Carnifex Ferry Battlefield State Park, experienced significant blowdown as a result of the 2012 derecho. According to National Park Service inventory data, stem density at Carnifex Ferry decreased approximately 16\% between 1999 and 2012 as a result of this disturbance event (L. Strickler, 
personal communication; Wood et al., 2009). This and surrounding areas experienced a range of damage, from broken branches to snapped and uprooted stems, providing a unique opportunity to study the short-term impact of wind-created canopy gaps of known age on radial growth of surviving trees.

The first objective of this study was to test the sensitivity of Nowacki and Abrams' (1997) radial growth averaging method to changes in the criteria used to identify past canopy disturbance. I hypothesized that using less conservative criteria would exaggerate disturbance frequency, as well as conflate smaller disturbances with short-term climatic trends. The second objective was to identify factors that influence the extent of radial growth increase in trees surviving a canopy release event. I hypothesized that increases in ring width would positively correlate with the increase in light available to individual surviving trees as well as with increasing diameter of nearby downed trees, and further, that radial growth response would differ according to the sampled individual's canopy position, species and diameter. Finally, this study assessed whether or not a period of three years post-disturbance was sufficient to allow detection of a severe canopy disturbance event, as well as which method was most likely to identify the year of disturbance correctly.

\section{Methods and Analysis}

\section{Study Area}

I sampled at two locations near Summersville, West Virginia—a state park on the rim of the Gauley River Canyon, and a wildlife management area adjacent to Summersville Lake (Figures 2 and 3). Carnifex Ferry Battlefield State Park (CFSP; 38 $12^{\prime} 10^{\prime \prime}$ N, 80 56' 18" W) and Summersville Lake Wildlife Management Area (SWMA; 38 $13^{\prime} 14^{\prime \prime}$ N, 80 51' 59" W) are 
situated on the unglaciated Allegheny Plateau, at middle elevation sites around 500 meters above sea level (Fenneman, 1928). Bedrock underlying this dissected plateau is Paleozoic sandstone and shale of the Pottsville group (Hicks, 1998). Soils are well drained sandy loam or clay (West Virginia Division of Natural Resources, 2015).

Climate of the region is characterized broadly as hot continental, with hot humid summers and cold winters. Average annual precipitation ranges from 100-140 cm, and is evenly distributed throughout the year (Hicks, 1998). The frost-free growing season averages one hundred and fifty days in length (Hicks, 1998).

The Lower Gauley River watershed is located along the eastern edge of the central hardwood forest delineated by Hicks (1998). Braun (1950) classified the specific vegetation association occurring in the area as mixed mesophytic, and under Dyer's (2006) reclassification of the eastern North American forest regions, it lies on the western edge of the Appalachian oak section within the broader mesophytic forest association. Notably, the eastern hemlock (Tsuga canadensis L.) in this area is in decline, having been infested by hemlock wooly adelgid (Adelges tsugae Annand) since approximately 2004 (Wood et al., 2009).

\section{Carnifex Ferry Battlefield State Park}

Carnifex Ferry Battlefield State Park is a protected Civil War battle site, established in 1935. The first European pioneers recorded in the vicinity of CFSP arrived in 1775 in the area of Peter's Creek and Koontz Bend several kilometers to the northwest (Brown, 1954). The McClung and Campbell families also settled nearby in 1786 and 1794, respectively, in the area north of CFSP now referred to as Kesler's Cross Lanes (Nicholas County Historical and Genealogical Society, 1985). The land where CFSP currently resides was granted to William Carnifex ('Carnefix' and 'Carnifax' are alternative spellings also recorded) around 1824. 
However, the primary Carnifex residence was located south of the Gauley River, at the mouth of the Meadow River, where they ran a ferry service (Stahlgren et al., 2007). Old road grades are still visible throughout the park, including the 'old ferry road' trail, as evidence of this past activity.

The first recorded European homestead within the boundaries of the present-day park was that of William Carnifex's granddaughter, Mary Ann McVey, who married Henry Patterson and was granted the land in 1855 (Brown, 1954). The Pattersons owned the land at the time of the Civil War battle in September of 1861. Since the Battle of Carnifex Ferry is considered one of the most important Civil War battles fought in the state, and it also retains significance regarding West Virginia attaining statehood, protection of the site from widespread logging after the battle may have been a matter of respect. However, the Carnifex's were listed as farmers in the 1860 census, so it is likely that portions of their land were cleared for farming at some point, perhaps most likely the flatter land toward the interior of the park (Stahlgren et al., 2007).

In terms of stand composition, CFSP is dominated by large, old-growth eastern hemlock (30\% of stems per hectare; West Virginia Division of Natural Resources, 2015; Table 2), tulip poplar (Liriodendron tulipifera L.; 11\% of stems per hectare), oak species (Quercus alba L. and Q. rubra L.; $13 \%$ of stems per hectare), and maple species (Acer saccharum Marsh. and A. rubrum L.; $24 \%$ of stems per hectare). Blackgum (Nyssa sylvatica Marsh.), hickory species (Carya tomentosa (Lam.) Nutt. and Carya glabra (Mill.) Sweet), and sourwood (Oxydendrum arboreum L.) are also present, but less frequent. Additionally, rhododendron (Rhododendron maximum L.) is a significant member of the understory in many areas. 


\section{Summersville Lake Wildlife Management Area}

Summersville Lake Wildlife Management Area is a managed recreation area covering nearly 2,500 hectares surrounding a man-made lake. It is currently a popular destination for hunting, fishing, hiking and other outdoor activities. The nearby town of Summersville was established in 1820, when it became the Nicholas county seat (Brown, 1954). The land was likely occupied by one of several families after 1830 , but specific ownership is challenging to determine. Nicholas county had about 1,853 inhabitants in 1820, indicating a population density of only one person per square mile, but after the county was established in 1818 , then officially incorporated in 1850, population began increasing more rapidly, growing to 4,627 in 1860, and 11,403 in 1900 (Brown, 1954).

The nearest community to SWMA was likely Gad, a village too small for a post office, which was flooded following the construction of Summersville Dam. Given its proximity to both Summersville and the Gauley River, parts of SWMA may have been cleared for agriculture or pasture land between 1820-1880, after which remaining timber was likely harvested, as it was unprotected at that point (Clarkson, 1964). The Summersville Dam was built by the United States Army Corps of Engineers between 1960-1966 in order to alleviate flooding (Nicholas County Nicholas County Historical and Genealogical Society, 1985). Shortly after completion of the dam, management of the land around Summersville Lake was largely given to the West Virginia Department of Natural Resources for wildlife management, although fish and wildlife management responsibilities are shared between the two organizations.

In contrast to CFSP, the SWMA site is an even-aged second-growth forest with sparse understory. Dominant species, however, are similar. Red and sugar maples are most prevalent (53\% of stems per hectare; Table 2), with tulip poplar (22\% of stems per hectare) and mainly 
white and red oak species (14\% of stems per hectare) also common. Black birch (Betula lenta L.) and mockernut hickory (Carya tomentosa (Lam.) Nutt.) are also present, but in fewer numbers. Rhododendron grows in places, but is largely confined to north-facing slopes.

\section{Dendroecological Sampling Design}

I selected 11 study plot locations at CFSP and 9 locations at SWMA (Figure 3).

Selection was based on preliminary ground surveys so that each plot location had similar slope and species composition and that sampled trees were outside the influence of any neighboring gaps. I excluded locations that had slope greater than $30^{\circ}$, a threshold value used by Stan and Daniels (2010) to minimize the potential confounding effect of steep slopes on tree growth and light availability. In plots that incorporated more than one downed canopy tree, the gap maker with larger diameter was considered the center of the plot, while the locations of other downed trees were noted. When a plot was established, I recorded details regarding the GPS coordinates of the plot center, characteristics of the windthrown tree(s), and characteristics of surviving trees. I made an effort to establish plots in a range of gap conditions, from one small downed tree to blowdowns larger than 15 trees. Because of these selection criteria, sampling was not random, but designed to minimize the influence of confounding factors such as steep topography and adjacent gaps, while maximizing the range of light environments represented.

The scale of this study was that of the individual tree, as the growth of trees was assessed and compared based on their unique characteristics and location. The rationale behind a finescale analysis is that the responses of individual trees to canopy release can differ widely, and the goal of the study was to quantify the factors that influence these growth patterns. I chose to sample white oak and tulip poplar because they are both common within SWMA and CFSP. Although it would have been preferable to sample species of differing shade tolerance for 
comparison, as oak and tulip poplar are both moderately shade intolerant, only a few other options existed (Kobe et al., 1995). Specifically, I avoided using eastern hemlock due to the confounding effects of hemlock wooly adelgid and I excluded maple because it was infrequent at many of the old growth CFSP plots.

In July and August of 2016, I took core samples from surviving white oak and tulip poplar individuals to provide ring width data for analyzing the growth release associated with a gap created by windthrown trees. I sampled surviving trees greater than $10 \mathrm{~cm}$ diameter at breast height (DBH) using the $n$-tree distance method, rather than a fixed-radius plot, in order to ensure even sampling effort at each plot, regardless of varying forest density (Lynch and Wittwer, 2002). I assigned $n=5$, meaning that I sampled the five white oak and the five tulip poplar individuals nearest to the plot center (Figure 4). However, I also set a maximum sampling radius, as defined by the height of the downed tree at plot center, in order to limit coring to trees within the range of influence of the downed tree. As a result, several plots contained fewer than five individuals because of low forest density. From each sampled tree, I extracted two cores at breast height from opposite sides of the tree using an increment borer, at an angle perpendicular to the slope of the ground, except when it was necessary to avoid significant visible injury or rot. Finally, to confirm date of gap formation, I also collected 27 cross sections from the bases of windthrown trees within my study plots.

\section{Light Availability Sampling Design}

I used hemispherical photographs and a spherical densiometer to assess the light environment at each cored tree (Beaudet and Messier, 2002; Jennings et al., 1999; Jonckheere et al., 2001; Macfarlane and Ogden, 2012). I used a fisheye lens, Canon Rebel T3i digital camera, and tripod to take pictures at a $180^{\circ}$ angle, approximately one meter off the ground. Photographs 
were oriented such that the top of the image was pointed north for consistency, and the camera was used in automatic focus mode to reduce user error. I took photographs at plot center and at each cored surviving tree. The photographs at surviving trees were taken one to two meters from the base of the given tree toward the center of the plot (Figure 4). In addition, I used a spherical densiometer to provide a secondary measure of canopy closure at each photo point for comparison to the hemispherical photograph results. I calculated the average of four separate readings taken in approximately the cardinal directions for each photo point.

\section{Sample Preparation and Data Analysis}

I air-dried, mounted, and sanded all tree core and cross section samples using progressively finer grit sandpaper according to Stokes and Smiley (1968). I measured all annual growth rings using a stereo microscope, fitted with a sliding measurement stage and Measure J2X software (Voor Tech Consulting, 2008). Following skeleton plotting and crossdating my samples against an existing master chronology from CFSP, I used Grissino-Mayer et al.'s (1997) program COFECHA to confirm annual dating (Cockrell et al., 2017).

The $R$ (R Core Team, 2016) package dplR (Bunn, 2008) was used to calculate mean series for those trees that produced two crossdated cores, so as to prevent the exaggeration of any one tree's growth response. I also included trees with only one crossdated core in the chronology, without further adjustment (Supplemental Material B). I used the $R$ package TRADER to assess the strength and duration of the increase in radial growth associated with a known canopy disturbance event, the 2012 derecho (Altman et al., 2014). I used the TRADER function for Nowacki and Abrams' (1997) radial growth averaging method (RGA) to calculate percent growth change. I chose RGA due to its simplicity, given the extra site- and species-specific information necessary for methods such as boundary line or absolute increase (Black and 
Abrams, 2003; Lorimer and Frelich, 1989; Black et al., 2009). Furthermore, RGA has been used successfully in the central Appalachian region, with results comparable to boundary line or absolute increase, as long as sufficiently conservative criteria are used (Rentch et al., 2002; Trotsiuk et al., in prep.; Copenheaver et al., 2014).

I assessed the sensitivity of the RGA method to changes in threshold criteria and moving window length by detecting canopy disturbance over the full length of four chronologies: CFSP tulip poplars, SWMA tulip poplars, CFSP oaks, and SWMA oaks. I used TRADER to run RGA multiple times: first with moving window held at a constant symmetrical 15 years before and after while testing percent growth thresholds of $25 \%, 50 \%, 100 \%$, and then with percent growth threshold kept at a conservative 50\% while testing moving window lengths of 10 years before and after, and 15 years before with 5 years after. This provided a comparison of how the threshold used to discriminate between disturbed and non-disturbed years on a tree level influences the results of potentially stand-level disturbance history reconstructions.

Since RGA traditionally requires at least 10 years following a disturbance to calculate growth change reliably, the shortened period since the 2012 disturbance ( 3 years of measurable ring widths) was a concern. I took three distinct approaches to detecting a growth increase with this added challenge: 1) adding 7 years of growth via random sampling from each series' most recent 10 ring widths, in order to extend each series sufficiently to use the default 10 year window for RGA to detect the year 2012; 2) using an asymmetrical window of 15 years before and 3 years after the disturbance, also using RGA, similar to McLachlan et al. (2000); and 3) utilizing Druckenbrod et al.'s (2013) time series analysis method, Curve Intervention Detection (CID), which does not require a specific window length for detecting periods of increased growth because it uses autoregressive modeling instead of a moving average to detect release 
events. CID analysis was completed using a MATLAB executable file scripted by Druckenbrod (MathWorks, Inc., 2000; D.L. Druckenbrod, personal communication, 2015).

I used the image processing software WinSCANOPY $2013 a$ to analyze the hemispherical photographs and to calculate several measures of understory light availability, including openness and leaf area index (LAI) at each photo point (Regent Instruments Inc, 2013). I used the original method of calculating LAI, as used by Miller (1967) and Welles and Norman (1991). LAI represents the quantity of leaf material in two dimensions by calculating the area of foliage per square meter of ground $\left(\mathrm{m}^{2} / \mathrm{m}^{2}\right)$. In contrast to LAI and spherical densiometer values, which represent the portion of sky filled with vegetation, openness indicates the fraction of an image classified as open sky. Openness can be calculated in three dimensions for a particular vertical portion of the canopy.

Because of time constraints, I was only able to analyze a subset $(n=48)$ of the hemispherical photographs. However, this subset still provided an opportunity to assess how measures of canopy structure compared to the use of a spherical densiometer. I preferentially chose photographs to analyze based on how overcast the sky appeared, as I observed that the sunnier photographs blurred the boundary between foliage and sky in a way that seemed to underestimate the amount of foliage actually present. However, the impact of this bias may be negligible compared to the importance of the threshold used to differentiate pixels as sky or tree (Leblanc et al., 2005; Macfarlane and Ogden, 2012).

I then made scatter plots of LAI and spherical densiometer values against a simple estimate of each tree's growth response following 2012. I calculated this value as a ratio, using the simple formula: $m_{\mathrm{after}} / m_{\text {before, }}$ where $m$ represents the mean of ring widths in the three years before or after 2012. To avoid confounding effects of the disturbance year, I excluded 2012 
growth rings from this calculation. This growth change ratio (hereafter referred to as GCR) method facilitated the interpretation of results, where values around one indicated no growth response, values greater than one indicated a release following 2012, and values between zero and one indicated suppressed growth post-disturbance. I included two different light estimates to compare values derived from hemispherical photographs to those derived from a spherical densiometer. However, I had a spherical densiometer value for each cored tree $(n=181)$, but only LAI values from the 48 analyzed hemispherical photos, so this discrepancy in sample depth limited the types of comparisons I could make.

I used scatter plots and linear regression equations to explore the relationship between light availability after canopy disturbance and the magnitude of growth increase experienced by surviving individuals. Further comparisons examined potentially differing responses by site, species, and canopy class, to better inform our understanding of how individual trees respond to canopy gaps created by windthrow. Finally, to elucidate the factors governing disturbance response beyond light availability, I examined the relationship between both diameter of the gapmaker and diameter of the cored tree, and magnitude of growth change. I determined the significance of all linear regressions at a minimum level of $p<0.10$.

\section{Results}

I collected 345 core samples from 181 surviving white oak $(n=89)$ and tulip poplar $(n=$ 92) individuals to provide ring width data for analyzing the growth release associated with the gap created by windthrown trees (Table 1; Supplemental Material B). The length of tree-ring records at SWMA were limited by the age of the trees I sampled, with only 90 years of recorded 
growth for tulip poplar and 151 years for white oak. However, both records at CFSP were longer than 220 years, with white oak stretching back 360 years to 1655 .

In regards to the results of the dated cross sections, the outer ring dates of $78 \%$ of the 27 downed trees I sampled corresponded to either 2012 or 2013, with about half of those trees dying in each year (Supplemental Materials C). Two individuals died prior to 2012, and the remaining four died in the years following 2013.

\section{Sensitivity Analysis of Radial Growth Averaging Method}

Changing the moving average window and the threshold for minimum percent growth change (PGC) produced different results for the number and rate of disturbances detected by RGA (Figures 5 and 6). All chronologies were sensitive to these changes, showing at least a three-fold increase in the number of disturbances detected per century from the most conservative to the most liberal criteria. However, the shortest chronology (SWMA tulip poplars) was especially sensitive, with an increase in detected disturbances from 1 event per century, to 24 events per century. The SWMA sites were also generally more significantly impacted by the use of an asymmetrical window of 15 years before and 5 years after, creating a possibly spurious periodicity of disturbance every 4-5 years (Figure 5e). On the other hand, both CFSP chronologies produced the greatest number and rate of disturbances under the $25 \%$ threshold/symmetrical 15 year moving window criteria combination, but were not as affected by the use of an asymmetrical window. With the exception of the most conservative criteria (100\% threshold/15 year window), variation in the rate of disturbance generally decreased as criteria became more liberal (Figures 5 and 6). Furthermore, RGA detected certain event years regardless of the criteria used, although seemingly less significant events surrounding these years changed in number and timing. One example of this pattern is the year 1754 in the CFSP oak 
chronology, which indicates a release in all but the most conservative criteria; but in the 10 years preceding this event, anywhere between zero to six additional events are detected from one set of criteria to the next (Figure 5b-e).

\section{Radial Growth Response to 2012 Derecho}

None of the three methods tested detected a release in more than $10 \%$ of trees at a given site for the year 2012 (Table 3; Figures 7 and 8). With the conservative 50\% growth change threshold, methods 1 and 2 indicated no released trees at the SWMA plots, and only 1-2 released oaks and 2 released tulip poplars at CFSP, out of 46 and 44 total individuals, respectively. Method 3, CID, likewise did not identify any released trees at either site, indicating that all ring width residuals following 2012 were found to be below $99.9 \%$ of the observed distribution of residual means. Instead, mean disturbance trend decreased sharply in 2012 (Figure 8).

The number of released trees differed between sites. At SWMA, method 1 only indicated one released tulip poplar individual, and even that result was problematic, nor did it meet more conservative percent growth change criteria (Table 3; Figure 7). Method 2 pointed to one released oak at SWMA meeting the minimum $25 \%$ growth change criteria. Conversely, about $10 \%$ of CFSP oaks indicated a release under methods 1 and 2 (4 and 6 individuals out of 46, respectively), with at least one of those individuals releasing more than $50 \%$ in both cases. About $5 \%$ of tulip poplars released at CFSP at a 50\% threshold. However, tulip poplars were generally less responsive, regardless of the method used.

\section{Response to Light Availability}

Based on visual examination alone, larger gaps, and thinner canopies generally produced higher values for the measure of openness, while smaller gaps and thicker canopies generated larger values of canopy closure estimates (i.e. LAI and SD; Supplemental Materials A). Further, 
LAI and openness were modestly correlated with the associated spherical densiometer values $\left(\mathrm{R}^{2}\right.$ $=0.22$ and $0.16 ; p=0.002$ and 0.009 ; Figure 9). As I expected, the shape of these relationships differed, as LAI indicated a positive relationship, while openness indicated a negative relationship to $\mathrm{SD}$ values.

When SD data were plotted against GCR in 2012, no strong relationship emerged (Figure 10a and 11; Table 4a). When all data were included, SD values did not indicate any correlation with GCR ( $p=0.39)$, but diverging relationships emerged when data were divided by site, species, and canopy class. As anticipated, the most significant of these involved intermediate and suppressed individuals at both locations. At SWMA, both intermediate and suppressed individuals showed a positive relationship between SD and GCR, indicating that increased canopy closure was associated with increased growth release $\left(\mathrm{R}^{2}=0.23\right.$ and 0.13 , respectively), but the relationship was not significant ( $p=0.11$ and 0.56 , respectively). At CFSP, intermediate trees showed a negative relationship, with slope $=-0.114\left(\mathrm{R}^{2}=0.13 ; p=0.23\right)$. When $\mathrm{SD}$ data were divided by species, tulip poplar individuals came the closest to significance in dominant and intermediate canopy classes, the former indicating positive relationship (slope $=0.025, \mathrm{R}^{2}=$ $0.24, p=0.11$ ) to GCR, and the latter indicating negative relationship ( $p=0.16)$.

LAI showed slight positive correlation with GCR with all data included (slope $=0.347$, $\mathrm{R} 2=0.06, p=0.12 ;$ Figure $10 \mathrm{~b}$ and 12 ; Table $4 \mathrm{~b}$ ). Once data were separated by site, species, and canopy class, a few stronger relationships appeared. Codominant individuals at both CFSP and SWMA indicated insignificant positive relationship to GCR (slope $=0.756$ and $0.163 ; \mathrm{R}^{2}=0.14$ and $0.036 ; p=0.25$ and 0.60 ). Similar to the results from SD data, intermediate individuals showed opposite relationship at SWMA versus at CFSP. However, when intermediate 
individuals from both sites were included to bolster sample depth, linear regression indicated a significant positive relationship between LAI and GCR (slope $=2.07, \mathrm{R}^{2}=0.45$, and $p=0.07$ ). This moderate significance appears to be primarily from the oaks in this case, as both dominant and intermediate oaks showed some significantly positive correlation between LAI and GCR (slope $=0.237$ and 2.25, $\mathrm{R}^{2}=0.97$ and 0.89 , and $p=0.01$ and 0.05 ).

The diameter of downed trees from each plot overall indicated a significant, but slight positive relationship to growth change, suggesting that cored individuals near larger downed trees experienced slightly greater release than those near small gapmakers (slope $=0.006, \mathrm{R}^{2}=$ 0.024 , and $p=0.04$; Figure10c and 13; Table 4c). No significantly different relationships emerged when I separated the data by species, but separating by site indicated significant positive relationships in CFSP intermediate trees (slope $=0.03, \mathrm{R}^{2}=0.26$, and $p=0.07$ ) and SWMA codominant trees (slope $=0.006, \mathrm{R}^{2}=0.072$, and $p=0.04$ ). Finally, the diameter of the cored trees exhibited moderate negative relationship with GCR (slope $=-0.005, \mathrm{R}^{2}=0.017$, and $p=0.09$ ), with mildly stronger relationships appearing in CFSP individuals (slope $=-0.01, \mathrm{R}^{2}=$ 0.05 , and $p=0.04$ ) and tulip poplar trees (slope $=-0.011, \mathbf{R}^{2}=0.044$, and $p=0.06$; Figure $10 \mathrm{~d}$ and 14; Table 4d). However throughout these analyses, despite a few significant $p$-values, the frequent combination of small coefficients with low $\mathrm{R}^{2}$ and low $p$-values indicates that although there may be a consistent trend in these data, there is also a large amount of variance. Therefore, each of these variables likely contributes to GCR, but alone, is largely unable to explain the majority of variation present. 


\section{Discussion}

\section{Sensitivity of Growth Release Criteria}

I found that although the radial growth averaging method is sensitive to changes in the criteria used, several specific disturbance events are robust to these changes when multiple criteria are compared (Figures 5 and 6). Examples of this stability are: a) 1934, which appears in both oak chronologies; b) 1889, which appears in the SWMA oak chronology; c) 1971 and 1999/2000, which appear in both tulip poplar chronologies (except not always under the most conservative criteria); d) 1909, which appears reliably in both CFSP chronologies; e) 1681 and 1754, which show up in CFSP oaks in four out of five methods. These results are supported by Rubino and McCarthy (2004), who found that when a range of criteria were tested, RGA consistently detected three to four particular event years within a 100 year period, although the total number of events detected was not consistent. Likely, these persistent events represent larger, stand-level canopy disturbances, although caution is warranted when the goal of a study is to identify smaller events, as these may be detected less reliably (Copenheaver et al., 2014; Rentch et al., 2002). Trotsiuk et al. (in prep.) echoed this result as well, indicating that higher thresholds produce fewer false positives, but more false negatives. Most agree that the method and specific criteria appropriate for disturbance reconstruction may be site-specific, based on local disturbance regime, characteristics of a site, forest composition, and the purpose of the study.

Regardless of site or species, setting the growth change threshold to $100 \%$, with 15 year adjacent windows produced the most conservative of disturbance results (Figures 5 and 6). However, CFSP and SWMA responded differently to more lenient criteria. Both oak and tulip poplar individuals at CFSP indicated the highest rate of disturbance under a $25 \%$ threshold 
between symmetrical 15 year windows, while both species at SWMA showed the most disturbances under a 50\% threshold with an uneven window size of 15 years before and 5 years after each growth change value. This discrepancy indicates that SWMA individuals were more sensitive to changes in window length, while CFSP individuals were more sensitive to changes in percent growth change threshold. My results regarding a 100\% threshold with 15 year symmetrical windows being the most conservative criteria are consistent with the findings of Rubino and McCarthy (2004), who also identified this combination as one of the most conservative, out of the 28 methods they examined. Notably, Nowacki and Abrams (1997) developed their radial growth averaging method specifically to detect disturbances in older, overstory oaks, which they determined did not respond to disturbance sufficiently to be detected by the more conservative criteria (50-100\% growth increase) used by Lorimer and Frelich (1989). Thus, the discrepancy observed in the number of disturbances detected between different criteria could be due to RGA being a more appropriate method for mature stands like CFSP, rather than younger, second-growth stands like SWMA. That said, the intermediate criteria (50\% threshold, with symmetrical 15 year adjacent windows) seemed the most robust or stable, as it produced similar rates of disturbance between species at each site. Similar findings were reported by Trotsiuk et al. (in prep.), when they suggested that the original RGA criteria (50-100\% growth increase) used by Lorimer and Frelich (1989) produced the most reliable and flexible results, regardless of forest type.

\section{Radial Growth Response to 2012 Derecho}

Although many have characterized growth releases associated with a known canopy disturbance event date, either natural or mechanical in origin, to my knowledge none have attempted to do so less than five years after the event (Anning, 2013; Druckenbrod et al., 2013; 
Pitt and Lanteigne, 2008; Rentch et al., 2002; Rodgers et al., 2006; Trotsiuk et al., in prep.). Because of the 10-year moving window commonly used in disturbance detection methods, attempting this analysis fewer than five years post-disturbance posed a particular challenge (Nowacki and Abrams, 1997). While recognizing the limitations of the methods, exploring the short-term response of trees to disturbance and how it is modulated by factors such as forest age, canopy structure, and species composition could improve our current understanding of forest trajectory under recent climate and land use shifts.

The three methods used in this study did not identify 2012 as a disturbance year in all but a few cases (Figure 7 and 8; Table 3). Several possible explanations exist for this false negative result. Given the severity of the damage inflicted by this event, which may have been greater than any other event in the modern record across southern West Virginia, one possible explanation is that damage to the bark and root systems of surviving trees from such widespread blowdown may have delayed the growth response of survivors (Cowell, S., personal communication; Furgione, 2013; Strickler, L., personal communication). Furthermore, analysis of cross sections from trees that created these gaps revealed that several may have been formed in the years following 2012, narrowing the expected growth response time even further (Supplemental Materials C).

In the case of tulip poplar, growth response may also have been confounded by a recent outbreak of the leaf-mining poplar weevil (Odontopus calceatus Say) which is estimated to have defoliated more acreage $\left(2341.3 \mathrm{~km}^{2}\right)$ in West Virginia in 2015 than was affected by either hemlock wooly adelgid mortality or gypsy moth defoliation in the same year (Forest Health Programs, 2016). Although poplar weevil infestation rarely results in mortality in wellestablished individuals, growth can be slowed due to decreased leaf volume (Burns, 1971). I 
observed this effect in many of my tulip poplar samples, as the last two years of growth were either visibly suppressed or missing altogether. Trees may be especially vulnerable when young or if an outbreak occurs in conjunction with some other unfavorable condition such as drought (Burns, 1971). A major outbreak has not occurred since the 1960s, so this convergence of events could potentially confound disturbance detection of the derecho alone.

A third possible reason the methods used did not detect a release is given in another West Virginia oak study, in which Rentch et al. (2002) found that a lag of one to three years generally occurred between a disturbance event and the associated growth release, indicating that many individuals at my study sites may not have been able to respond to their increased access to light in the three years of growth I was able to analyze. Finally, regarding life history and shade tolerance traits, a lack of response could be attributed to the species sampled in this study. More mature trees tend to respond to disturbance more conservatively than sub-canopy individuals, but the majority of sampled individuals in this study were canopy trees due to their relatively greater abundance (Nowacki and Abrams, 1997).

However, findings concerning shade tolerance indicate that tulip poplar and oak species do respond to increased light from canopy openings, and may even exhibit a stronger radial growth response than more shade tolerant species (with the exception of eastern hemlock), especially at higher light levels between 10-100\% (Anning, 2013; Kobe et al., 1995; Pacala et al., 1996; Runkle, 1998). On the other hand, it remains likely that this stronger response in such shade intolerant species would only be observed in the gaps large enough to provide sufficiently high light levels to elicit a response (Canham, 1988). When considered together, these factors indicate that, at least with disturbances severe enough to cause significant damage to surviving 
trees, 5-10 years should be considered the shortest time period post-event for adequate detection of recent disturbances.

Since a release was not reliably detected in 2012, analysis of the impact of light conditions on growth response was not likely to produce notable results. However, the use of hemispherical photographs in conjunction with tree rings is a novel approach to disturbance analysis, and it provided both expected and unexpected results. When I included all data points in scatter plots relating light variables to growth response, regardless of tree characteristics, it revealed no relationship in spherical densiometer values and a slight positive relationship in leaf area index (Figure 10). The LAI findings run counter to previous findings like those of Rentch et al. (2002), as increasing LAI indicates increasing leaf density. Consequently, a positive relationship here, between LAI and growth change implies that smaller gaps produced larger increases in growth, at least in these dominant and intermediate oaks. I would have expected this result in a more shade tolerant species, as they grow faster in low light, but it was not expected of oak or tulip poplar (Kobe et al., 1995; Pacala et al., 1996). However, this counter-intuitive relationship is likely inconclusive, as I suspect many of the cored individuals have not yet responded to the fullest extend to the 2012 derecho, and in fact are likely still recovering from injury to bark and root systems (Everham and Brokaw, 1996; Rentch et al., 2002).

Despite having a smaller sample size, LAI indicated stronger linear relationships in nearly every analysis when compared to SD values (Table 4a-b). Supporting other descriptions of the limitations of SD measurements, these findings indicate that although SD captures some of the variability represented by measurements derived from hemispherical photographs (Figure 9), hemispherical photo methods such as LAI and openness may be better suited to this type of analysis (Comeau, 2000). The results of this study suggest the importance of further exploration 
regarding the best way to capture light availability and evaluate its influence on radial growth, especially in sub-canopy individuals.

My findings regarding light environment, although not conclusive, indicate that the relationship to radial growth may differ according to canopy class, as suppressed and intermediate individuals exhibited a stronger relationship between light availability and radial growth than did individuals inhabiting the canopy (Table 4). This observation supports those from the literature, as many have concluded that once a tree has reached the canopy, it is less likely to respond to canopy disturbance, ostensibly because it already has access to light (Black and Abrams, 2003; Lorimer and Frelich, 1989; Nowacki and Abrams, 1998). However, the shape of the relationship in these sub-canopy individuals was not consistent across sites or method of light measurement. This discrepancy may be related to patterns in catastrophic wind damage reported by others, in which damage primarily affected large trees, but indirect damage and mortality was also noted in smaller size classes due to their increased vulnerability to damage from falling neighbors (Everham and Brokaw, 1996; Peterson, 2007). In this way, the response of sub-canopy individuals to canopy disturbance may be less predictable than that of dominant or codominant individuals, although this relationship warrants further study.

\section{Conclusions}

The results of this study indicated that the original criteria for the radial growth averaging method of detecting disturbance in tree rings (i.e. $50 \%$ growth change threshold and symmetrical 15 year windows) is an appropriate method of detecting past disturbance in mixed mesophytic forests. Particular care should be taken when applying RGA to shorter chronologies however, to ensure that the window used is long enough to reduce the detection of false positives. 
Furthermore, although RGA was somewhat resilient to changes in the criteria used, the results of this study suggested that comparing the results of multiple criteria may aid in narrowing down event years to only the most robust.

Analysis of radial growth following the 2012 derecho at two locations near Summersville, West Virginia revealed negligible release in all but a few trees. Likely explanations for this null result include slow recovery from damage to surviving individuals, inhibited growth in tulip poplar individuals due to weevil infestation, and potential lag time between an event and detectable tree release. Further analysis of growth response suggested a slight positive relationship between leaf area index at the time of sampling and growth change, although this topic needs further investigation. Sub-canopy individuals (i.e. suppressed and intermediate trees) may exhibit a more pronounced response to increases in leaf area than their overstory counterparts. In general, this study revealed the limitations of using existing disturbance detection methods to identify a release with only three years of measurable growth following the event of interest. 


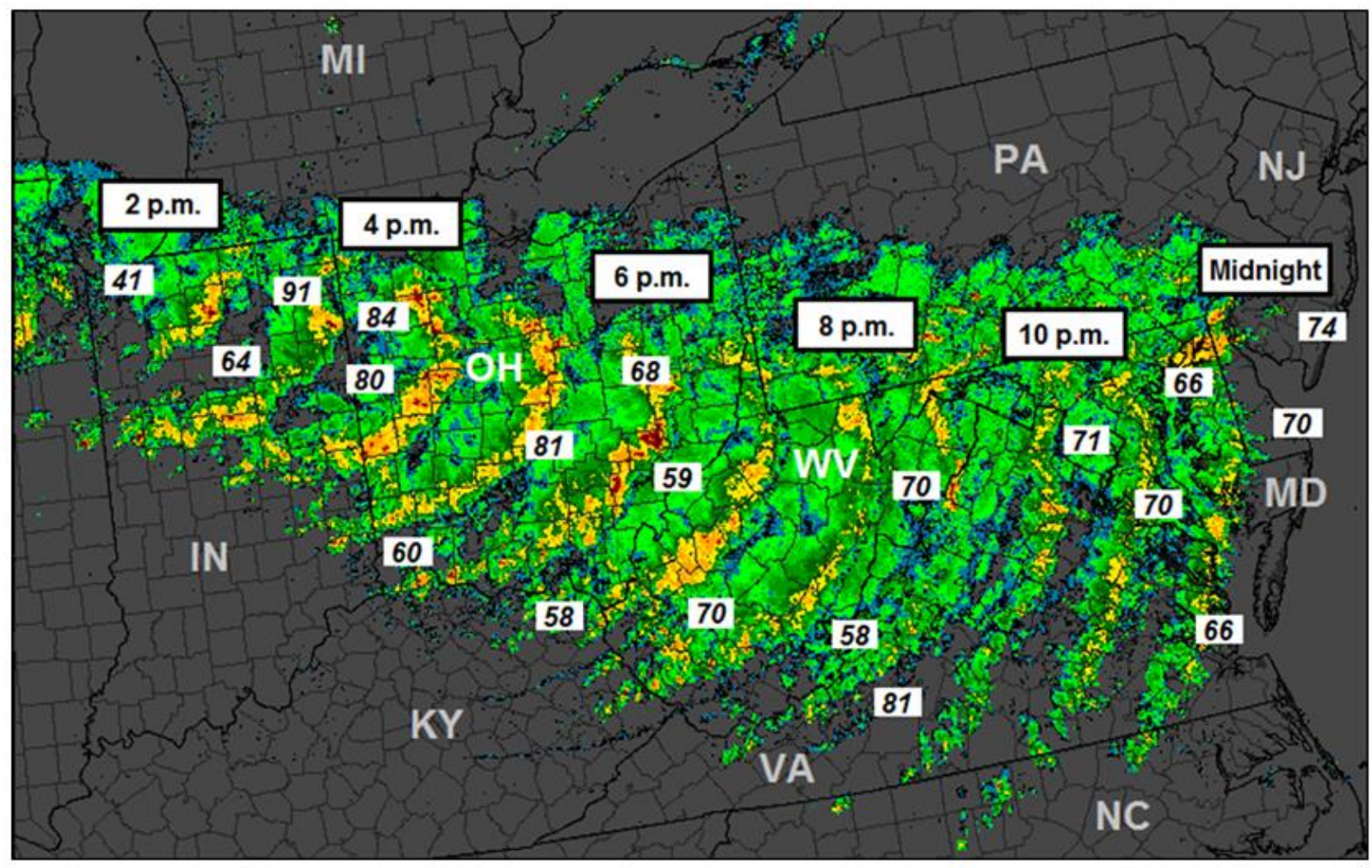

Figure 1. Map of radar reflectivity imagery from June 29, 2012, the date of the derecho investigated in this study. The average pace of the convective system was nearly 27 meters per second, and it traveled more than $1000 \mathrm{~km}$ in total. Image from Corfidi (2017).

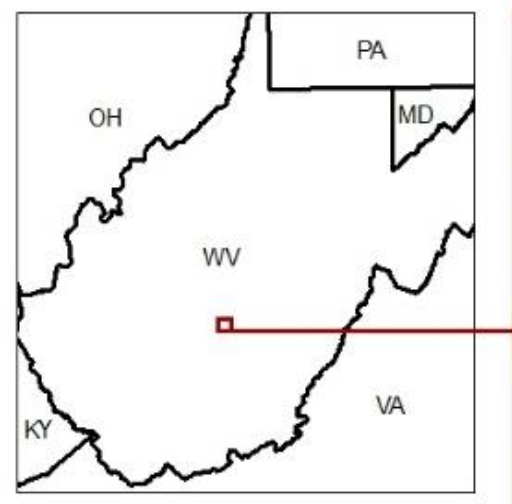

Figure 2. Map of the

locations of Summersville Lake Wildlife Management Area (SWMA) and Carnifex Ferry Battleground State Park (CFSP) within West Virginia.

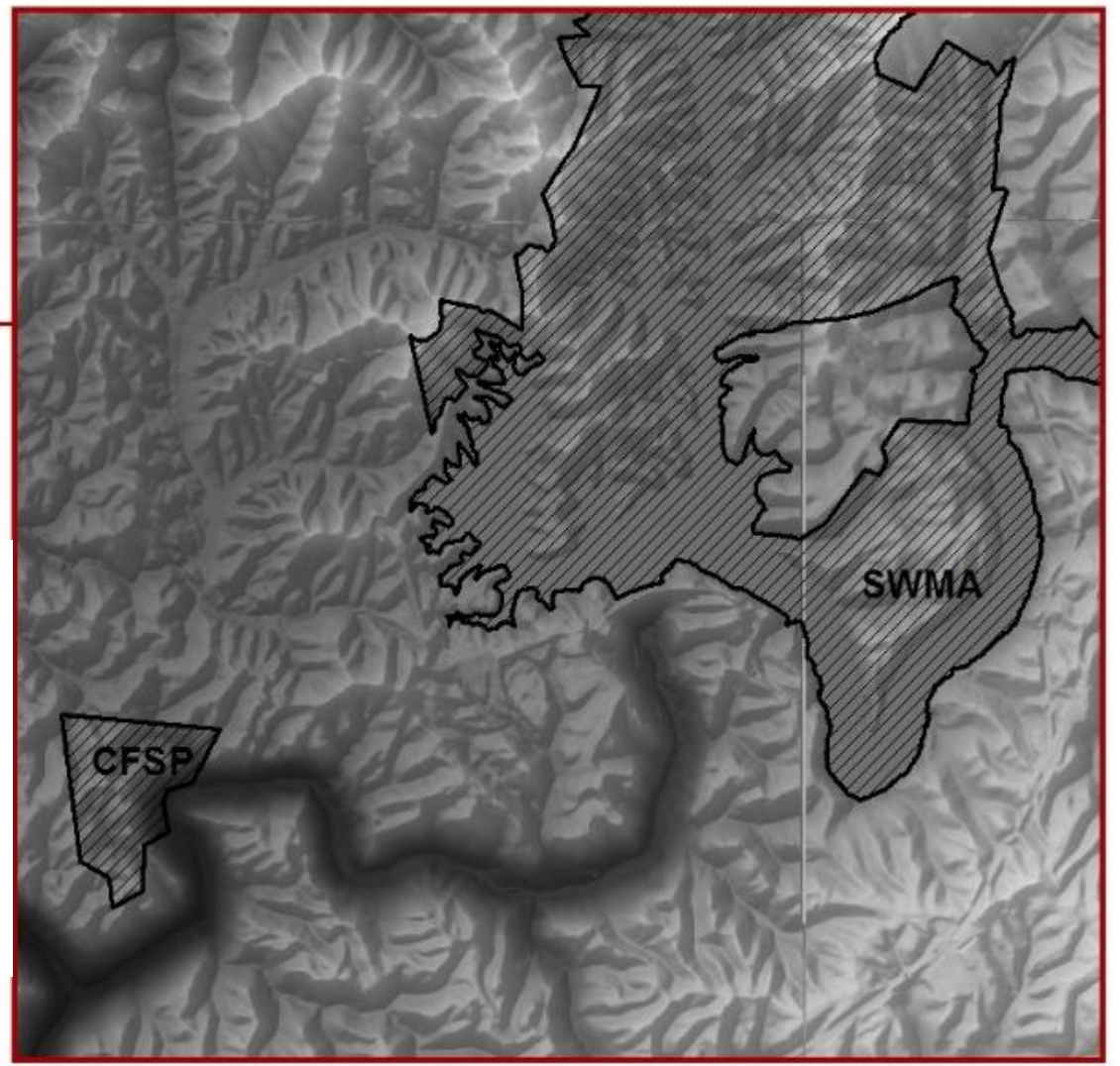


Figure 3. Map of plot locations at Carnifex Ferry and Summersville Lake. Plots are indicated by solid black triangles.
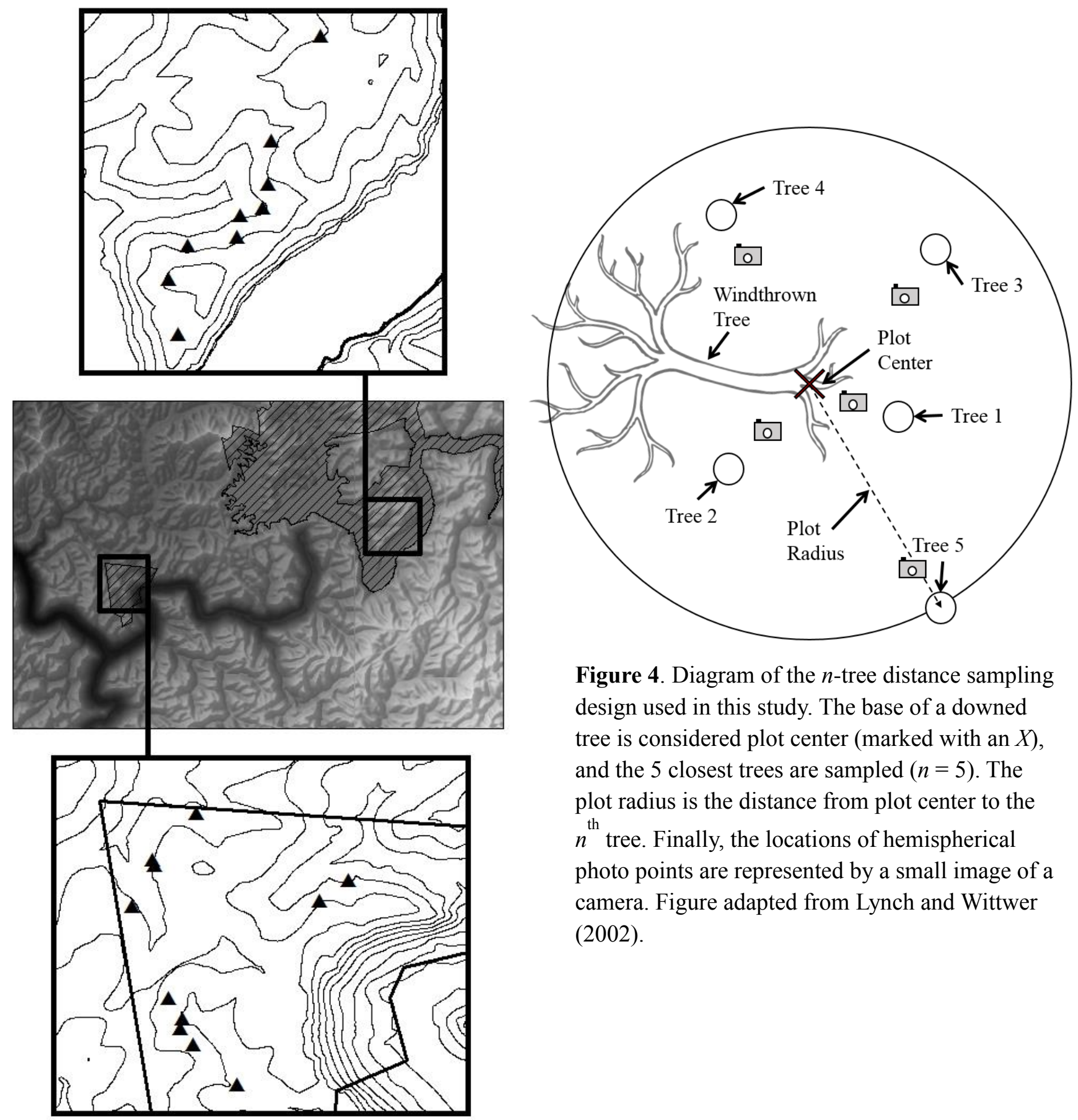

Figure 4. Diagram of the $n$-tree distance sampling design used in this study. The base of a downed tree is considered plot center (marked with an $X$ ), and the 5 closest trees are sampled $(n=5)$. The plot radius is the distance from plot center to the $n$th tree. Finally, the locations of hemispherical photo points are represented by a small image of a camera. Figure adapted from Lynch and Wittwer (2002). 
Table 1. Summary of the characteristics of the two sites sampled, Carnifex Ferry (CFSP) and Summersville Lake (SWMA). Included are estimates of tree density, mean diameter at breast height (DBH) for both species sampled (L. tulipifera and Q. alba), and details of the chronologies created from these species.

\begin{tabular}{|c|c|c|c|c|c|c|c|c|c|c|}
\hline \multirow[b]{2}{*}{ Site Name } & \multirow[b]{2}{*}{ Site Code } & \multirow{2}{*}{\begin{tabular}{|c|} 
Tree Density \\
(stems/ha)
\end{tabular}} & \multicolumn{2}{|c|}{ Mean DBH $(\mathrm{cm})$} & \multicolumn{2}{|c|}{ No. Trees Sampled } & \multicolumn{2}{|c|}{ Chronology Length } & \multicolumn{2}{|c|}{ Interseries Correlation } \\
\hline & & & Liriodendron & Quercus & Liriodendron & Quercus & Liriodendron & Quercus & Liriodendron & Quercus \\
\hline $\begin{array}{l}\text { Carnifex Ferry Battlefield } \\
\text { State Park, Summersville, } \\
\text { WV }\end{array}$ & $\begin{array}{l}\text { CFSP or } \\
\text { CFQ/CFL }\end{array}$ & 431 & 44.9 & 48.4 & 44 & 46 & $\begin{array}{l}1789-2015 \\
\text { (226 years) }\end{array}$ & $\begin{array}{r}1655-2015 \\
\text { (360 years) }\end{array}$ & 0.665 & 0.574 \\
\hline $\begin{array}{l}\text { Summersville Lake Wildlife } \\
\text { Management Area, } \\
\text { Summersville, WV }\end{array}$ & $\begin{array}{l}\text { SWMA or } \\
\text { SWQ/SWL }\end{array}$ & 508 & 39.2 & 44.2 & 45 & 46 & $\begin{array}{l}1925-2015 \\
\text { (90 years) }\end{array}$ & $\begin{array}{c}1864-2015 \\
\text { (151 years) }\end{array}$ & 0.674 & 0.575 \\
\hline
\end{tabular}

\begin{tabular}{|c|c|c|c|c|c|}
\hline \multicolumn{3}{|c|}{ CFSP } & \multicolumn{3}{|c|}{ SWMA } \\
\hline Species & $\begin{array}{l}\text { Relative } \\
\text { Density }\end{array}$ & $\begin{array}{l}\text { Absolute } \\
\text { Density }\end{array}$ & Species & $\begin{array}{l}\text { Relative } \\
\text { Density }\end{array}$ & $\begin{array}{c}\text { Absolute } \\
\text { Density }\end{array}$ \\
\hline Tsuga canadensis & $30 \%$ & 131 & $\begin{array}{l}\text { Acer spp. } \\
\text { (rubrum, saccharum) }\end{array}$ & $53 \%$ & 269 \\
\hline $\begin{array}{l}\text { Acer spp. } \\
\text { (rubrum, saccharum) }\end{array}$ & $24 \%$ & 104 & Liriodendron tulipifera & $22 \%$ & 112 \\
\hline $\begin{array}{l}\text { Quercus spp. } \\
\text { (alba, rubra) }\end{array}$ & $13 \%$ & 54 & $\begin{array}{l}\text { Quercus spp. } \\
\text { (alba, rubra, velutina) }\end{array}$ & $14 \%$ & 71 \\
\hline Liriodendron tulipifera & $11 \%$ & 46 & Betula lenta & $5 \%$ & 25 \\
\hline $\begin{array}{l}\text { Carya spp. } \\
\text { (tomentosa, glabra) }\end{array}$ & $8 \%$ & 35 & Carya tomentosa & $2 \%$ & 10 \\
\hline Oxydendrum arboreum & $5 \%$ & 23 & & & \\
\hline Nyssa sylvatica & $4 \%$ & 14 & & & \\
\hline Total & $95 \%$ & & & $96 \%$ & \\
\hline
\end{tabular}

Table 2. Forest composition data for Carnifex Ferry (CFSP) and Summersville Lake (SWMA). Relative density represents the percent of trees surveyed of each species, and absolute density is the percent composition multiplied by the total density recorded in table 1 (stems/ha). 
Figure 5. Results of RGA sensitivity analysis shows years with released trees in four chronologies: 1) swl=SWMA tulip poplars, 2) swq = SWMA oaks, 3) $c f l=$ CFSP tulip poplars, and 4) $c f q=$ CFSP oaks. Each set of graphs represents a different set of criteria applied to the radial growth averaging method of disturbance detection, as printed in the top left corner of each. Graphs arelisted in order of most conservative to least conservative criteria. Disturb ances are differentiated based on the number of trees released by each, whereby blue dashes indicate fewer trees, and pink to red dashes show more trees affected.
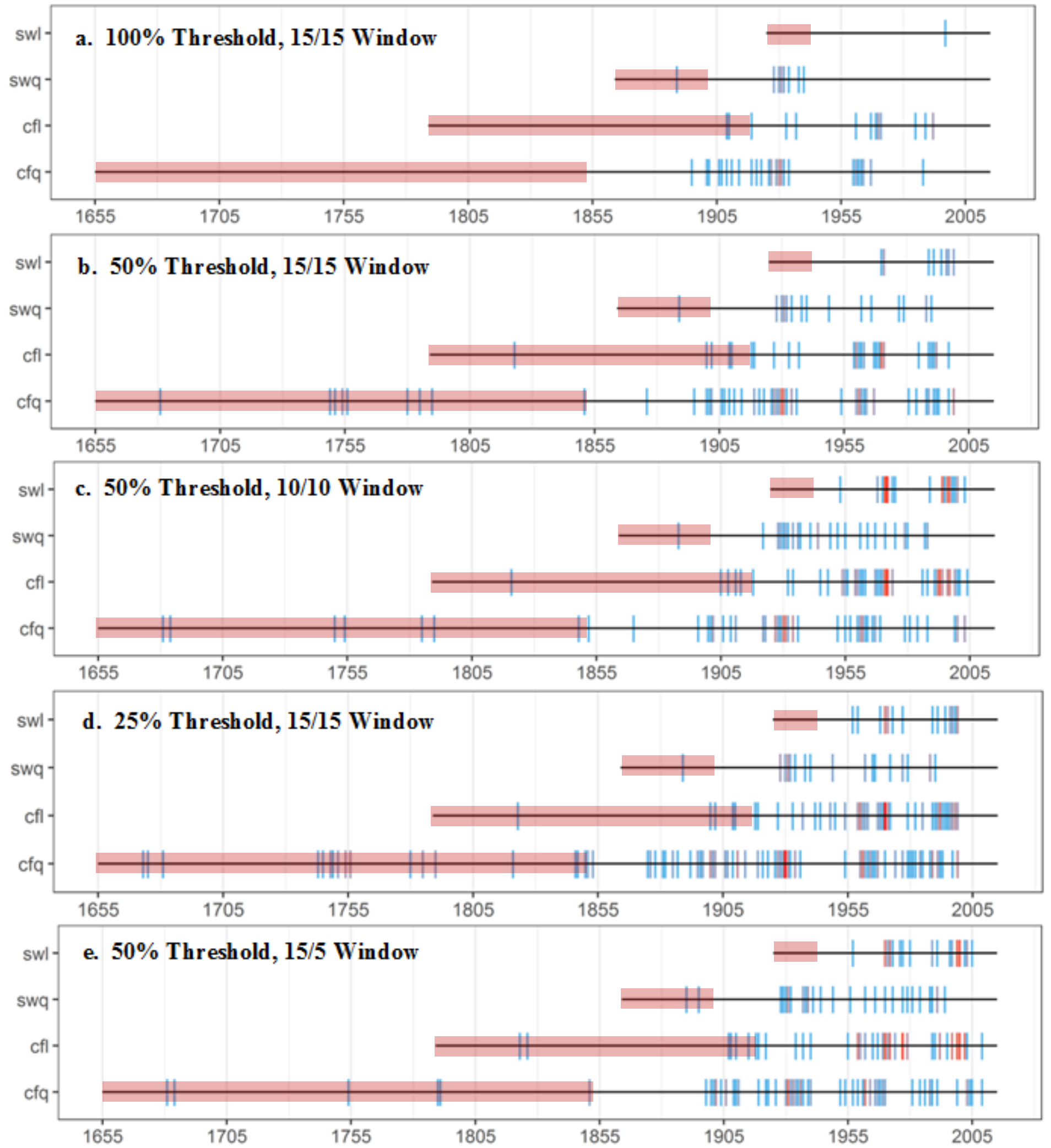

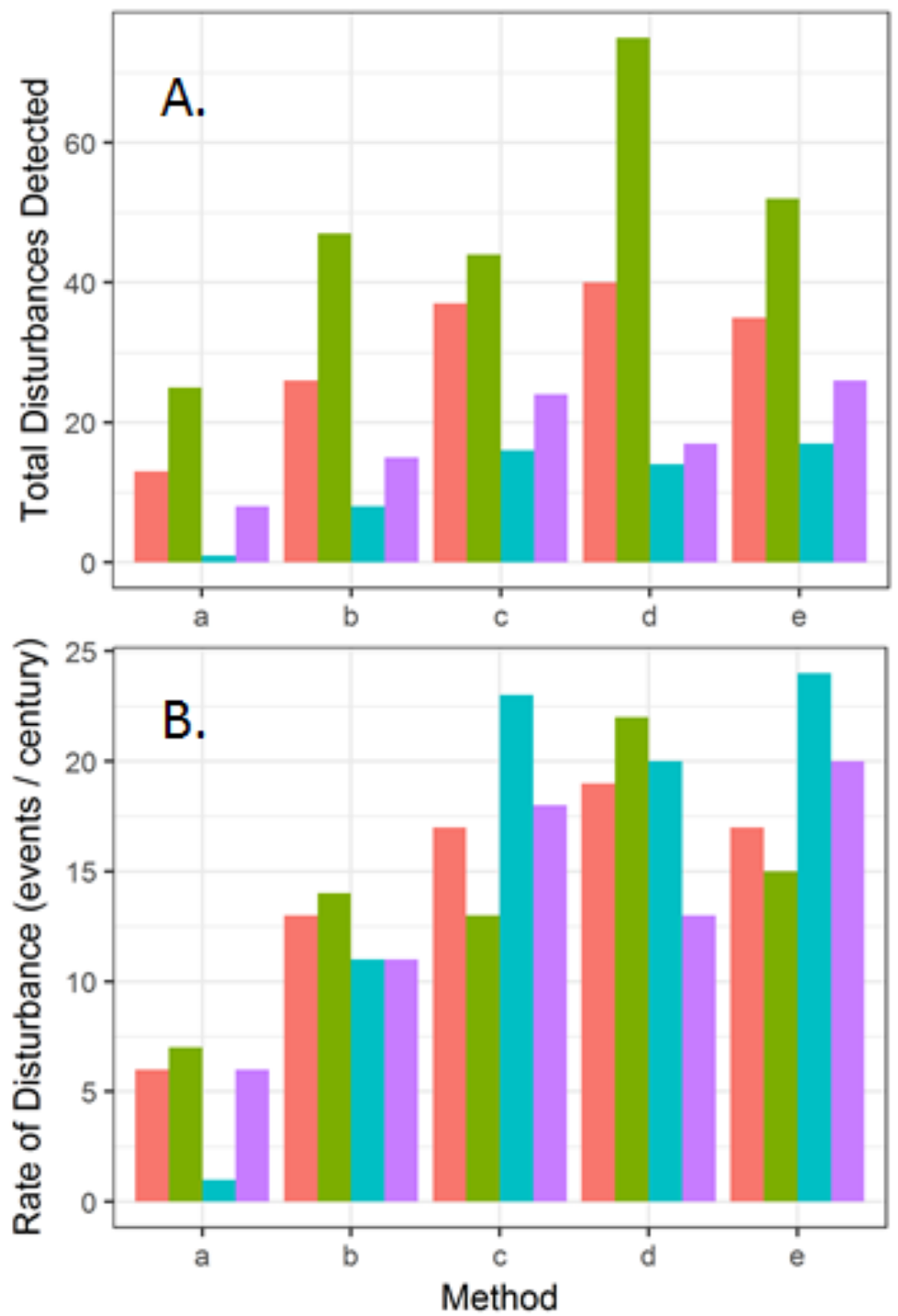

Figure 6. Results of using different thresholds and window lengths in RGA to detect past canopy disturbance in 4 chronologies. Included are A) total number of events detected, and B) the rate of disturbance (events/century). The different criteria used are as follows, in order of most conservative to least conservative criteria:
a. 100\% Threshold, 15/15 Window
b. 50\% Threshold, $15 / 15$ Window
c. 50\% Threshold, 10/10 Window
d. 25\% Threshold, 15/15 Window
e. $50 \%$ Threshold, $15 / 5$ Window

\section{Chronology \\ CFL \\ CFQ \\ SWL \\ SWQ}

Table 3. Summary of the results of three methods used to detect the 2012 derecho: 1) extending each series, 2) using an asymmetrical window, and 3) using a time series intervention method. For each method, the number of trees showing a release in 2012 is listed. Methods one and two are segregated to show a) trees with release between $25-49 \%$, and $b$ ) the number of trees with release $\geq 50 \%$.

\begin{tabular}{|c|c|c|c|c|c|c|c|}
\hline & \multirow{3}{*}{ Method } & \multicolumn{4}{|c|}{ Trees Released in 2012} & \multirow{3}{*}{3} & \multirow{3}{*}{$n$} \\
\hline & & \multicolumn{2}{|c|}{1} & \multicolumn{2}{|c|}{2} & & \\
\hline & & $25-49 \%$ & $\geq 50 \%$ & $25-49 \%$ & $\geq 50 \%$ & & \\
\hline \multirow{2}{*}{ SWMA } & Liriodendron & 1 & 0 & 0 & 0 & 0 & 45 \\
\hline & Quercus & 0 & 0 & 1 & 0 & 0 & 46 \\
\hline \multirow{2}{*}{ CFSP } & Liriodendron & 1 & 2 & 0 & 2 & 0 & 44 \\
\hline & Quercus & 2 & 2 & 5 & 1 & 0 & 46 \\
\hline
\end{tabular}



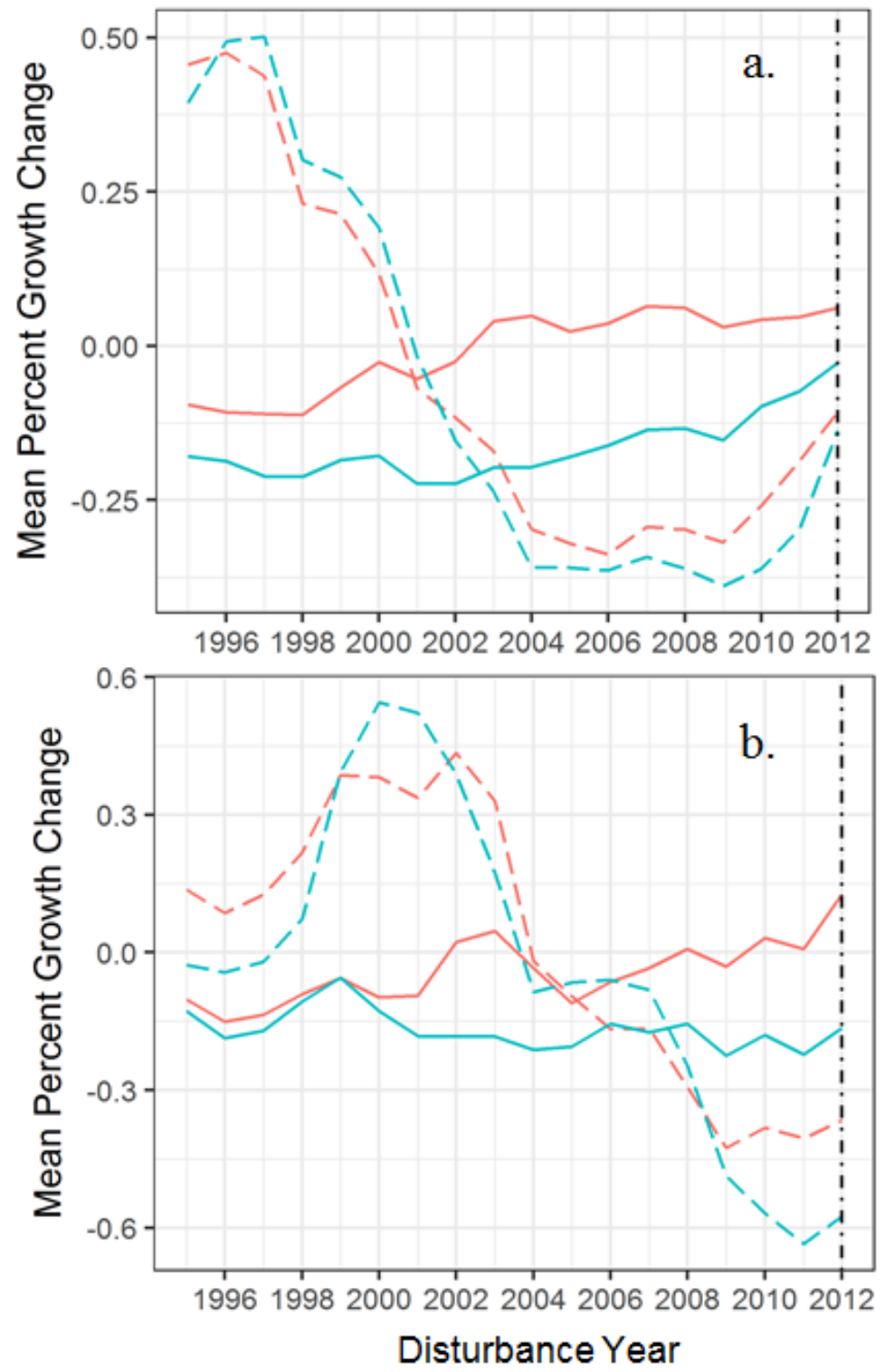

Figure 7. Results of two RGA methods, used to detect the 2012 derecho: a) extending each series and b) using an asymmetrical window. Graphs show the mean value of percent growth change calculated for each year from 1995-2012. Each value represents the difference in average ring width between the period after and the period before each year tested for disturbance. Color of the line indicates CFSP (red) or SWMA (blue), and line type shows the species (dashed = tulip poplar; solid = Quercus spp.) .

\section{Species \\ - - Liriodendron \\ - Quercus}

Site

- Summersville

Figure 8. Results of Curve Intervention Detection (CID) analysis, used to detect the 2012 derecho. Graph shows the mean standardized disturbance series, which represents the average disturbance trend present in sampled trees. Color of the line indicates CFSP (red) or SWMA (blue), and line type shows the species (dashed = tulip poplar; solid = Quercus spp.) .

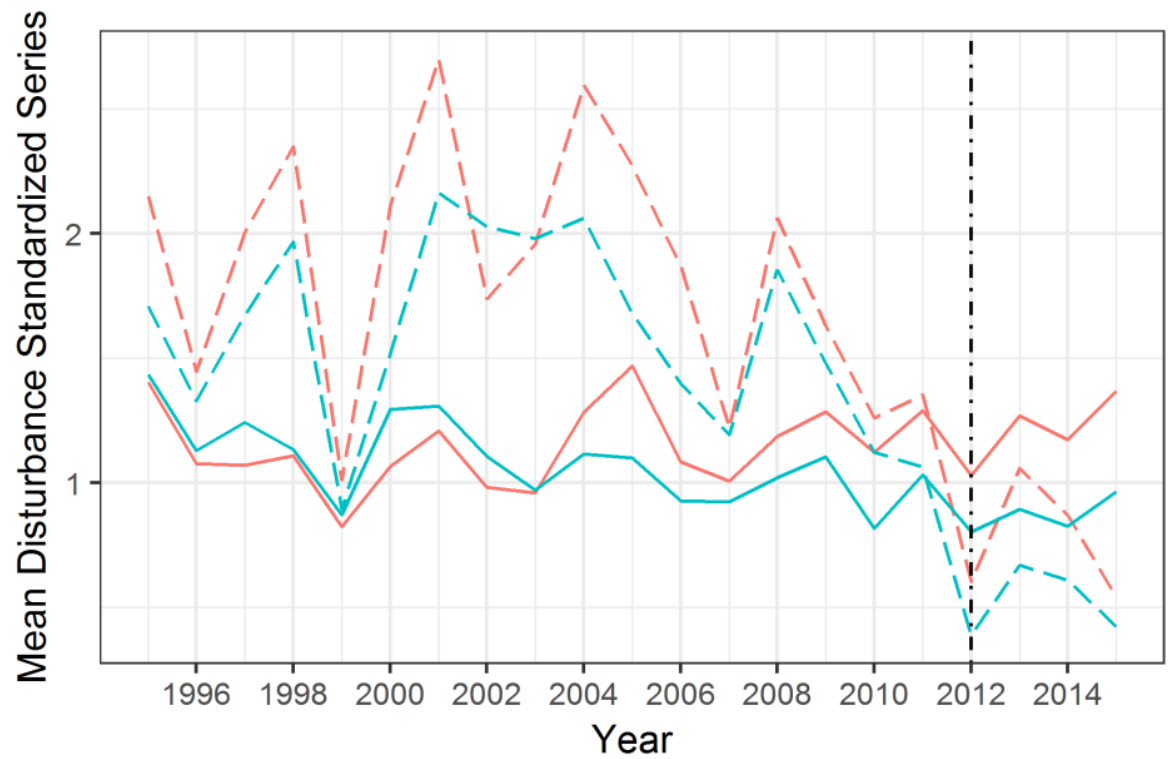



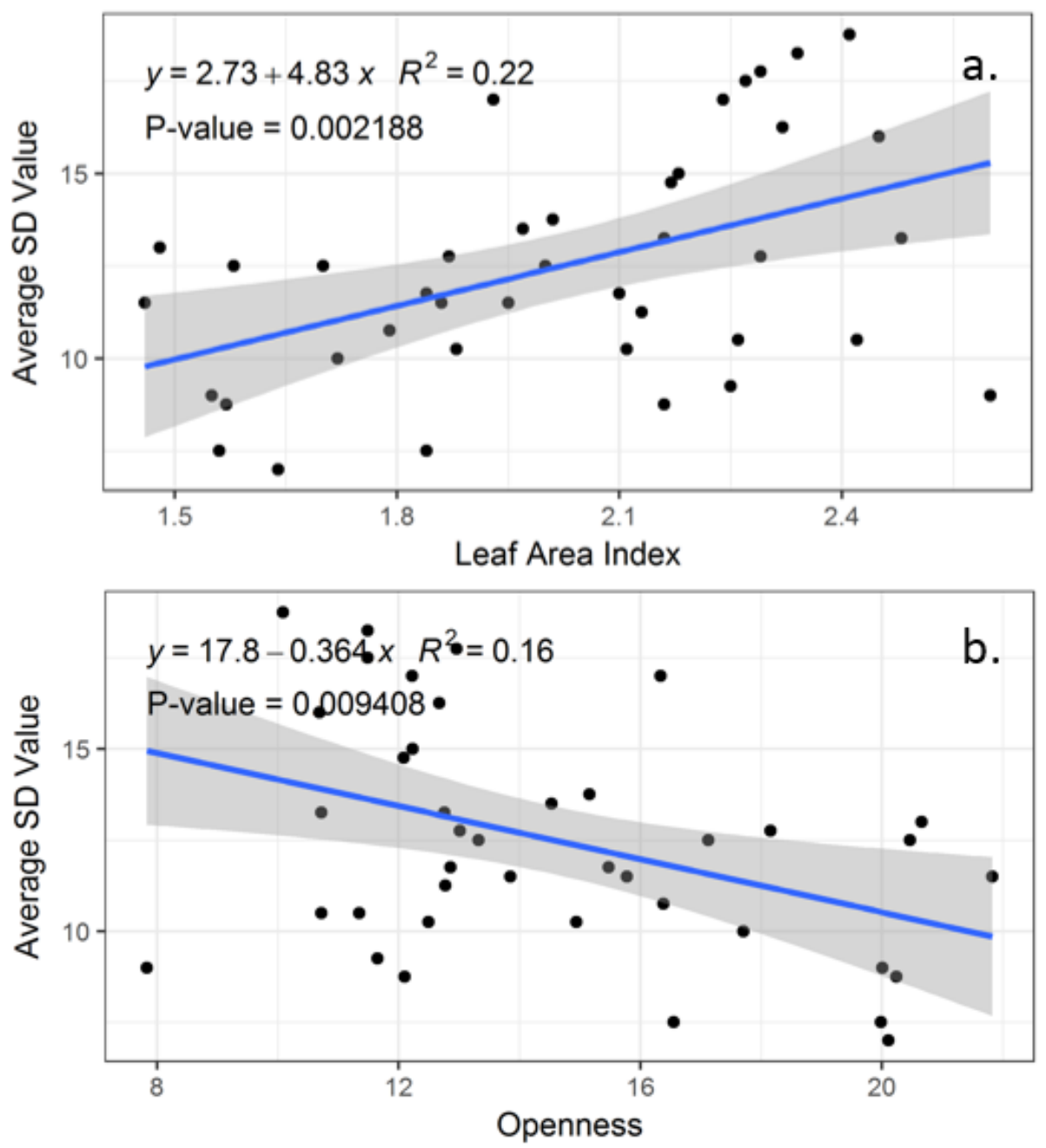

Figure 9. Relationship between spherical densiometer values and two measures of light availability derived from hemispherical photographs: a) Leaf area index 2000 (LAI) and b) Openness. Corresponding linear regression equations, $\mathrm{R}^{2}$ values, and $p$-values are printed in the upper left corner of each graph. Error bars represent $95 \%$ confidence intervals. 


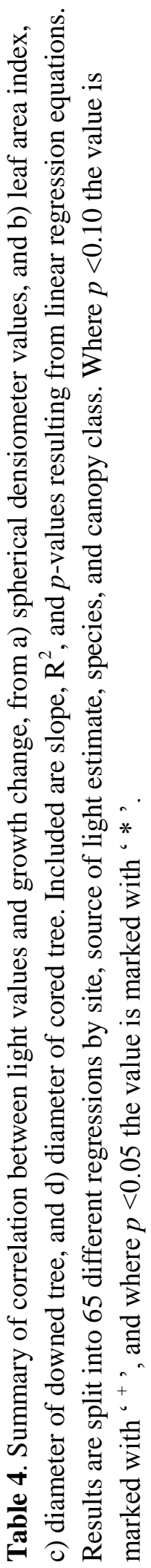

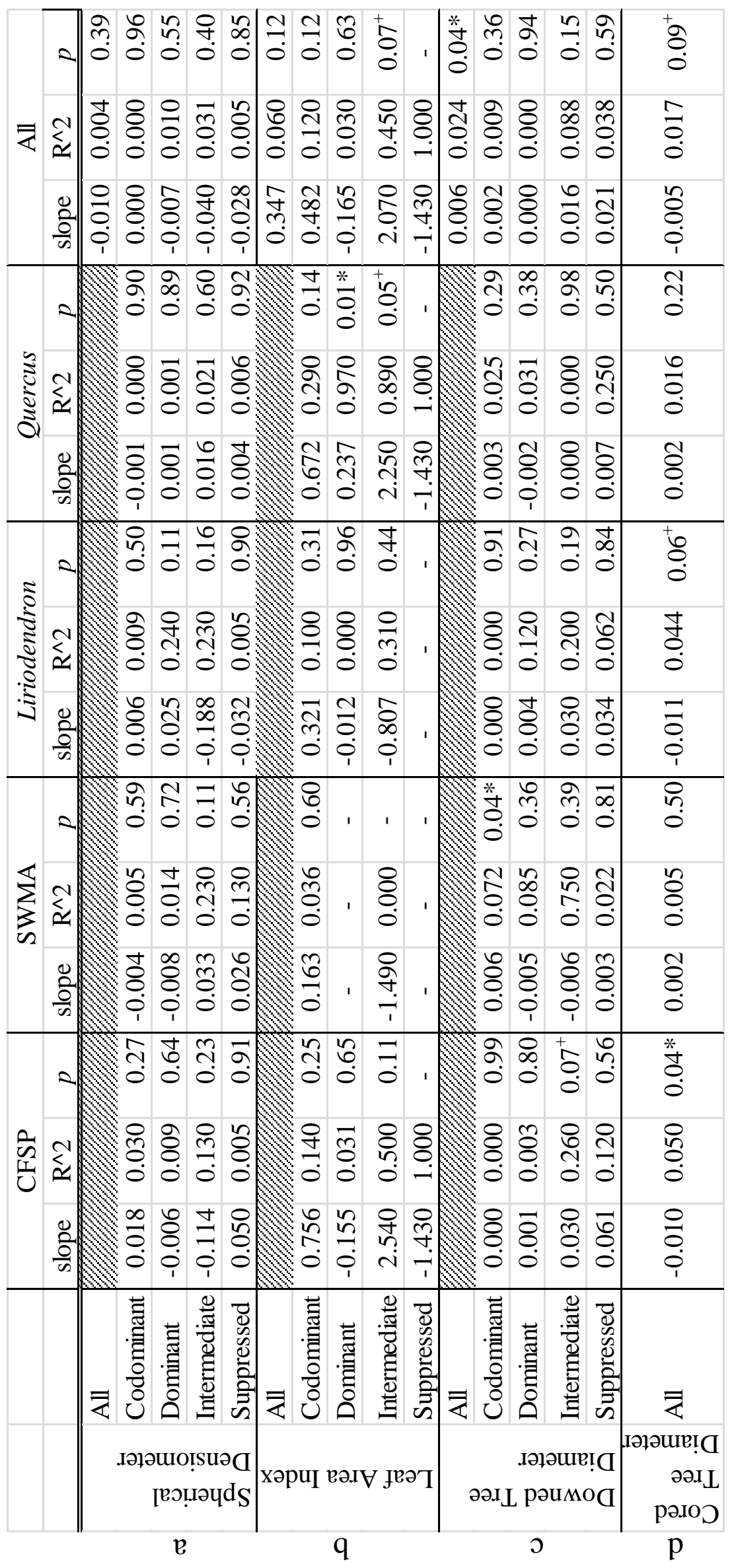



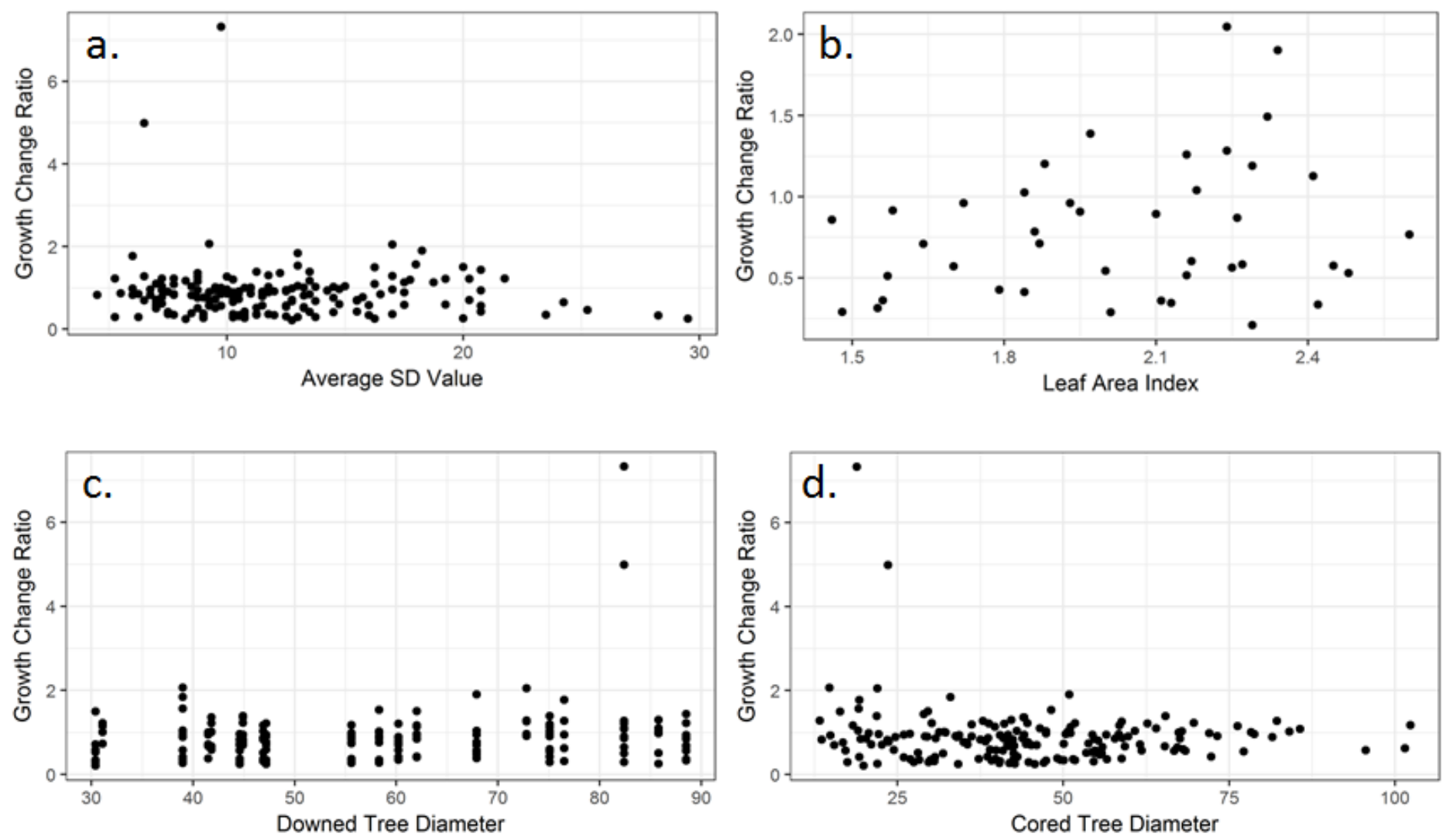

Figure 10. Relationship between 2012 growth change ratio (GCR) and a) spherical densiometer values, b) leaf area index (LAI), c) downed tree diameter, and d) cored tree diameter. These plots are composed of the full dataset $(n=181)$. Regression equation information can be found in table 4 where row and column are labeled 'all.' 
a. Carnifex Ferry Cores
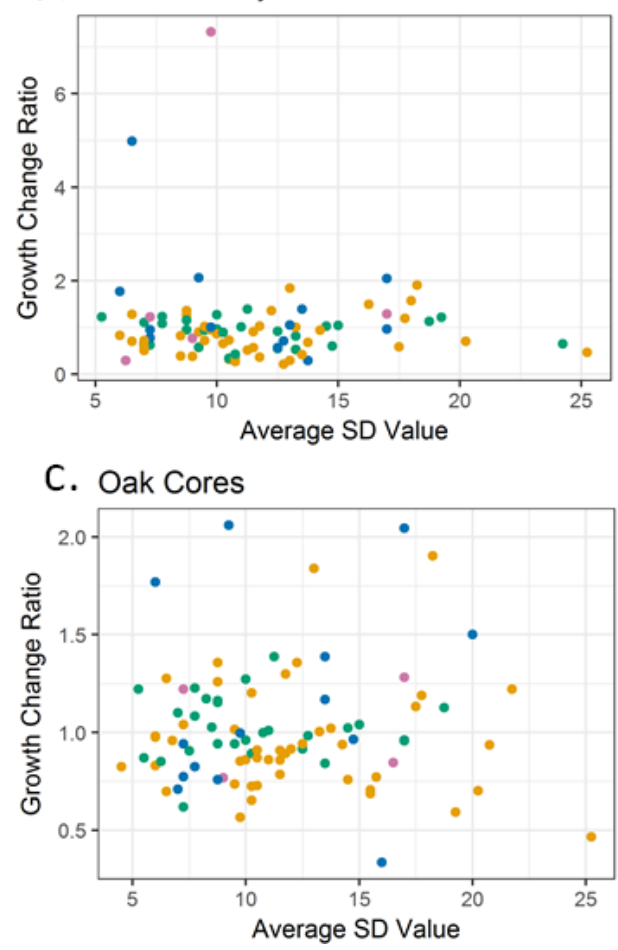

b. Summersville Lake Cores

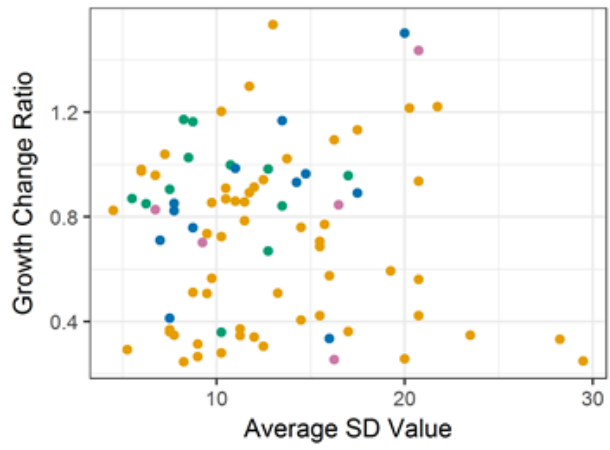

d. Tulip Poplar Cores

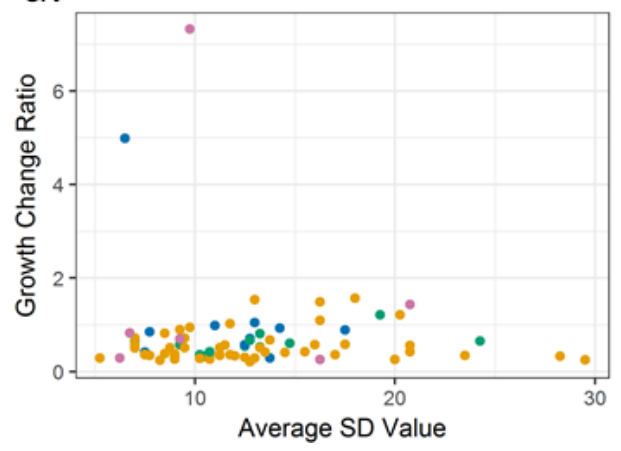

Figure 11. Relationship between 2012 growth change ratio (GCR) and spherical densiometer values, with data separated by site (a-b) and species (c-d). Color of points represents the canopy class of the corresponding individual. Regression equation information can be found in table 4.

a. Carnifex Ferry Cores

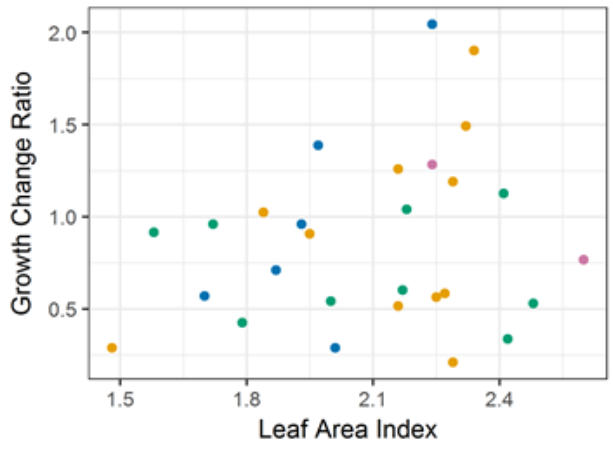

C. Oak Cores

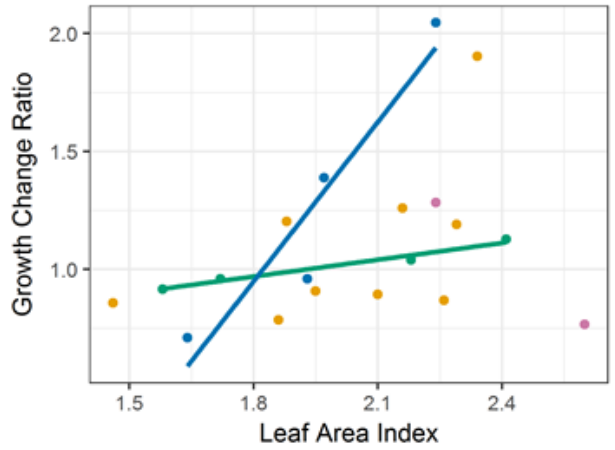

b. Summersville Lake Cores

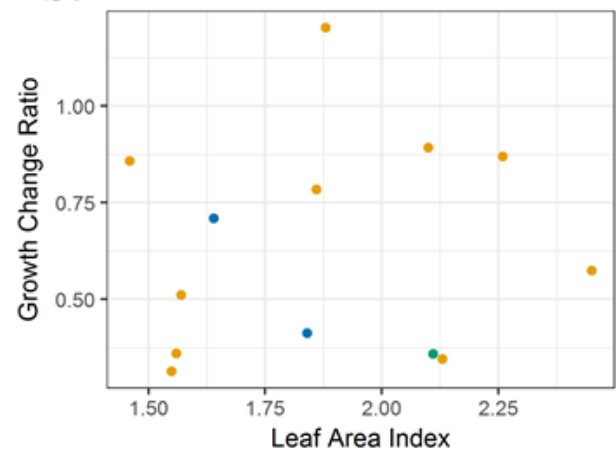

Canopy Class

- Codominant

- Dominant

- Intermediate

- Suppressed d. Tulip Poplar Cores

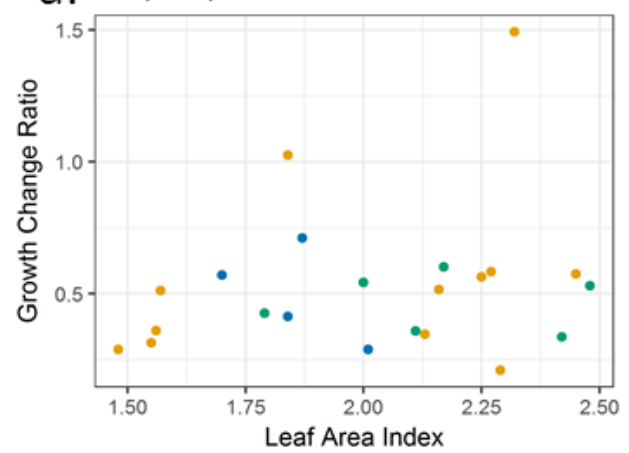

Figure 12. Relationship between 2012 growth change ratio (GCR) and leaf area index (LAI), with data separated by site (a-b) and species (c-d). Color of points represents the canopy class of the corresponding individual. Lines of best fit are shown where correlation is significant. Regression equation information can be found in table 4. 

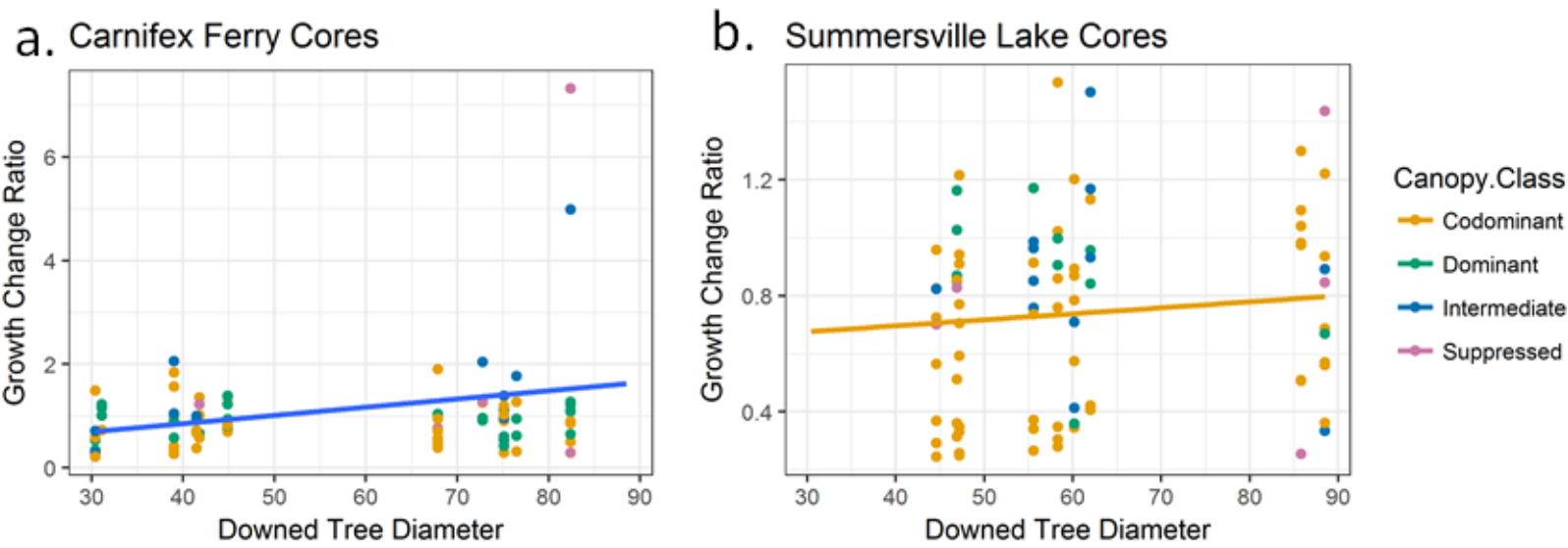

\section{Oak Cores}

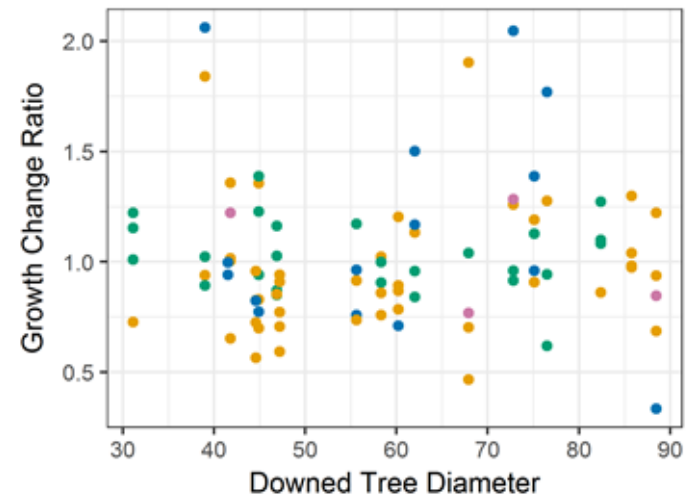

d. Tulip Poplar Cores

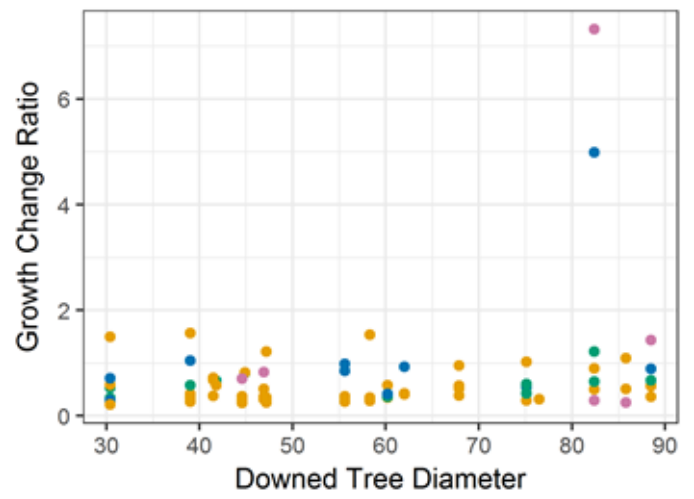

Figure 13. Relationship between 2012 growth change ratio (GCR) and diameter of the downed tree associated with each plot, with data separated by site (a-b) and species (c-d). Color of points represents the canopy class of the corresponding individual. Lines of best fit are shown where correlation is significant. Regression equation information can be found in table 4.

a. Carnifex Ferry Cores

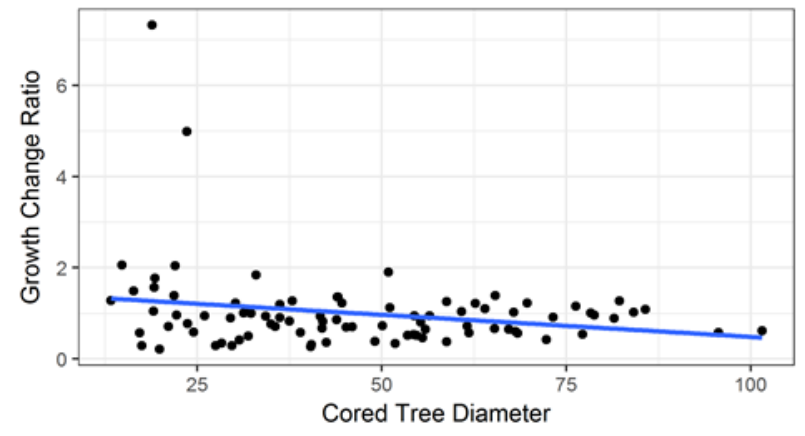

C. Oak Cores

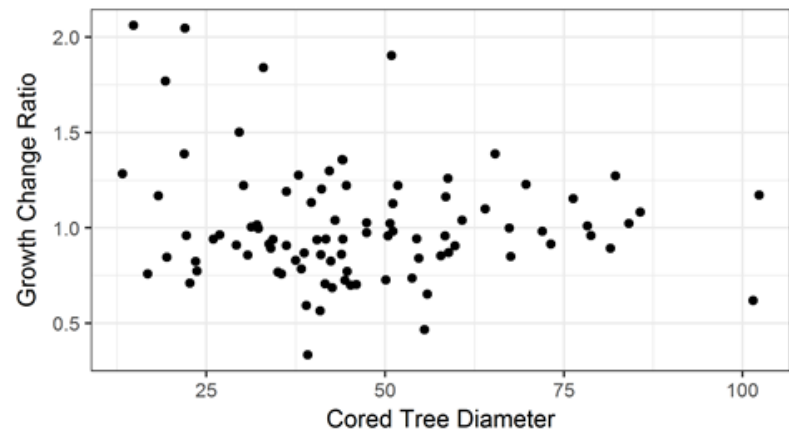

b. Summersville Lake Cores

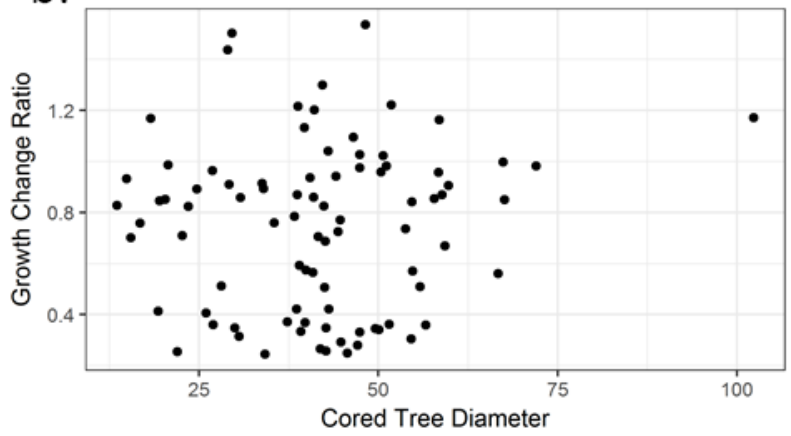

d. Tulip Poplar Cores

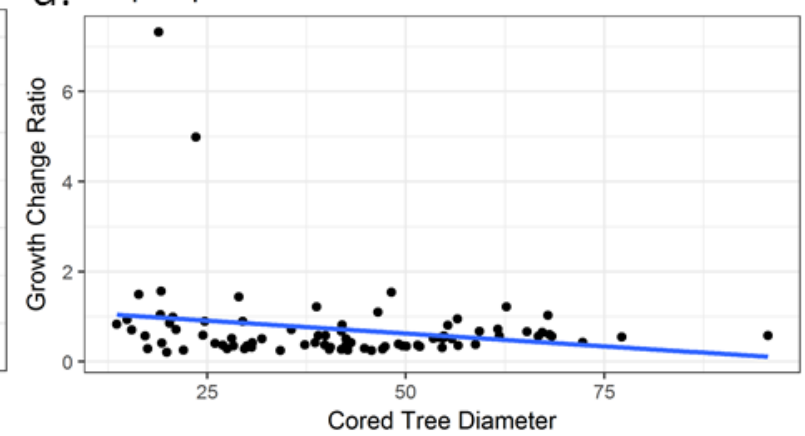

Figure 14. Relationship between 2012 growth change ratio (GCR) and diameter of the sampled tree, with data separated by site (a-b) and species (c-d). Lines of best fit are shown where correlation is significant. Regression equation information can be found in table 4. 


\section{References}

Altman J, Dolezal J, Cerny T, and Song J. 2013. Forest response to increasing typhoon activity on the Korean peninsula: evidence from oak tree-rings. Global Change Biology 19:498-504.

Altman J, Fibich P, Dolezal J, and Aakala T. 2014. TRADER: A package for Tree Ring Analysis of Disturbance Events in R. Dendrochronologia 32:107-112.

Anning AK. 2013. Prescribed fire and thinning effects on tree growth and carbon sequestration in mixed-oak forests, Ohio, USA. Ph.D. Dissertation. Ohio University.

Bartlein PJ. 2013. Paleoclimate: Timescales of Climate Change, in SA Elias and CJ Mock, eds. Encyclopedia of Quaternary Science (2nd edition). Elsevier, Waltham, MA. pp. 93-101.

Beaudet M and Messier C. 2002. Variation in canopy openness and light transmission following selection cutting in northern hardwood stands: an assessment based on hemispherical photographs. Agricultural and Forest Meteorology 110:217-228.

Bhuta AAR, Kennedy LM, Copenheaver CA, Sheridan PM, and Campbell JB. 2008. Boundary line growth patterns to determine disturbance history of remnant longleaf pine (Pinus palustris P. Mill.) in mixed forests of southeastern Virginia. Journal of the Torrey Botanical Society 135:516-529.

Black BB and Abrams MD. 2003. Use of boundary-line growth patterns as a basis for dendroecological release criteria. Ecological Applications 13:1733-1749.

Black BB, Abrams MD, Rentch JS, and Gould PJ. 2009. Properties of boundary-line release criteria in North American tree species. Annals of Forest Science 66:1-19.

Braun EL 1950. Deciduous Forests of Eastern North America. Hafner Press. New York, NY.

Brown WG. 1954. History of Nicholas County, West Virginia. The Dietz Press, Inc. Richmond, VA.

Bunn AG. 2008. A dendrochronology program library in R (dplR). Dendrochronologia 26:115-124. Retrieved from http://doi.org/10.1016/j.dendro.2008.01.002.

Burns DP. 1971. Yellow-Poplar Weevil. US Department of Agriculture, Forest Service, Forest Pest Leaflet 125:1-5.

Clark JS, Royall DP, and Chumbley C. 1996. The role of fire during climate change in an eastern deciduous forest at Devil's Bathtub, New York. Ecology 77:2148-2166.

Clarkson RB. 1964. Tumult on the Mountains: Lumbering in West Virginia-1770-1920. 
McClain Printing Company. Parsons, WV.

Cockrell SW, de Graauw KK., Ziegler AM, and Hessl AE. 2017. Precision dating of Cook's

Mill, a Civil War era structure in West Virginia. Dendrochronologia 4: 20-26.

Comeau P. 2000. Measuring light in the forest. British Columbia Ministry of Forests Research

Program, Extension Note 42. pp1-7.

Copenheaver CA, Seiler JR, Peterson JA, Evans AM, McVay JL, and White JH. 2014. Stadium

Woods: A dendroecological analysis of an old-growth forest fragment on a university campus. Dendrochronologia 32:62-70.

Corfidi SF. 2017. June 29, 2012 Derecho: The Ohio Valley/Mid-Atlantic Derecho of June 2012. NOAA-NWS-NCEP Storm Prediction Center Website. Retrieved from http://www.spc.noaa.gov/misc/AbtDerechos/casepages/jun292012page.htm.

Delcourt HR and Delcourt PA 1996. Pre-Columbian Native American use of fire on southern Appalachian landscapes. Conservation Biology 11:1010-1014.

Druckenbrod DL, Pederson N, Rentch J, and Cook ER. 2013. A comparison of time seris approaches for dendroecological reconstructions of past canopy disturbance events. Forest Ecology and Management 302:23-33.

Dyer JM. 2006. Revisiting the deciduous forests of eastern North America. Bioscience 56:341-352.

Everham EM and Brokaw NVL. 1996. Forest damage and recovery from catastrophic wind. The Botanical Review 62:113-185.

Forest Health Programs. 2016. 2015 Forest Health Highlights: West Virginia. USDA Forest Service, Northeastern Area State and Private Forestry Report. Retrieved from https://www.fs.fed.us/foresthealth/fhm/fhh/fhh_15/WV_FHH_2015.pdf.

Furgione LK. 2013. The historic derecho of June 29, 2012. National Oceanic and Atmospheric Administration: Assessment of Service.

Grissino-Mayer HD, Holmes RL, and Fritts HC. 1997. The international tree-ring data bank program library version 2.1 user's manual. Laboratory of Tree-Ring Research, University of Arizona, Tucson, AZ.

Hanson JJ and Lorimer CG. 2007. Forest structure and light regimes following moderate wind storms: implications for multi-cohort management. Ecological Applications 17:1325-1340. 
Hicks RR. 1998. Ecology and Management of Central Hardwood Forests. John Wiley and Sons, Inc. New York, NY.

Jennings SB, Brown ND, and Sheil D. 1999. Assessing forest canopies and understorey illumination: canopy closure, canopy cover and other measures. Forestry 71:59-73.

Jonckheere I, Fleck S, Nackaerts K, Muys B, Coppin P, Weiss M, and Baret F. 2001. Review of methods for in situ leaf area index determination Part I. Theories, sensors and hemispherical photography. Agricultural and Forest Meteorology 121:19-35.

Kobe RK, Pacala SW, Silander Jr. JA, and Canham CD. 1995. Juvenile tree survivorship as a component of shade tolerance. Ecological Applications 5:517-532.

Krebs CJ. 2009. Ecology: The Experimental Analysis of Distribution and Abundance. Pearson Education, Inc. San Francisco, CA.

Leblanc SG, Chen JM, Fernandes R, Deering DW, and Conley A. 2005. Methodology comparison for canopy structure parameters extraction from digital hemispherical photography in boreal forests. Agricultural and Forest Meteorology 129:187-207.

Lorimer CG. 2001. Historical and ecological roles of disturbance in eastern North American forests: 9,000 years of change. Wildlife Society Bulletin 29:425-439.

Lorimer C and Frelich LE. 1989. A methodology for estimating canopy disturbance frequency and intensity in dense temperate forests. Canadian Journal of Forestry 19:651-663.

Lynch TB, and Wittwer RF. 2002. Per tree estimates with $n$-tree distance sampling: an application to increment core data. In: McRoberts RE, Reams GA, Van Deusen PC, Moser JW, eds. Proceedings of the Third Annual Forest Inventory and Analysis Symposium; GTR. NC-230. St. Paul, MN: U.S.D.A., Forest Service, North Central Research Station: 1-4.

Macfarlane C and Ogden GN. 2012. Automated estimation of foliage cover in forest understorey from digital nadir images. Methods in Ecology and Evolution 3:405-415.

MathWorks, Inc. 2000. MATLAB: The Language of Technical Computing: Computation, Visualization, Programming. MathWorks, Inc., Natwick, MA.

McCarthy J. 2001. Gap dynamics of forest trees: A review with particular attention to boreal forests. Environmental Reviews 9.1:1-59.

McEwan RW, Pederson N, Cooper A, Taylor J, Watts R., and Hruska A. 2014. Fire and gap dynamics over 300 years in an old-growth temperate forest. Applied Vegetation 
Science 17:312-322.

McLachlan JS, Foster DR, Menalled F. 2000. Anthropogenic ties to late-successional structure and composition in four New England hemlock stands. Ecology 81:717-733.

Miller JB. 1967. A formula for average foliage density. Australian Journal of Botony 15:141-144.

Muscolo A, Bagnato S, Sidari M, and Mercurio R. 2014. A review of the roles of forest canopy gaps. Journal of Forestry Research 25:725-736.

Nicholas County Historical and Genealogical Society, Inc. 1985. Nicholas County West Virginia History. Walsworth Press, Inc. Salem, WV.

Nowacki GJ and Abrams MD. 1997. Radial-growth averaging criteria for reconstruction disturbance histories from presettlement-origin oaks. Ecological Monographs 67: 225-249.

Nowacki GJ and Abrams MD. 2008. The demise of fire and "mesophication" of forests in the eastern United States. BioScience 58:123-138.

Oliver CD and Larson BC. 1996. Forest Stand Dynamics. John Wiley and Sons, Inc. New York, NY.

Pacala SW, Canham CD, Saponara J, Silander Jr JA, Kobe RK, and Ribbens E. 1996. Forest models defined by field measurements: estimation, error analysis, and dynamics. Ecological Monographs 66:1-43.

Paletto A and Tosi V. 2009. Forest canopy cover and canopy closure: comparison of assessment techniques. European Journal of Forest Research 128:265-272.

Papaik MJ and Canham CD. 2006. Species resistance and community response to wind disturbance regimes in northern temperate forests. Journal of Ecology 94:1011-1026.

Pederson N, Dyer JM, McEwan RW, Hessl AE, Mock CJ, Orwig DA, Rieder HE, and Cook BI. 2014. The legacy of episodic climatic events in shaping temperate, broadleaf forests. Ecological Mondographs 84:599-620.

Peterson CJ. 2000. Catastrophic wind damage to North American forests and the potential impact of climate change. The Science of the Total Environment 262:287-311.

Peterson CJ. 2007. Consistent influence of tree diameter and species on damage in nine eastern North America tornado blowdowns. Forest Ecology and Management 250:96-108.

Pitt D and Lanteigne L. 2008. Long-term outcome of precommercial thinning in northwestern 
New Brunswick: growth and yield of balsam fir and red spruce. Canadian Journal of Forest Research 8:592-610.

R Core Team. 2016. R: A language and environment for statistical computing. R Foundation for Statistical Computing, Vienna, Austria. Retrieved from https://www.R-project.org/.

Regent Instruments, Inc. 2013. WinSCANOPY. Canopy Structure and Solar Radiation.

Rentch JS, Desta F, Miller GW. 2002. Climate, canopy disturbance, and radial growth averaging in a second-growth mixed-oak forest in West Virginia, USA. Canadian Journal of Forest Research 32:915-927.

Rodgers JC, Gamble DW, McCay DG, and Phipps S. 2006. Tropical cyclone signals within treering chronologies from Weeks Bay National Estuary and Research Reserve, Alabama. Journal of Coastal Research 22:1320-1329.

Rubino DL and McCarthy BC. 2004. Comparative analysis of dendroecological methods used to assess disturbance events. Dendrochronologia 21:97-115.

Runkle JR. 1998. Changes in Southern Appalachian canopy tree gaps sampled thrice. Ecology 79: $1768-1780$.

Stahlgren L, Jones M, Burdin R, and Mabelitini B. 2007. Historical Archaeological Survey: New River Gorge National River and Gauley River National Recreation Area. University of Kentucky and the Kentucky Heritage Council. Kentucky Archaeological Survey Report No. 143. Retrieved from: http://core.tdar.org/document/372161/historical-archaeologicalsurvey-new-river-gorge-national-river-and-gauley-river-national-recreation-area.

Stan AB and Daniels LD. 2010. Calibrating the radial-growth averaging method for detecting releases in old-growth forests of coastal British Columbia, Canada. Dendrochronologia 28:135-147.

Stokes MA and Smiley TL.1968. An Introduction to Tree-Ring Dating. University of Arizona Press, Tucson, AZ.

Trotsiuk V, Druckenbrod D, Martin-Benito D, Orwig D, Bishop D, Barker-Plotkin A, Fraver S, and Pederson N. In preparation. Testing the efficacy of tree-ring methods for detecting past canopy release events using experimental data and known events. Methods in Ecology and Evolution.

Turner MG. 1989. Landscape ecology: The effect of pattern on process. Annual Review of Ecology and Systematics 20:171-197. 
Turner MG. 2010. Disturbance and landscape dynamics in a changing world. Ecology 91 : 2833-2849.

Voor Tech Consulting. 2008. Measure J2X.

Walker S.A and Mote TL. 2005. Derecho hazards in the United States. Bulletin of the American Meteorological Society 86:1577-1592.

Welles JM and Norman JM. 1991. Instrument for indirect measurement of canopy architecture. Agronomy Journal 83:818-825.

West Virginia Division of Natural Resources. 2015. West Virginia Natural Heritage Program Vegetation Plots. Plots2-WV database of community ecology plots. West Virginia Natural Heritage Program, WVDNR, Elkins, WV.

Wood JM, Wood PB, and Perez J. 2009. Hemlock ecosystem monitoring of New River Gorge National River and Gauley River National Recreation Area vegetation and bird communities: 1998-2008. National Park Service Northeast Region. Natural Resources Report NPS/NER/NRR—2009/019. 


\section{Supplemental Materials}

A. Examples of light data results for four trees sampled. The tree ID appears in the top left corner of the first picture in each row. From left to right, the first picture shows the gap in the plot in question, while the second picture is the hemispherical photo corresponding to the given tree. Finally, the values appearing to the right of the pictures represent data derived from the hemispherical photo, and from field estimates via spherical densiometer (SD Avg).

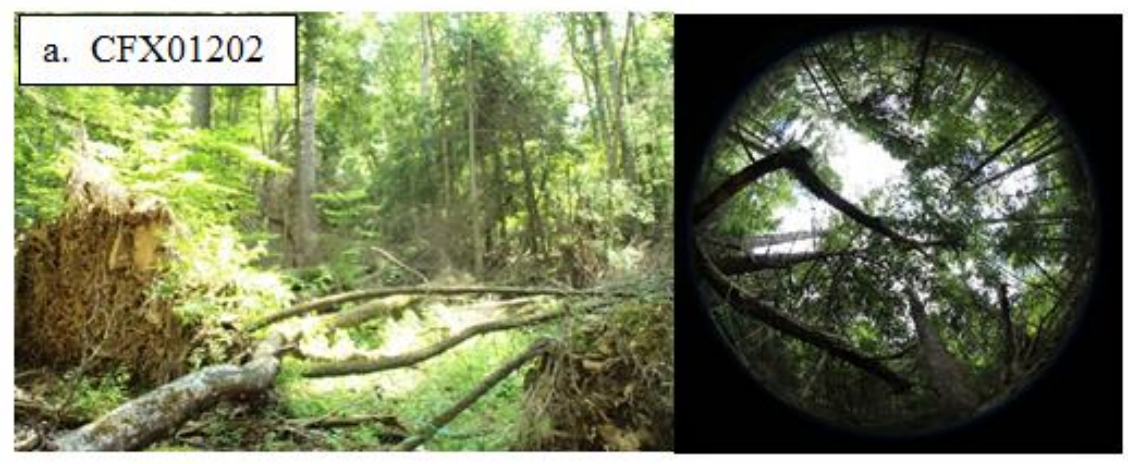

\begin{tabular}{|ll|}
\hline Openness & 12.1 \\
LAI 2000 & 2.16 \\
SD Avg & 8.75 \\
\hline
\end{tabular}

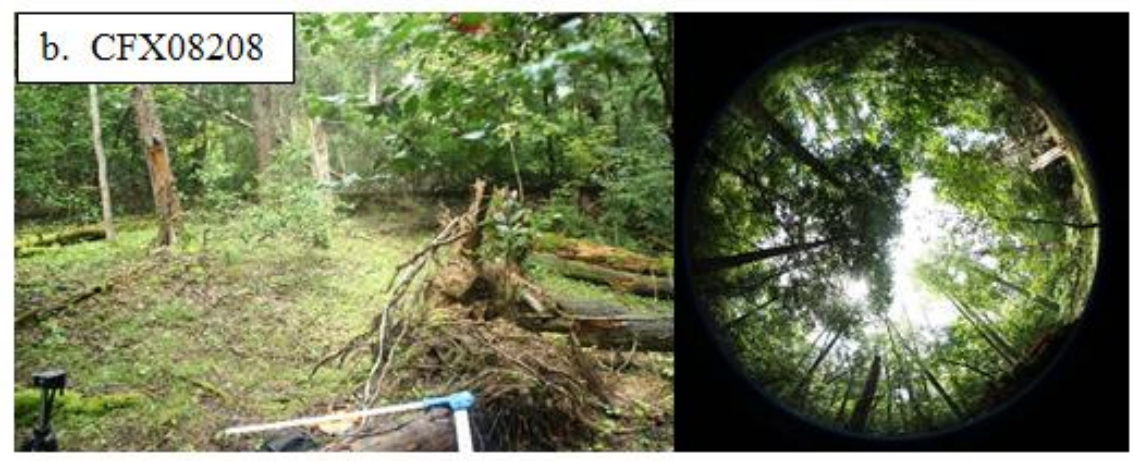

\begin{tabular}{|ll|}
\hline Openness & 11.49 \\
LAI 2000 & 2.27 \\
SD Avg & 17.5 \\
\hline
\end{tabular}
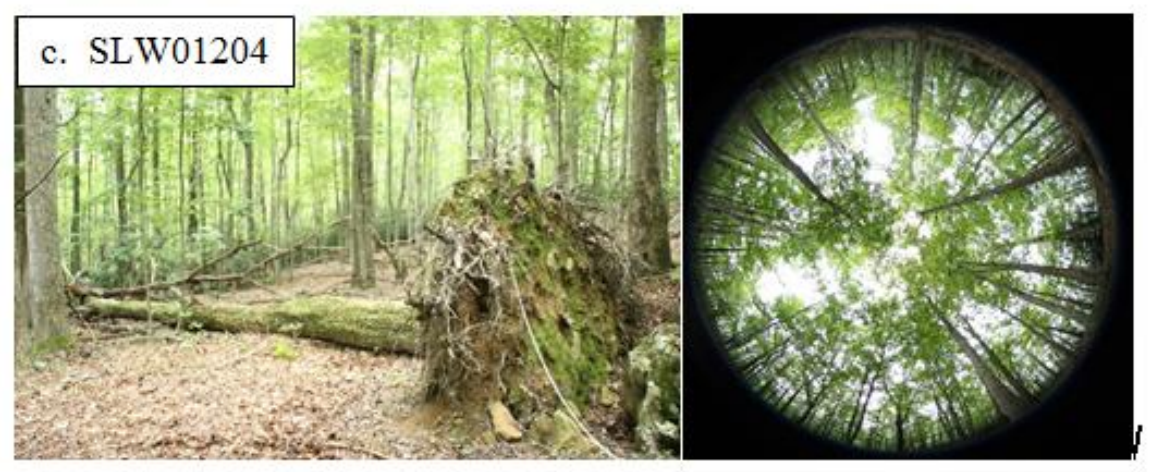

\begin{tabular}{|ll|}
\hline Openness & 20.11 \\
LAI 2000 & 1.64 \\
SD Avg & 7 \\
\hline
\end{tabular}

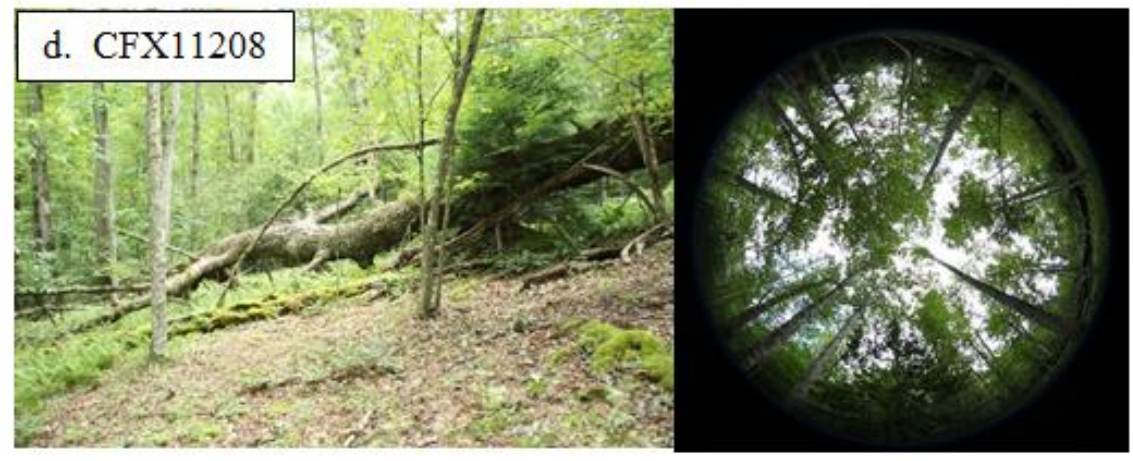

\begin{tabular}{|ll|}
\hline Openness & 17.13 \\
LAI 2000 & 1.7 \\
SD Avg & 12.5 \\
\hline
\end{tabular}




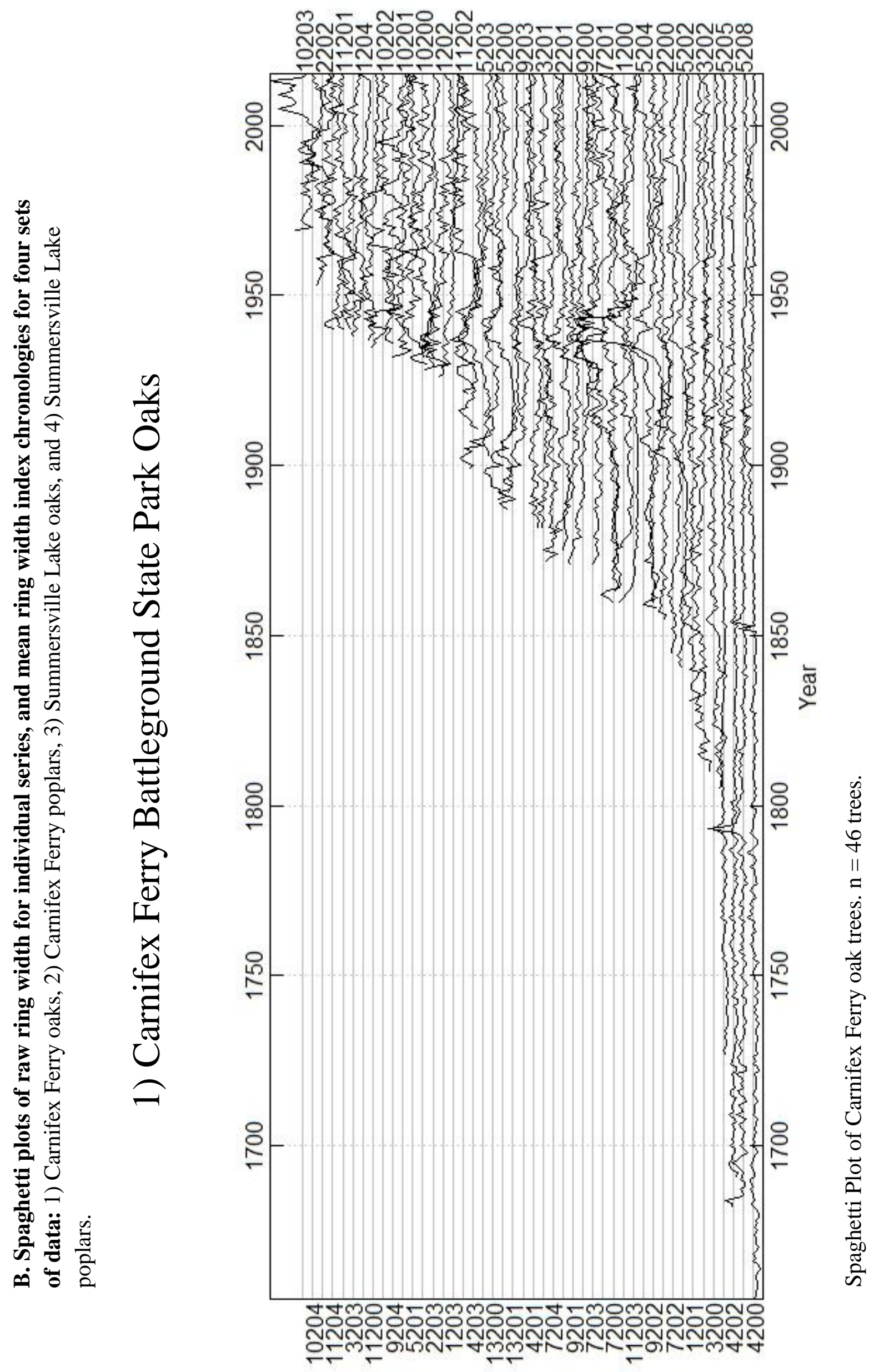




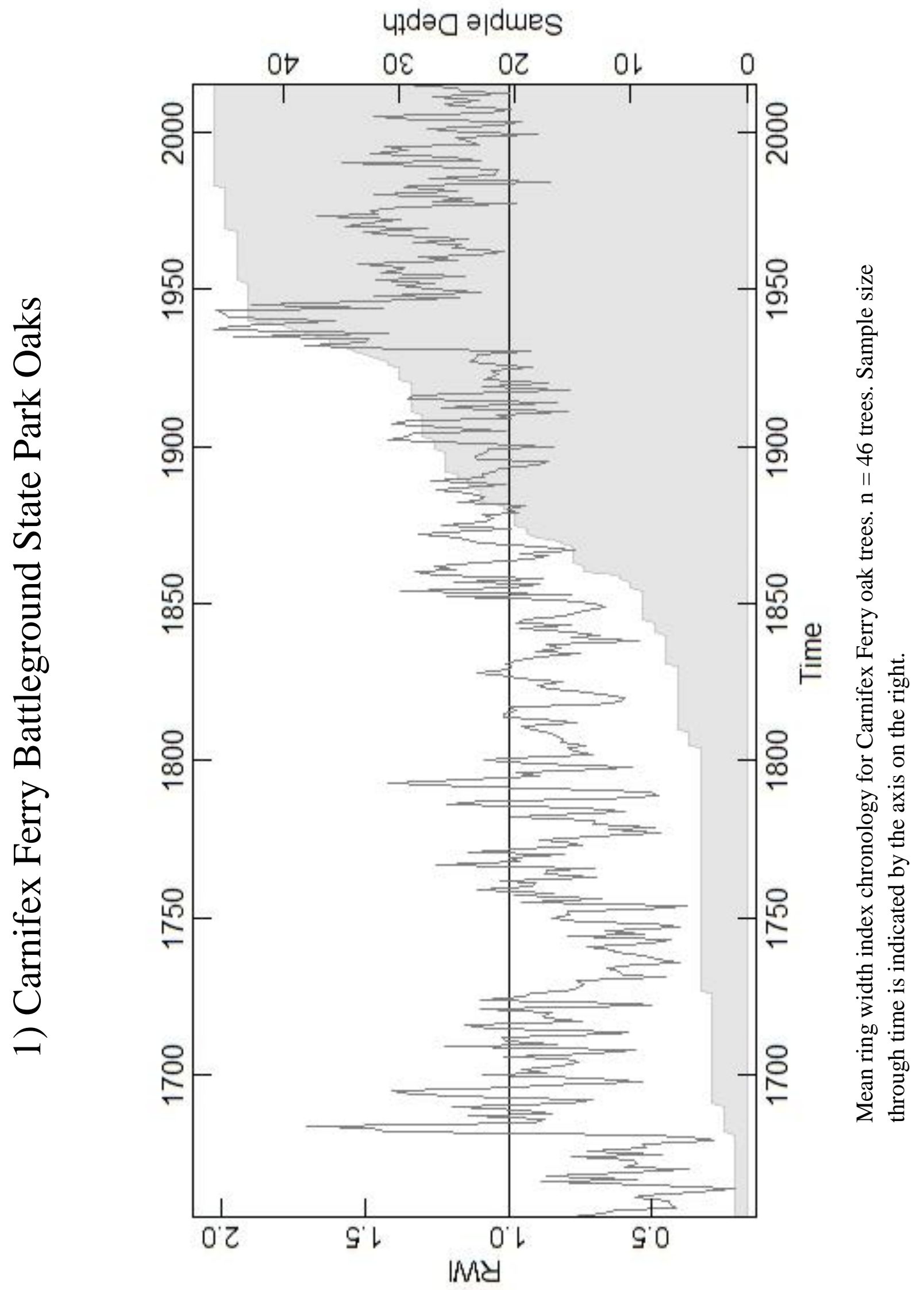




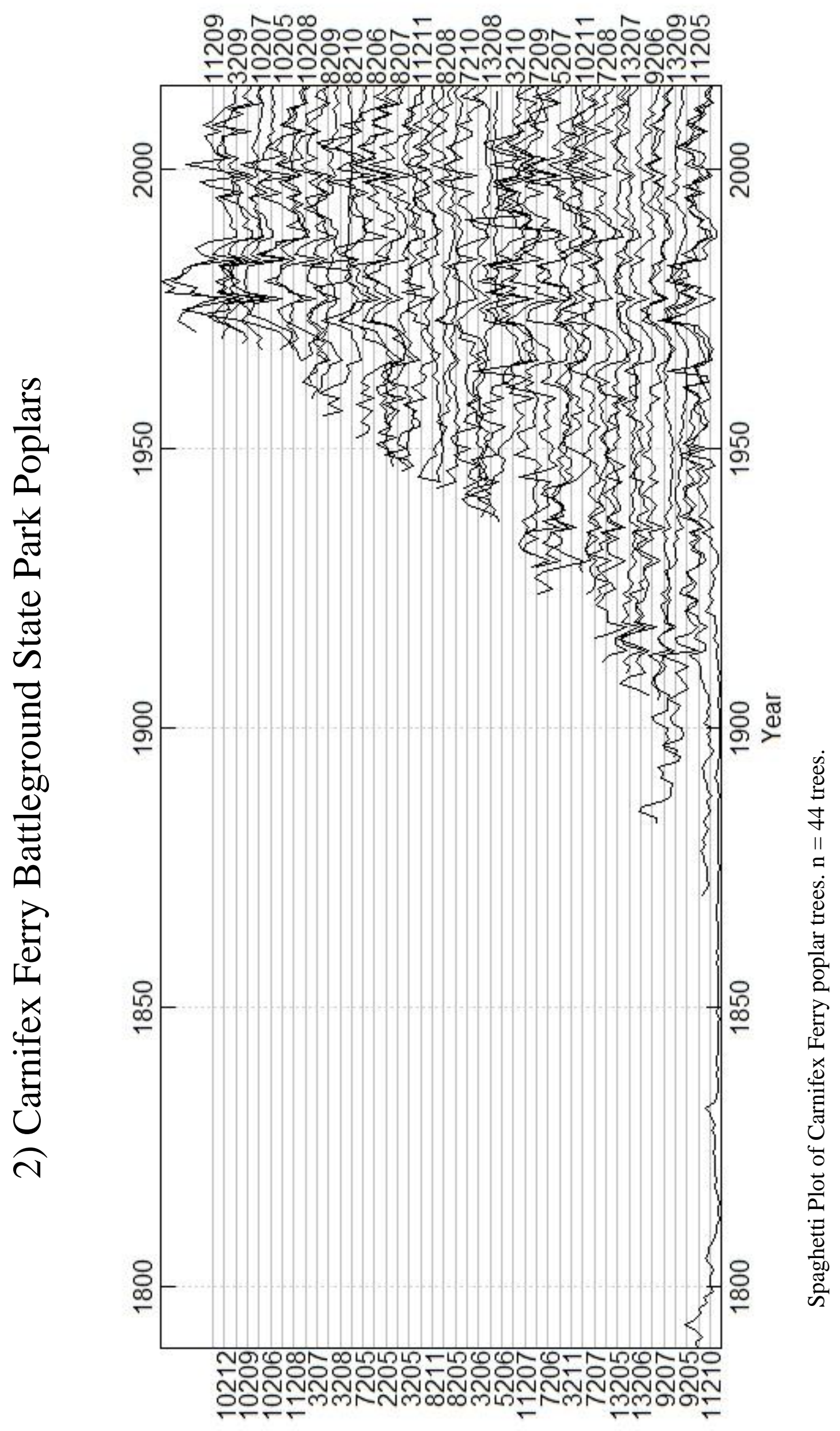




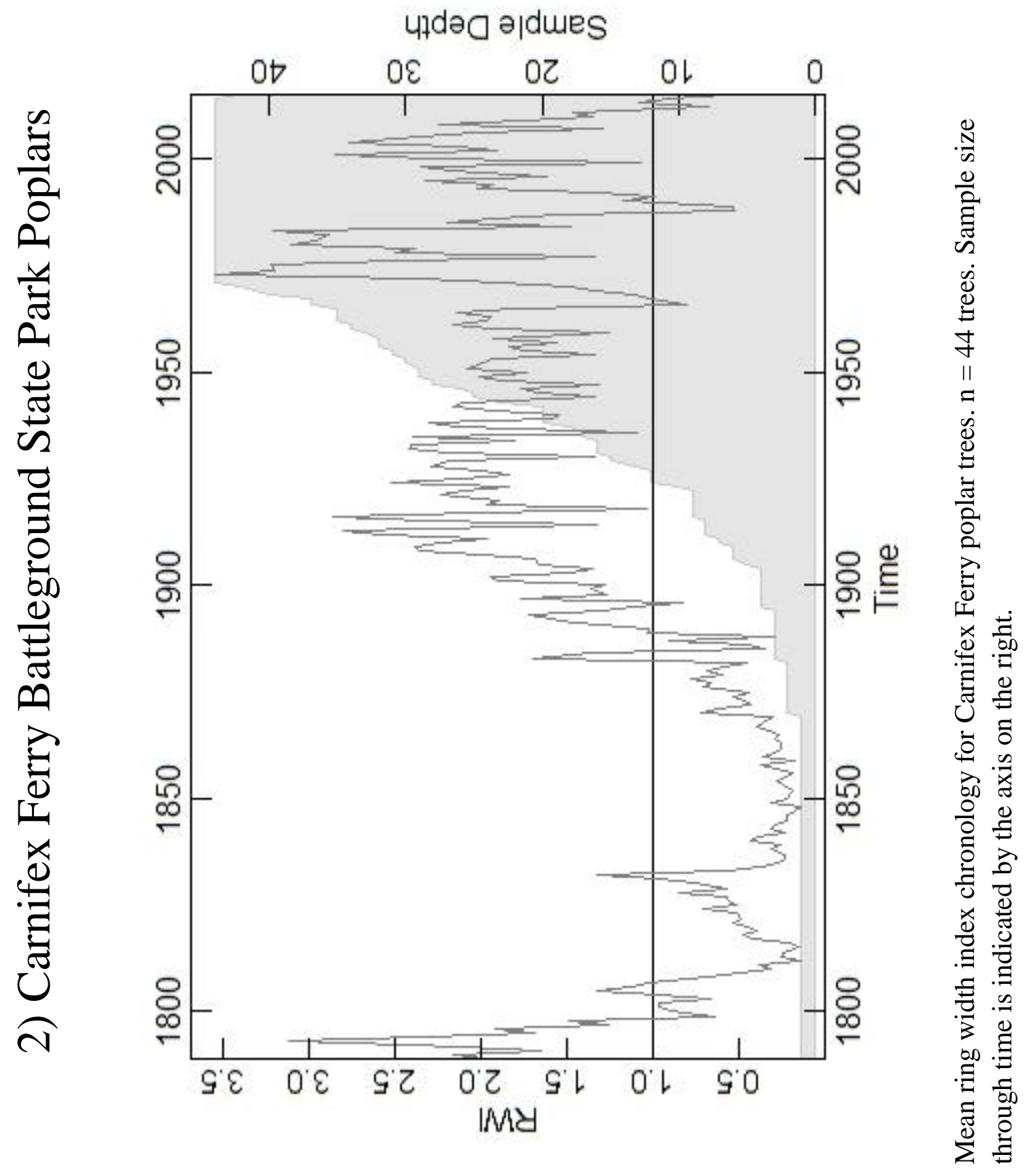




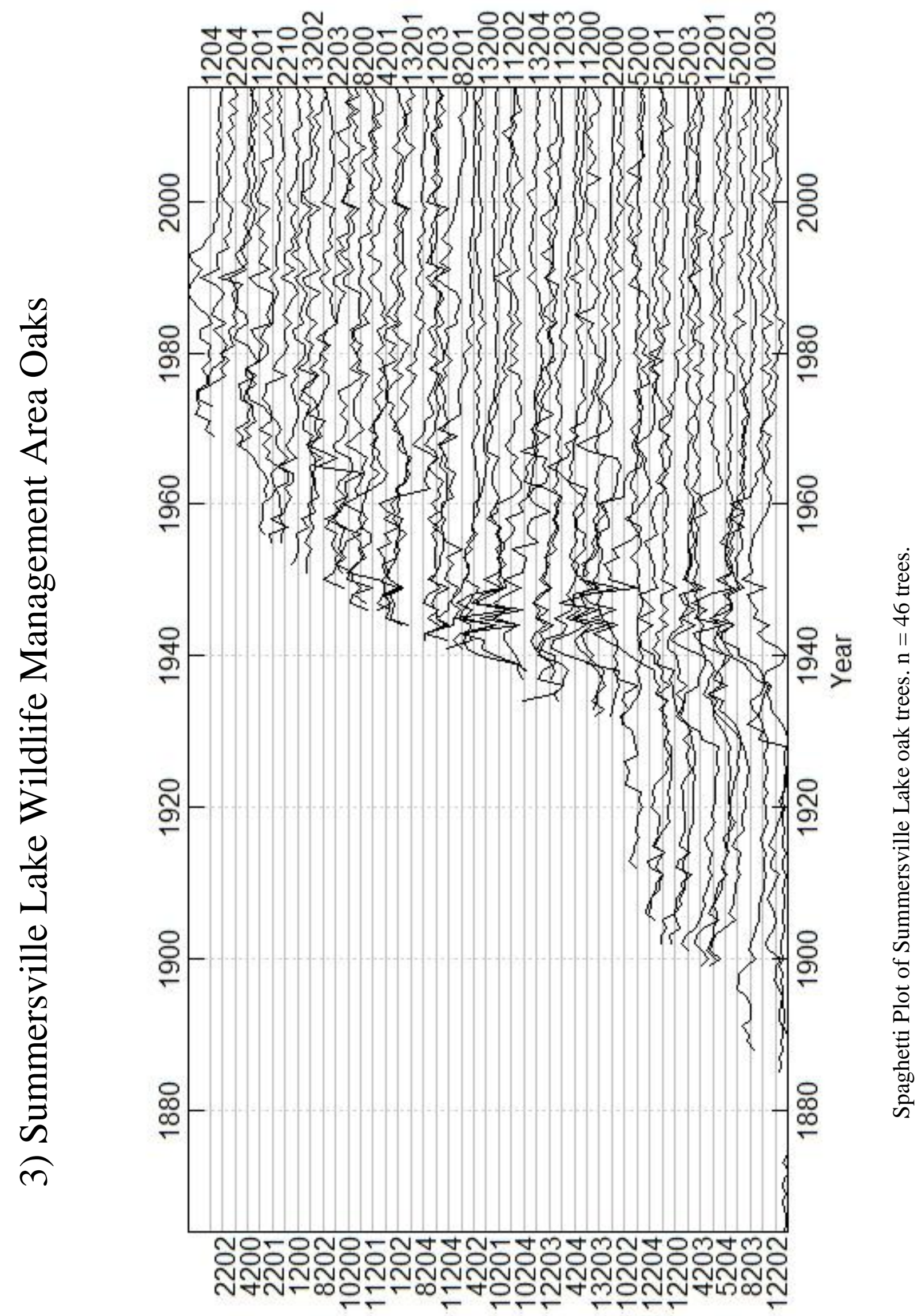




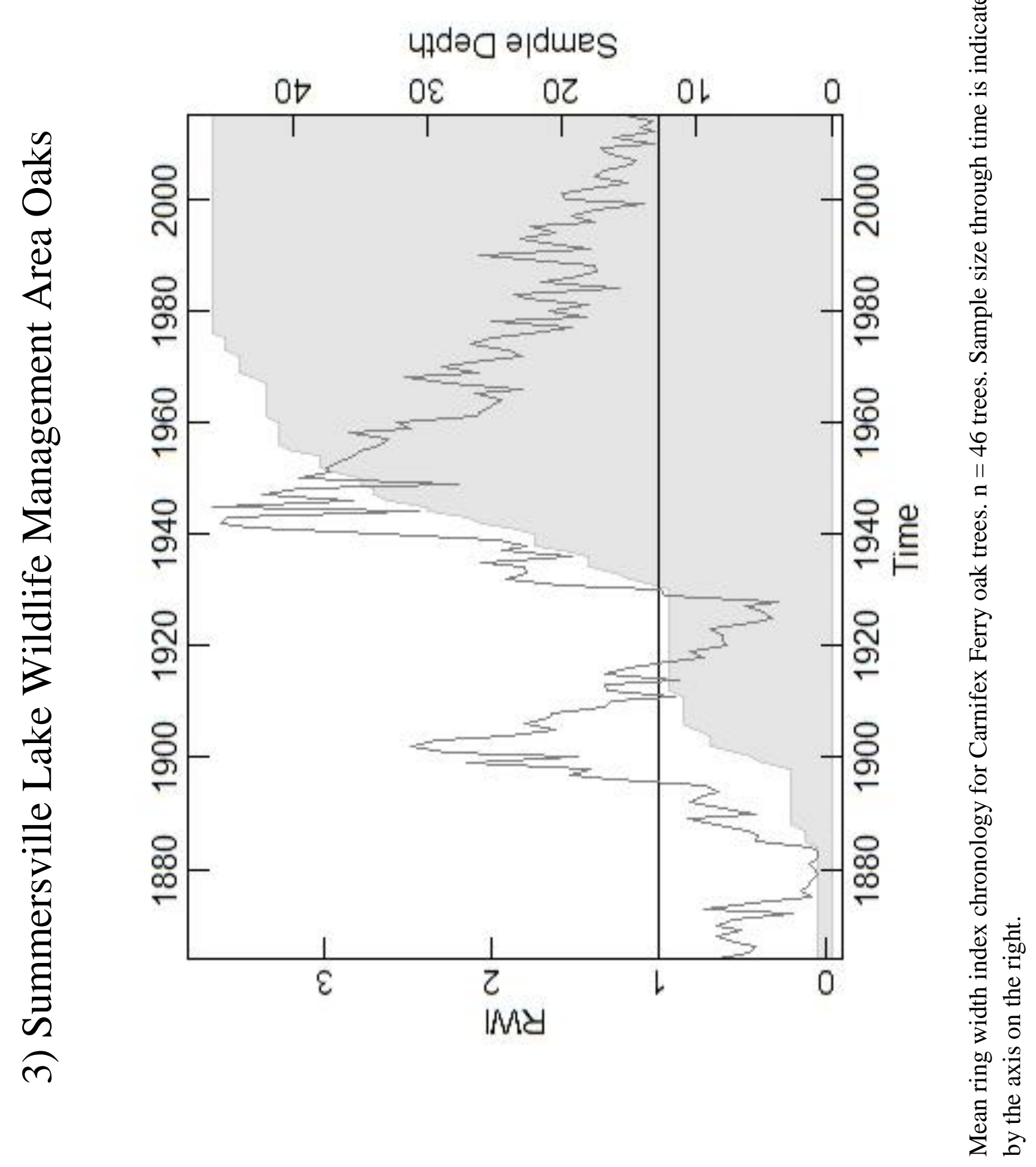




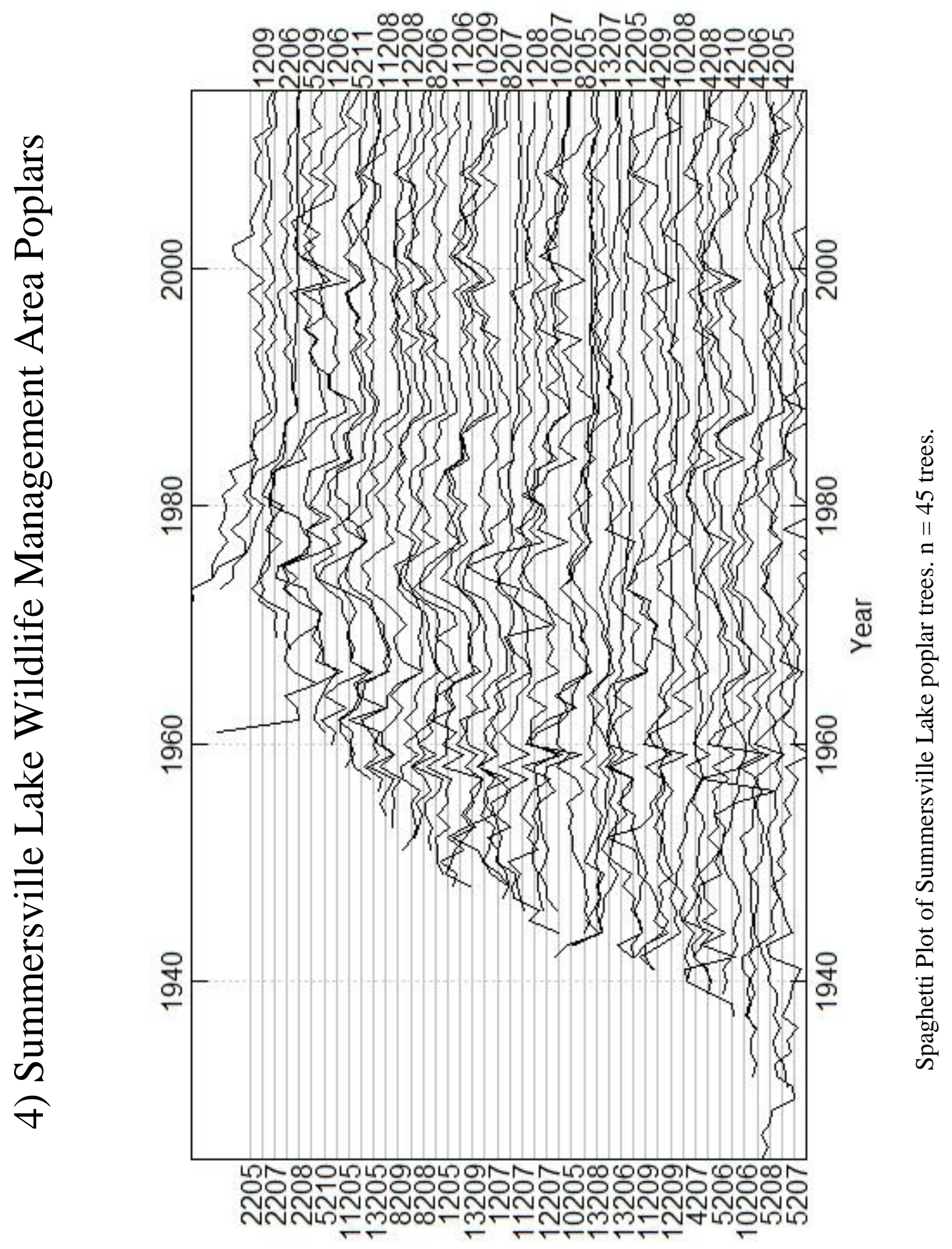




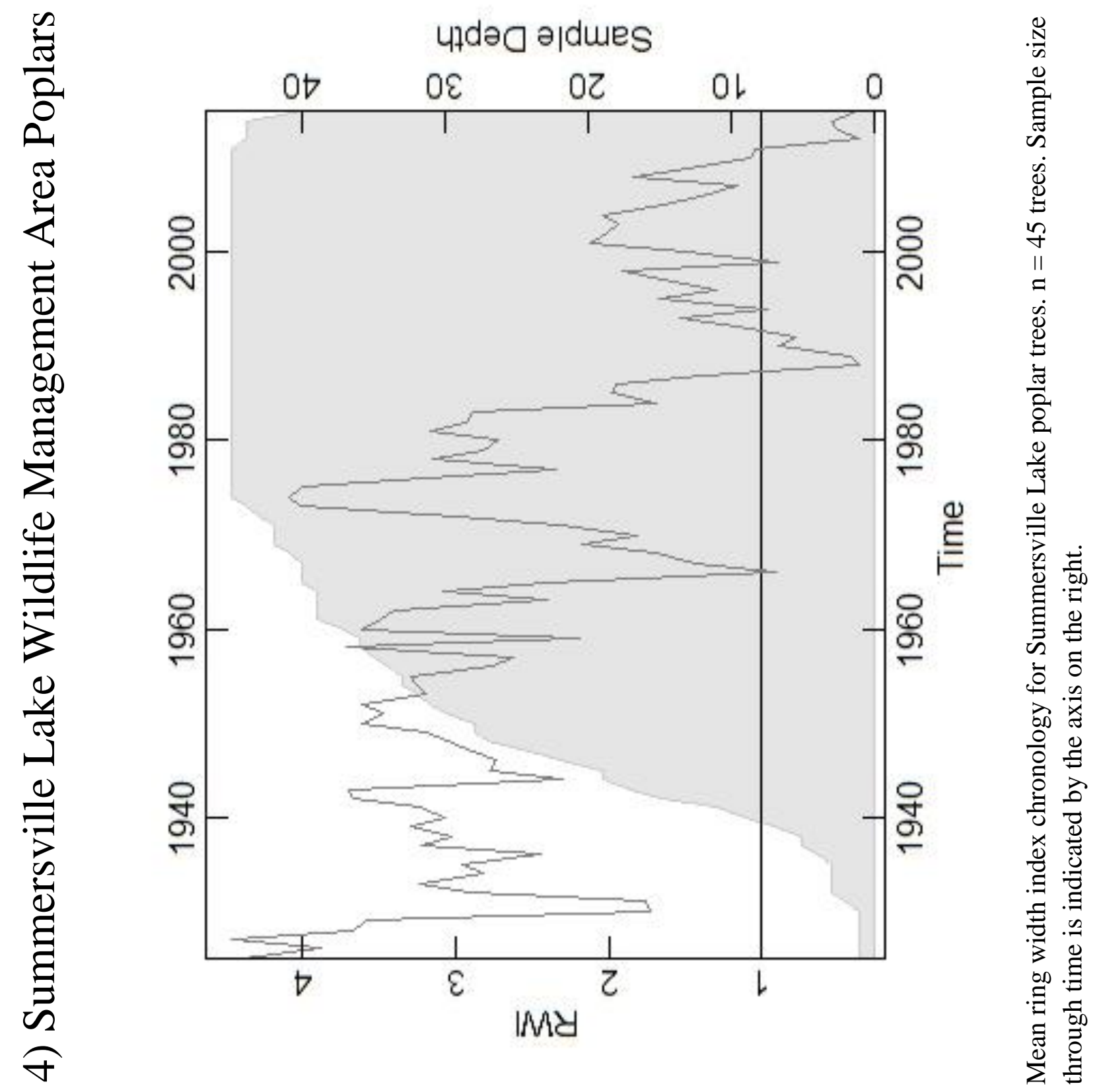


C. Dates of death for $\mathbf{2 7}$ downed trees within study plots. The color of the bars represents the site, CFSP or SWMA. The results indicate that the majority of gapmakers that were sampled in this study died in either 2012 or 2013.

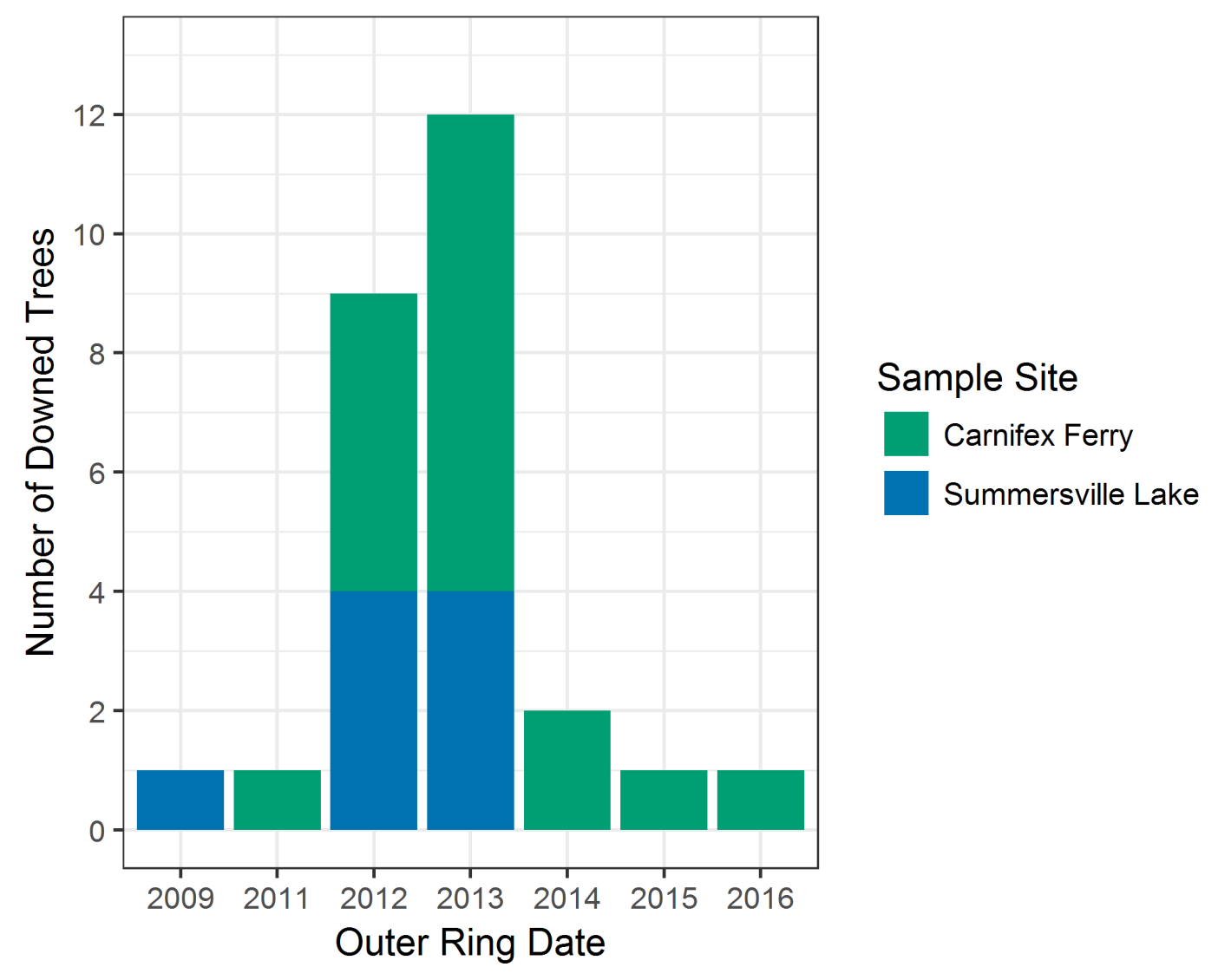




\section{Chapter 2. Exploring Mesoscale Disturbance in Eastern North American Forests}

\section{Introduction}

Forest disturbance regimes in eastern North America have typically been thought to be dominated by local gap dynamics, and thereby seen as regionally asynchronous and not strongly linked to or driven by larger scale climate variation (Fraver and White, 2005; Hicks, 1998; McCarthy, 2001; Oliver and Larson, 1996; Runkle, 1982; Schleeweis et al., 2013). However, several recent studies indicate the possibility of past regional-scale disturbances; in particular, a massive event leading to widespread canopy gaps in the late 1700s (Pederson et al., 2014). Pederson et al. (2014) suggested that regional-scale disturbance could be triggered by widespread preceding drought conditions, which decrease the resiliency of trees to disturbance damage. Similarly, regarding the possibility of synergistic effects from different disturbances (e.g., wind and fire), McEwan et al. (2014) concluded that widespread forest structure and composition changes may follow temporally overlapping disturbances that together act as a filter for surviving species.

Another cause of regionally synchronous disturbance may be anthropogenic disturbance. Schleeweis et al. (2013) estimated that in terms of forest area affected, timber harvest was the most prominent canopy change process in the eastern United States during the past 20 years. Historically, anthropogenic influence has shaped the forests of eastern North America in waves, affecting specific locations at slightly different times: from gradual westward movement of lowland agricultural clearing during European settlement into the late 1700s, increased logging and industrialization following the Civil War through 1920, and finally a modern legacy of forest protection and management post-1930 (Clarkson, 1964; Hicks, 1998; Pyne et al., 1996). A better understanding of these regional disturbance dynamics and their interaction with anthropogenic 
influence over century time scales would complement our existing knowledge of local-scale processes, which may improve predictions of species range shifts and changes in forest trajectory associated with future land management and climatic shifts.

Trees surviving disturbance are often suppressed, scarred, or released by the event, creating a record of past disturbance events within their annual growth rings. In this way, treering analysis has been applied successfully to studying the historical occurrence of many disturbances, including fire (Buell et al., 1954; Schuler and McClain, 2003), ice storms (Lafon and Speer, 2002; Smolnik et al., 2006), insect damage (Naidoo and Lechowicz, 2001; Swetnam and Lynch, 1989), and windthrow (Nowacki and Abrams, 1997). Most studies examining the dynamics of canopy disturbance infer that an abrupt increase in ring widths, or step change, is caused by a local canopy disturbance event (McEwan et al., 2014; Pederson et al., 2014; Rodgers et al., 2006). Studies of radial growth response to mechanical thinning 'disturbances' indicate that increases in percent canopy removed correlate with increased magnitude of percent growth change, and that this response can occur over a period of ten years (Anning, 2013; Rentch et al., 2002).

Much of our present knowledge of forest disturbance has been derived from study at the level of individual site dynamics. However, the growing size of online data storage and sharing, and advanced computing have made analyzing much larger data sets increasingly common (Pederson et al., 2014; Schleeweis et al., 2013; St. George, 2014). Here, I completed a mesoscale analysis of forest disturbance for eastern North America from 1600-2004 by analyzing 257 publicly available tree-ring chronologies from the International Tree Ring Data Bank (ITRDB). I investigated the occurrence of past disturbances via growth responses recorded in these ring width chronologies using the R package TRADER (Altman et al., 2014), which utilizes release 
detection methods such as the radial growth averaging criteria (Nowacki and Abrams, 1997). My aim was to explore and to compare patterns of spatial and temporal synchronicity and severity in past disturbance events, in order to evaluate the likelihood of past episodes of mesoscale disturbance in eastern North America.

The main objective of this study was to explore the characteristics of disturbance regimes across the forests of eastern North America. I answered the following questions: 1) What is the distribution of mean disturbance rate across eastern North America? and 2) Which ecoregions and species have the highest and lowest rates of disturbance? The secondary objective was to examine patterns in disturbance events in order to ascertain the degree of synchrony in occurrence across the region and within ecoregions. Spatial and temporal synchrony across sites would support the importance of less frequent, but perhaps more intense, periods of widespread disturbance (e.g. the late 1700s, Pederson et al. 2014), while an absence of synchrony would support past conclusions that these forests are governed mainly by local scale gap dynamics. If there is insufficient evidence of regional synchrony, are there synchronous events at sub-regional scales, for instance, at the scale of level II ecoregions (Commission for Environmental Cooperation, 1997)?

\section{Methods and Analysis}

\section{Tree Ring Data Retrieval from the ITRDB}

I downloaded 271 raw ring width files from sites across eastern North America from the International Tree Ring Data Bank (ITRDB), directly via the URL - ftp://ftp.ncdc.noaa.gov/pub/ data/paleo/treering/measurements/northamerica/. The ITRDB was initially created in 1974 by the University of Arizona's Laboratory of Tree-Ring Research as a publicly available archive of tree 
ring data and it currently contains more than 4000 records from every continent except Antarctica (Grissino-Mayer and Fritts, 1997; St. George, 2014).

Each tree-ring record is comprised of ring width data, including site information and sample identification, as well as metadata, which includes details like primary investigators, site latitude, longitude and elevation, tree species, and start and end dates of the record (Supplemental Materials A). The file format used for ring width data is the Tucson Decadal Format, which stores each individual tree's annual ring widths such that each row represents a new decade, and the first column is always the particular series ID (Holmes, 1994; Supplemental Materials B). Though the ITRDB does not include many details regarding the purpose of each collection, tree-ring records can be collected for a wide variety of purposes (e.g. climate reconstruction, disturbance detection, or ecological studies), each with a different sampling design. Here I assume that regardless of sampling strategy, the signal of past disturbance across sites would rise above the noise created by bias from differing collection purposes.

My initial data set was limited to United States sites east of the Mississippi River. I also included a few select sites from Canada, within the same extent of longitude. I then eliminated sites comprised of species that would have been inappropriate to use in disturbance analysis, including baldcypress (Taxodium distichum L.) and eastern redcedar (Juniperus virginiana L.). These species, although valuable to some dendrochronologists because of the length of record they provide in some locations, are generally not a component of closed-canopy forests and therefore less likely to respond to canopy disturbance events in a way that will be detected by the method used in this study. I also removed sites that had a sample size fewer than 10 trees. No further intentional exclusions were made, as I was interested in a broad picture of disturbance in 
eastern North America, with an implicit understanding that this scope encompasses several potentially disparate forest types (Figure 15).

The final data set consisted of 257 study sites after the exclusion of sites with inappropriate species or insufficient sample size (Table 5; Supplemental Materials A). Approximately thirty additional sites satisfied the site and species requirements, but formatting errors in these ring width files prevented their inclusion. The most common genera represented in the data set, in descending order, were oak (Quercus; 33\% of sites), hemlock (Tsuga; 23\% of sites), pine (Pinus; $20 \%$ of sites), and spruce (Picea; $11 \%$ of sites) (Figure 15; Table 5). Of the less frequent, miscellaneous species placed in the category Other, the most common were tulip poplar (Liriodendron tulipifera L.) and American chestnut (Castanea dentata).

\section{Site Level Disturbance Analysis}

I used the $R$ (R Core Team, 2016) packages dplR (Bunn, 2008) and TRADER (Altman et al., 2014) for analysis (Supplemental Materials D). I used TRADER to assess strength and duration of increases in radial growth (Altman et al., 2014). I used the TRADER function for Nowacki and Abrams' (1997) radial growth averaging method (RGA) to calculate percent growth change, as it is the simplest method for the sites in this study, given the extra site information necessary for methods such as boundary line or absolute increase (Black and Abrams, 2003; Lorimer and Frelich, 1989). Furthermore, recent studies indicate that RGA may exhibit more temporal accuracy, fewer false positives, and greater sensitivity than boundary line, absolute increase, or time series analysis methods (Copenheaver et al., 2014; Trotsiuk et al., in prep.).

I applied RGA to all downloaded tree-ring data in order to detect significant release years. Given the broad spatial scope of this data, I chose fairly conservative criteria for the 
analysis: symmetrical, 15-year windows and a 50 percent growth increase threshold. As the scale of analysis shifted from tree level, as produced by RGA output, to site level, disturbance criteria were further restricted, such that only years with greater than eight percent of trees releasing were considered disturbance years for a given site. Events with greater than eight percent of trees released represented only the upper $30 \%$ of events, in terms of percent of trees affected. This cutoff reduced noise in the list of event years by removing events from the data set that were likely due to isolated events affecting only one or two individuals at a site.

I calculated rate of disturbance as defined by the number of events per century, which provided a single value representing the disturbance regime at a site and allowed comparison of disturbance regimes across sites. For the sake of comparison at a scale below that of the region, all study sites were aggregated into groups according to the level II ecoregions defined by the Commission for Environmental Cooperation (1997; Figure 15). The boundaries of these ecoregions have been determined based on a number of natural and anthropogenic factors, but otherwise are largely arbitrary within the context of this study, providing just one possible method of breaking a large dataset into smaller groups. I performed analysis of variance (ANOVA) to assess a null hypothesis that mean rate of disturbance did not differ between a) level II ecoregions or b) species. Finally, Tukey's test for multiple pairwise post hoc comparisons of mean allowed me to identify which groups differed at a minimum $p<0.10$ significance level.

\section{Assessment of Regional Synchrony}

Defined here, synchrony is overlap in disturbance years across a higher percentage of sites within or between level II ecoregions than would be expected from random chance. Identifying past disturbance synchrony in eastern North America would be significant, as it would indicate the importance of larger, episodic events in shaping forests in the region. 
Furthermore, Pederson et al. (2014) suggested the potentially important role of drought and other climatic factors in these events, increasing the relevance of any findings in the context of uncertainties in current climate shifts and the implications on species' ranges and forest composition.

One important challenge of identifying regional synchrony was potential lag between an event and the resulting growth release. This time period can range from 3-7 years, and detectable release may continue for as long as 10 years (Anning, 2013; Copenheaver et al., 2014; Rentch et al., 2002). Consequently, when examining time series of release events from multiple sites, what may appear as several disparate events occurring across sites within a period of 10 years may in fact be a single event. The goal of the methods presented below was to smooth the disturbance results sufficiently to account for this potential variation in the time period between an event and the growth release at different sites. Furthermore, I avoided an approach that involved decadal or longer binning of events, as I and Trotsiuk et al. (in prep.) observed that this approach often results in such frequent disturbance it appears nearly continuous throughout the time series. To this end, I used two methods to test for synchrony: a moving window approach and a version of Ripley's K modified for use in one dimension. To compare synchrony results across sites, I selected sites from three level II ecoregions. I chose the Mixed Wood Shield (MWS), Atlantic Highlands (AH), and Ozark/Ouachita-Appalachian Forests (OAF) ecoregions for having adequate sample size and for representing slightly different forest types for comparison (Figure 15; Table 5).

The first method of assessing synchrony used a basic moving window to find the percent of sites releasing in successive windows of time. I compared the results of several different window lengths, including $3,5,7$, and 10 years. To be effective, the window size needed to 
minimize false grouping of separate events, while allowing for different disturbance response times. This moving count is essentially a smoothing function, so as I increased the window length, year-to-year variation decreased (Supplemental Materials C). I chose to use a five-year window for the remainder of this study, because it provided enough smoothing to isolate peaks in disturbance without removing longer periods of decreased disturbance. Within each window, I counted each site only once, even if it indicated release during multiple years of the window. This precaution helped prevent overestimating the importance of single sites and events.

To provide a more quantitative, robust analysis of regional synchrony, I also applied a version of the bivariate Ripley's $K$ function (Ripley, 1977), modified for one dimension by Gavin et al. (2006), to disturbance years. Further, I randomly selected only 15 sites within these groups for the modified Ripley's K analysis, so that sample size did not influence those results. I applied this method, hereafter referred to as K1D, using an executable produced by Dan Gavin (2010). K1D indicates whether or not events at different sites occurred simultaneously more than would be expected by random chance. The $K$ function was subsequently transformed to the $L$ function to facilitate interpretation. $L$ values greater than zero suggest synchrony (attraction), while $L$ values near zero indicate independence, and $L$ values less than zero suggest asynchrony (repulsion), within a particular window of $t$ years.

To assess the significance of K1D results, I calculated 99\% confidence envelopes from 1000 randomizations of event years. I used the 'circular' shift method of randomizing, whereby each randomization represented a shift of each record relative to the others random numbers of years. Gavin's (2010) K1D method also employed an edge correction, in which events occurring near the end of each record were wrapped to the start of that record. This strategy preserves the frequency of events at each site (Wiegand and Moloney, 2004). Confidence envelopes then 
represent the upper percentiles of the $K$ function resulting from these randomized lists of event dates. Applying K1D to release years allowed me to assess disturbance synchrony between sites over a range of temporal windows $(t)$, which provided for possible variation in the period of time each site took to respond to disturbance.

\section{Results}

\section{Disturbance Regimes of Eastern North America}

The overall mean disturbance rate, calculated from years indicating at least eight percent of trees releasing at a site between 1620-2004, was $4.6 \pm 3.0$ events per century $(n=257)$. With the exception of the Mississippi Alluvial and Southeast USA Coastal Plains (MACP) ecoregion, the distribution of values and mean rate of disturbance were similar across all seven eastern North American ecoregions (Figures 16 and 17). Three ecoregions differed significantly from MACP, Mixed Wood Plains ( $p<0.05)$, Mixed Wood Shield $(p<0.05)$, and Ozark-OuachitaAppalachian Forests $(p<0.1)$. MACP sites indicated the highest mean disturbance rate at 7 events per century, while all remaining ecoregions showed disturbance rate between 3.7 - 4.9 events per century (Table 5). Given a disturbance rate of 4.6 events per century, the average period between canopy disturbances in eastern North America was approximately 21 years, except in the MACP ecoregion, where return interval would have been 14 years, on average. Disturbance rate did not vary strongly by species (Figure 18). The one exception was a significant difference between hemlock and pine species $(p<0.05)$. Hemlock sites had the highest mean rate of disturbance at just over five events per century, with remaining species groups ranging from three to four events per century. 


\section{Spatial and Temporal Synchrony}

The three ecoregions I tested for synchrony in disturbance dates, Ozark/OuachitaAppalachian Forests (OAF), Mixed Wood Shield (MWS), and Atlantic Highlands (AH), each experienced at least one period with greater than or equal to $34 \%$ of sites indicating a release (Figure 19). OAF experienced peak disturbance events in 1708 (34\% of sites), MWS in 1936 (55\% of sites) and 1891-1900 (52\% of sites), and AH in 1665 (38\% of sites). At a broader scale, when these results were visually compared, a few periods emerged in which multiple ecoregions indicated elevated levels of disturbance (Figure 19). Examples of this overlap were centered on $1692,1722-1723,1774-1780,1848,1877$, and a staggered release that occurred between 19211932. Periods indicating low levels of disturbance also showed some overlap across ecoregions, including the 1760s, 1830s, 1910s, and recent decades following 1950. Synchrony within ecoregions declines post-1930, with fewer and fewer sites recording significant releases.

Applying K1D analysis to the three ecoregions showed some degree of synchrony between sites within each, at a variety of time scales (Figure 20). The OAF ecoregion demonstrated synchrony at time scales greater than 5 years, up to 250 years. Within MWS, the strongest synchrony occurs between 3-125 year time intervals, with synchrony less pronounced at longer time periods. Finally, the AH ecoregion shows synchrony in disturbance events at 10250 year spans. These findings indicate synchrony at multiple time scales, at a 99\% confidence level. 


\section{Discussion}

\section{Disturbance Regimes of Eastern North American Forests}

Most of the sites examined here indicated three to five disturbances per century, meaning that between three and five times per century, at least eight percent of trees at each site exhibited sufficient growth release to be detected by RGA (Figures 16 and 17). However, the rates reported in the present study should be interpreted and compared loosely, as the site-, species-, and canopy class-specific variation in disturbance response demonstrated by the previous chapter suggests that the use of one set of criteria for potentially different communities may be misleading. Furthermore, care should be exercised in extrapolating these conclusions to other forests of eastern North America, as much of the ITRDB is not necessarily representative of the broader region. Most of the ITRDB data is from publicly owned forests, which only account for around nineteen percent of eastern United States forests, and sampled individuals are generally much older than the majority of forests in the region, which largely remain under ninety years of age (Oswalt and Smith, 2007). Rates of disturbance reported in the literature for eastern North American forests also vary significantly, and contextualizing these findings to a broader scale should be done with caution. With this in mind, Nowacki and Abrams (1997), in their original radial growth averaging study located in central Pennsylvania (within the OAF ecoregion; Figure 15), found a disturbance return interval of 21 years in the historical record, lengthening to 31 years after 1900. This would place their estimate of disturbance rate within my own range, between three and five events per century. Similarly, Mclachlan et al. (2000) were less specific in their study, but concluded that a significant release event occurred every few decades ( $\sim$ three events per century) at their four New England sites (within MWP ecoregion). 
An exception to this typical rate of disturbance was in the MACP ecoregion, which experienced an average of seven release events per century. However, Schleeweis et al. (2013) also found a much higher rate of disturbance within southeastern and south-central United States (within MACP and SP ecoregions; Figure 15) using several publicly available spatial datasets like those available through the forest inventory and analysis program. Schleeweis et al. (2013) attributed larger mortality events to hurricanes, which exhibited return intervals as short as two to four years (as many as 50 events per century). Zeng et al. (2009) found a strong relationship between hurricane and tropical storm occurrence and the number of dead or damaged trees in the eastern United States, and their simulated map of the return frequency of these storms identified much of the MACP ecoregion as the most likely to experience impacts from Atlantic hurricanes and tropical storms. However, the extent of forest damage from these wind events may be quite variable and patchy over the landscape, especially in areas more than $50 \mathrm{~km}$ from the coast (Chambers et al., 2007; Schleeweis et al., 2013; Zeng et al., 2009). Therefore, I would not expect growth release for every storm landfall at a single site, which would explain the longer return interval indicated by my results (14 years compared to Schleeweis et al.'s 2-4 years).

The sites included in my study did not indicate strong variation in disturbance rate by species (Figure 18), which contrasts with the findings of Cho and Boerner (1991). In their study of gap size and forest composition (located within the Central USA Plains ecoregion; Figure 15), Cho and Boerner (1991) proposed that current canopy gaps are smaller than those that facilitated oak establishment in the past. If canopy gaps are currently insufficient for oak establishment, it may explain recent shifts in forest composition. More importantly, if this is the case I would expect oaks to reflect a higher historical disturbance rate relative to other species such as higher elevation spruce, which was not supported by my results. 
Another contradictory result was the lack of variation between mean rates of disturbance in spruce and pine species (Figure 18). The dominant form of disturbance in both southern pine stands (e.g. longleaf pine—Pinus palustris Mill., shortleaf pine—Pinus echinata Mill.) and northern boreal spruce-dominated stands (e.g. black spruce—Picea mariana) is fire, but with drastically different return intervals (Bogaert et al., 2015; Goetz et al., 2012; Palmquist et al., 2014). In southern pine stands, fire commonly returns annually, while fire regime in boreal spruce is much more complex, with anywhere from several decades to hundreds of years passing between events, because the landscape is less prone to drought (Palmquist et al., 2014; Van Bogaert et al., 2015). However, this difference was not supported by my results, despite my data containing many of these species. Pine chronologies included in this study showed the lowest average rate of disturbance, and did not significantly differ from the rate of disturbance found in spruce chronologies (Figure 18).

This unlikely similarity in average disturbance rate across species is likely due to combining results from many species that although from the same genus, have diverging life history traits, community associations, and geographic ranges. For example, included with southern pine species was white pine (Pinus strobus L.), which is more commonly found north of Georgia, and makes up several of my Canadian ITRDB sites. In contrast to southern pines, white pine generally experiences disturbance at intervals anywhere from 10-100 years, but an interval closer to 100 years likely produces the greatest species diversity in these communities (Beverly and Martell, 2004). Furthermore, a large number of the spruce records in the ITRDB, and more than 85 percent of the spruce chronologies I used in this study, are red spruce (Picea rubens Sarg.), a species whose disturbance regime is still poorly understood, but thought to be governed by spruce budworm (Choristoneura fumiferana Clemens) and spruce bark beetle 
(Dendroctonus rufipennis Kirby) outbreaks, as well as hurricanes in some parts of its range, rather than fire (Fraver and White, 2005; Khakimulina et al., 2016). Unlike black spruce which is uncommon south of the Great Lakes, red spruce occurs at high elevation sites as far south as the southern Appalachians. Oaks also span a considerable ecological and geographic range with eight different species located from southern Canada to northern Florida, and at least one ITRDB chronology in every ecoregion examined in this study (Figure 15).

Given the results of past research and the differences noted here, species likely does explain some degree of variation seen in disturbance rate across study sites in eastern North America. However, grouping sites by genus did not effectively isolate the impact of individual, contrasting species, resulting in very little variation between groups (Figure 18). As such, future studies seeking to understand regional disturbance patterns should perhaps employ principal component analysis or a multiple linear regression model to better understand and account for the interacting effects of species and geographic location on disturbance rate.

\section{Evidence of Spatial and Temporal Synchrony}

My findings indicated synchrony in disturbance dates within three ecoregions Ozark/Ouachita-Appalachian Forests, Mixed Wood Shield, and Atlantic Highlands (Figures 19 and 20). This result is in contrast to much of the existing literature on disturbance in eastern North American forests, which often reported or assumed that forests of eastern North America were dominated by gap phase dynamics or infrequent local-scale stochastic events (Fraver and White, 2005; Khakimulina et al., 2016; Oliver and Larson, 1996; Runkle, 1982; Schleeweis et al., 2013). However, a few studies have shown evidence of larger events affecting multiple sites in a region (Cho and Boerner, 1995; D’Amato and Orwig, 2008; McMurry et al., 2007; Pederson et al., 2014). Findings from a moving count of sites recording disturbance and K1D analysis in 
the present study support these suggestions of landscape-scale disturbance patterns. The sites within the three ecoregions I analyzed indicated at least decadal disturbance patterns in common, which suggests significant clustering of event dates in time, across multiple sites. Here, I pose a few plausible causes for specific periods of elevated disturbance observed within and between the three ecoregions examined in an analysis of disturbance synchrony.

The early European settlement period from mid-sixteenth century through much of the eighteenth century can be seen as a transitional period in eastern North American forests. Influence from Native American management practices rapidly dwindled as European diseases decimated Native populations, leaving forests to grow denser until settlers gradually moved westward, clearing low-lying areas for agriculture along the way (Clarkson, 1964; Hicks, 1998). Peaks in disturbance during this period (e.g. from Figure 19: 1665 in AH; 1708 in OAF; and 1692, 1722-1723 across multiple ecoregions) are therefore most likely attributable to weather events, while lulls in disturbance (e.g. the 1760s show lowered disturbance across ecoregions) may reflect limited human influence during the time period. For example, records indicate the occurrence of Atlantic hurricanes in 1666 and 1722, while several winters from the 1690s through the 1710 s are frequently noted in historic records for severe winters and late frosts in Europe and North America, possibly corresponding to the height of the Little Ice Age (Marusek, 2010). Supporting this explanation, a study by D'Amato and Orwig (2008) suggested correspondence between timing of disturbance across 18 sites near the AH ecoregion, each more than $50 \mathrm{~km}$ apart, which they likewise attributed to hurricanes and ice storms occurring within this transitional time period.

The years between 1770-1780 are particularly notable for deviations from usual patterns in climate and disturbance (Marusek, 2010; McMurry et al., 2007; Pederson et al., 2014). 
Historical documents report killing frosts in 1771 and 1774, multiple hurricanes and severe storms in 1772, 1775, 1776, and 1780, even a snowstorm in Florida in 1780 (Marusek, 2010; Pederson et al., 2014). Pederson et al. (2014) found that within the seven year period between 1774-1780, 41.3\% of 76 sites located throughout the Central Hardwood region indicated a release. Although around 15\% of my ITRDB data set was also included in Pederson et al.'s study, more than $30 \%$ of my own sites, regardless of ecoregion, also recorded a disturbance in within this seven year period (Figure 19). McMurry et al. (2007) added to these occurrences in identifying widespread wildfires in the spring of 1780 , in the vicinity of southern Canada and northeastern United States. Recent studies suggest that these years of widespread release events across eastern North America could be due to the convergence of climatic conditions such as drought with other disturbances such as ice or wind storms, fire, timber harvest, or hurricanes (McEwan et al., 2014; Pederson et al., 2014). Evidence from the present and previous studies indicates that the decade between 1771-1780 was an anomalous period that may have strongly influenced recruitment, and thereby forest structure and composition in the years that followed (Pederson et al., 2014).

Following the American Civil War and the collapse of many farming operations, rapid industrialization and improvements in steam transportation led to a logging boom between 18801920 in the Appalachian region (Clarkson, 1964). Further north, timber harvest occurred largely in two periods: initial harvest prior to 1850 , and widespread cutting of regrowth between 1890 and the 1900s (D’Amato and Orwig, 2008; Hicks, 1998; Pyne et al., 1996). The gypsy moth (Lymantria dispar L.), introduced in 1879 in Boston, Massachusetts, further contributed to the decline of mixed-oak stands during this time period. My findings indicated elevated disturbance corresponding to these periods of widespread anthropogenic disturbance in the region, with the 
most significant peaks in the AH ecoregion between 1840-1860 and 1880-1900, and in the MWS ecoregion between 1890-1900 (Figure 19). A period centered about 1848 was also a common peak across the three ecoregions, perhaps reflecting a convergence of anthropogenic influence and another surge of climate anomalies including late frosts, severe weather from Pennsylvania to Florida, and a notable hurricane that struck North Carolina in 1850 (Marusek, 2010).

In the modern period, my results indicated declining disturbance in all three ecoregions following a final peak between 1920-1936 (Figure 19). This final peak may be attributable to the gradual decline of American chestnut trees in the region, following the introduction of the Chestnut Blight (Cryphonectria parasitica Murrill) in the early 1900s (Hicks, 1998). In the New England area (AH and perhaps MWS ecoregions), a particularly destructive hurricane in 1938, followed by fires from increased fuel load in 1947, may also have contributed to this period of elevated disturbance (Pyne et al., 1996).

The obvious decline in disturbance events may be a direct result of forest protection efforts following the 1930s, which encompassed a wide variety of actions, including fire suppression, preservation of large tracts from logging, and active replanting efforts in clearcut areas. Pyne et al. (1996) noted that fire prevention efforts further increased after 1949, as fire risk became tied to national security and tenuous relations with the Soviet Union provoked fear of the atomic bomb. On the other hand, the lack of detected releases could be due to the age of many of these forests at the time they were sampled. Only about twenty percent of all the sites I used in these analyses were younger than one hundred years old in the late twentieth century, and the remaining sites were aging, mature stands, which are less likely to respond strongly to canopy disturbance (Black and Abrams, 2003; Lorimer and Frelich, 1989; Nowacki and Abrams, 1998). As only a handful of sites indicated disturbance following 1960, my findings may highlight the 
influence of forest protection measures on disturbance rates in eastern North American forests. However, a greater sampling effort is required in younger forests, as they are more representative of forests in the broader region, and may also provide a better record of disturbance in the past fifty years.

\section{Conclusions}

The findings of this study indicated common patterns and statistically significant synchrony in disturbance events at multiple time scales throughout forests of eastern North America. I did not find that species was strongly related to disturbance rate, although this result may be more indicative of grouping the data by genus than an actual absence of variation. Regional disturbance analysis suggested periods of elevated disturbance across eastern North America, including 1690-1710, 1774-1780, 1880-1900, and 1920-1936. Likely causes of these events were weather events, convergence of frost, hurricane, and fire damage, timber harvest, and human-introduced non-native pathogenic organisms, respectively. In this way, anthropogenic influence in the region was evident in the past 140 years. However, the decline in disturbance post-1930s was also notable for human involvement, as this trend may be directly related to forest protection efforts. These findings suggest the importance of further study regarding the interaction between anthropogenic disturbance and disturbance events driven by stochastic climate anomalies.

Conversely, since two-thirds of recorded events affected a relatively small percentage of trees at individual sites, the role of local canopy gap disturbances should not be discounted entirely. The average rate of disturbance ranged between three to seven events per century, with higher rates occurring only in southern coastal area frequently impacted by hurricanes; but the 
majority of disturbance events were not linked to regional events beyond common patterns. However, findings of Pederson et al. (2014) suggest that the infrequent, severe, wide-ranging events may exert a stronger influence on future forest structure and composition, even if underlying gap phase dynamics maintain base disturbance rates. Further research regarding the interplay between frequent, small disturbances and infrequent, widespread disturbances should be conducted to provide a more complete understanding of the role of disturbance in the forests of eastern North America. 


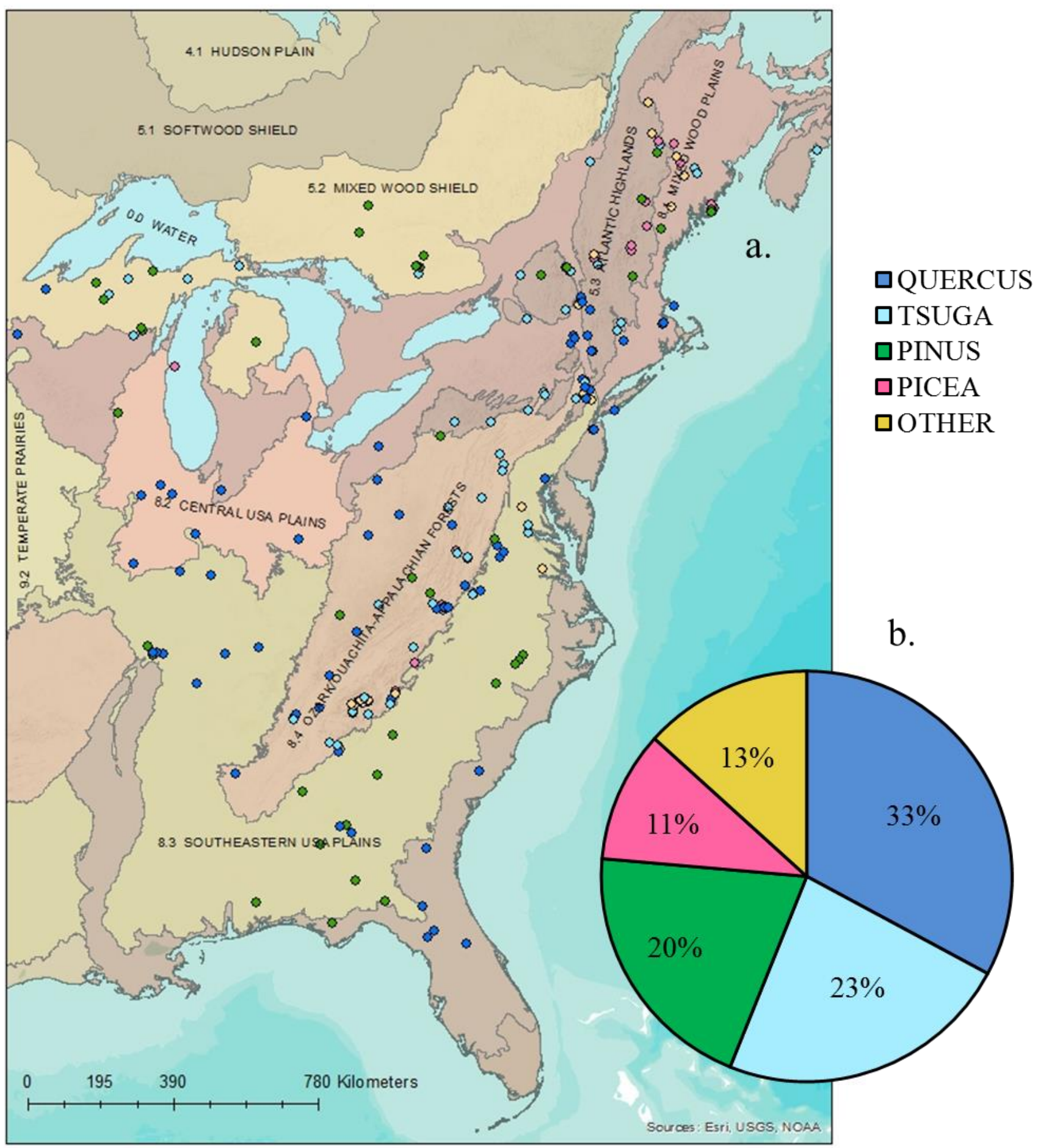

Figure 15. a) is a map of all ITRDB study site locations. The color of each point indicates the species or genus group making up the chronology at that location. The "other" category represents miscellaneous species that were less common than the major groups, but still fit within a mixed hardwood forest type. The underlying map is divided by Level II Ecoregions (Commission for Environmental Cooperation, 1997). b) displays a pie chart of the genus/species represented in the full data set shown on the map. Again, color indicates the corresponding species group. 


\begin{tabular}{c|c|c|c|c|c|}
\hline L2 Code & Abbrev. & Ecoregion & No. Sites & Mean Rate & Most Common Genera \\
\hline \hline 8.1 & MWP & Mixed Wood Plains & 36 & 4.0 & Tsuga, Quercus \\
\hline 6.5 & MWS & Mixed Wood Shield & 21 & 3.7 & Pinus, Tsuga \\
\hline 7.5 & AH & Atlantic Highlands & 40 & 4.4 & Tsuga, Quercus \\
\hline 8.2 & CP & Central USA Plains & 9 & 4.9 & Quercus \\
\hline 8.3 & SP & Southeastern USA Plains & 55 & 4.9 & Quercus, Pinus \\
\hline 8.4 & OAF & $\begin{array}{r}\text { Ozark/Ouachita-Applachian } \\
\text { Forests }\end{array}$ & 84 & 4.5 & Tsuga, Quercus \\
\hline 8.5 & MACP & $\begin{array}{c}\text { Mississippi Alluvial \& } \\
\text { Southeast USA Coastal Plains }\end{array}$ & 12 & 7.0 & Quercus \\
\hline
\end{tabular}

Table 5. Results from disturbance analysis, divided into level II ecoregions. "L2 Code" represents the numerical identification code for the corresponding ecoregion, while "Abbrev." shows the abbreviated code used in this paper. Data included are the number of sites encompassed by the ecoregion, mean rate of disturbance in events per century, and the most common genera making up chronologies in the ecoregion.
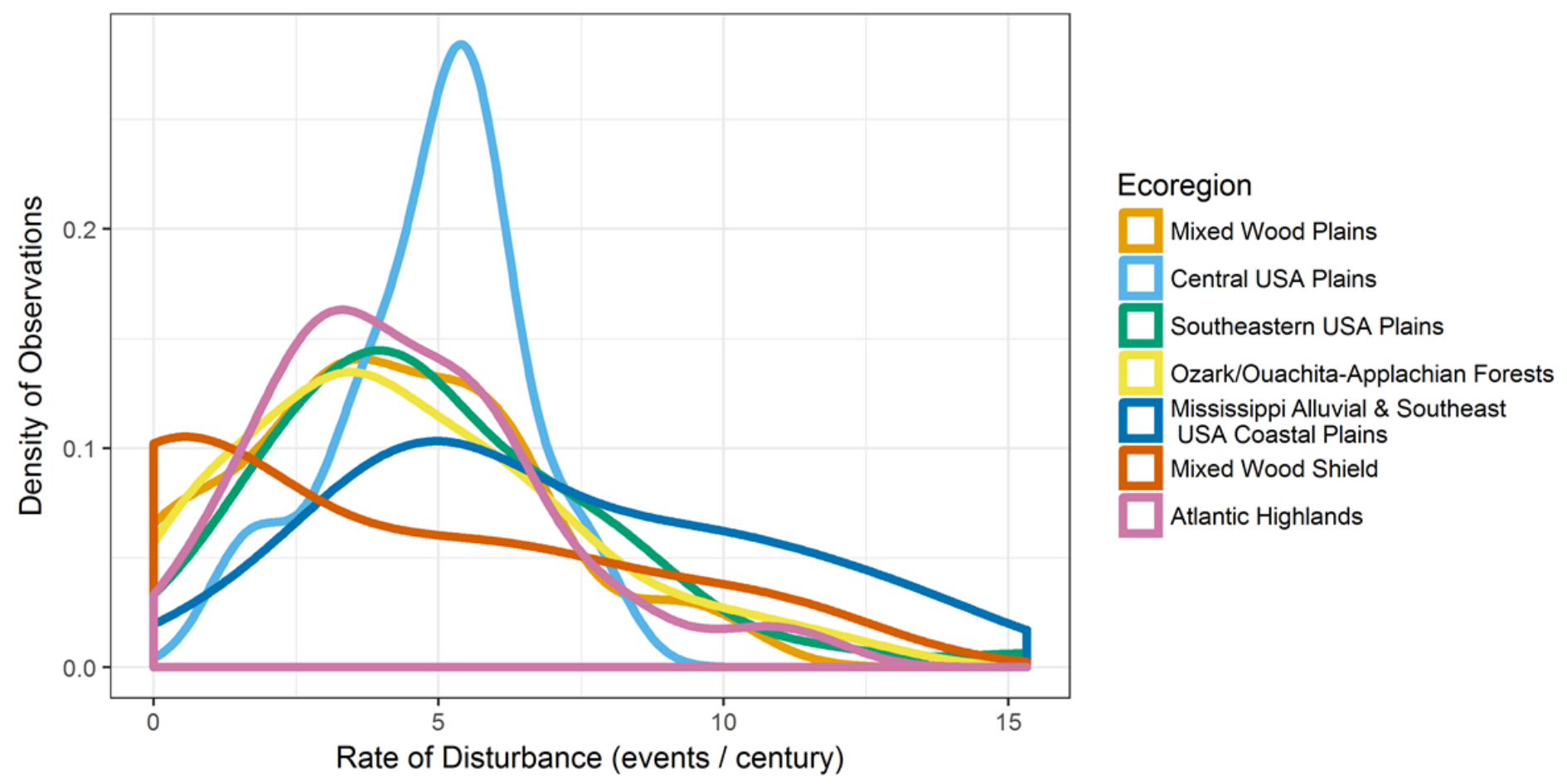

Figure 16. Density plot showing the distribution of rates of disturbance (events per century) calculated for all sites within each ecoregion. 


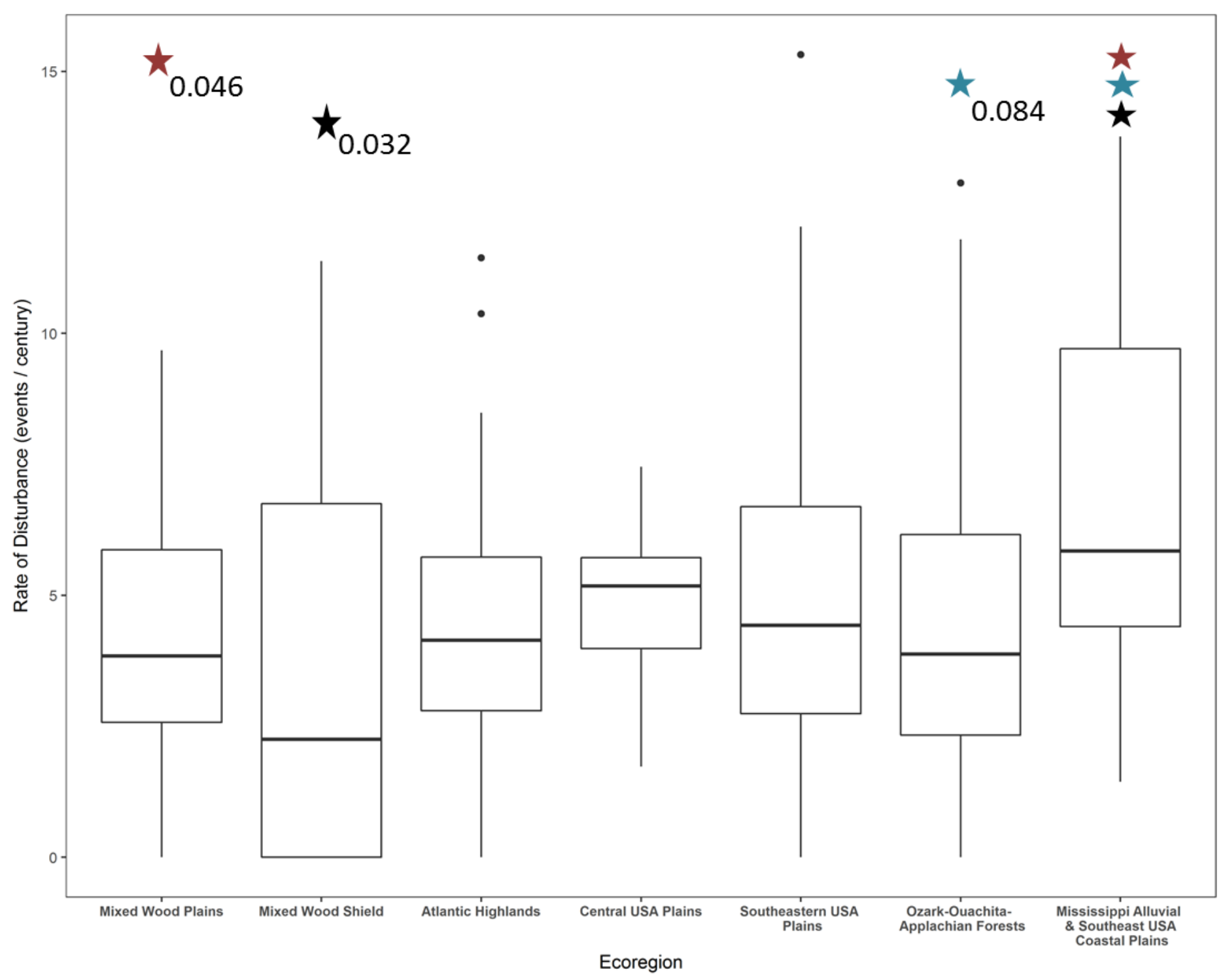

Figure 17. Boxplots of rates of disturbance (events per century) calculated for all sites, divided into ecoregions. Median, quantile ranges, and outliers are shown. Stars indicate pairs with significantly different means according to Tukey test $(\mathrm{p}<0.10$ or $\mathrm{p}<0.05)$. P-value is noted for each. 


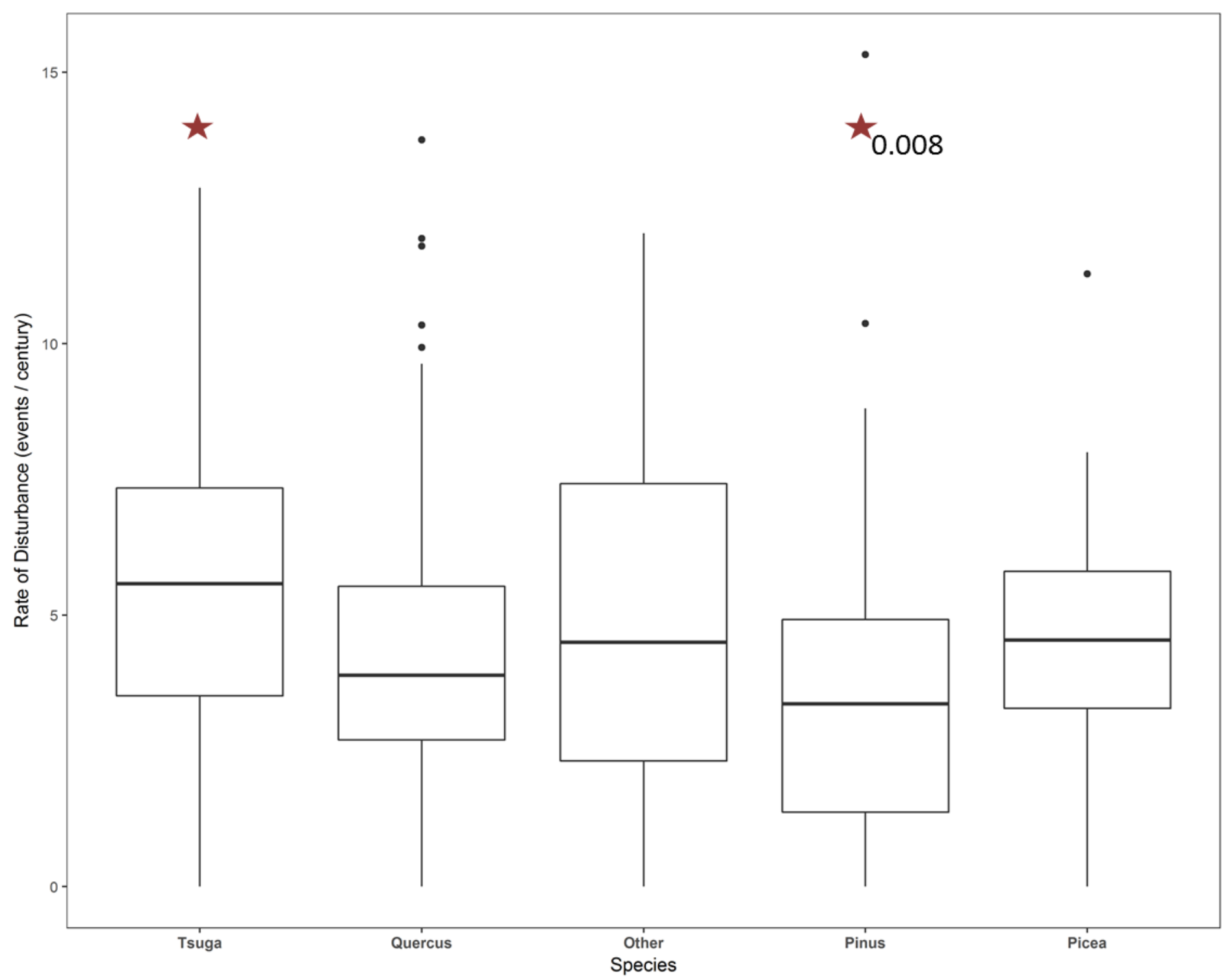

Figure 18. Boxplots of rates of disturbance (events per century) calculated for all sites, divided into species groups. Again, the "other" category consists of miscellaneous species that were less common than the major groups, but still fit within a mixed hardwood forest type. Median, quantile ranges, and outliers are as shown. Stars indicate pairs with significantly different means according to Tukey test $(\mathrm{p}<0.05)$. P-value is noted for each. 
Figure 19. Results of moving count method of analyzing synchrony. Results are shown for 3 ecoregions: a) Ozark/Ouachita-Appalachian Forests, b) Mixed Wood Shield, and c) Atlantic Highlands. Black lines indicate the percent of sites recording a disturbance in successive five-year moving windows. Blue lines indicate the sample depth of sites recording in each year.

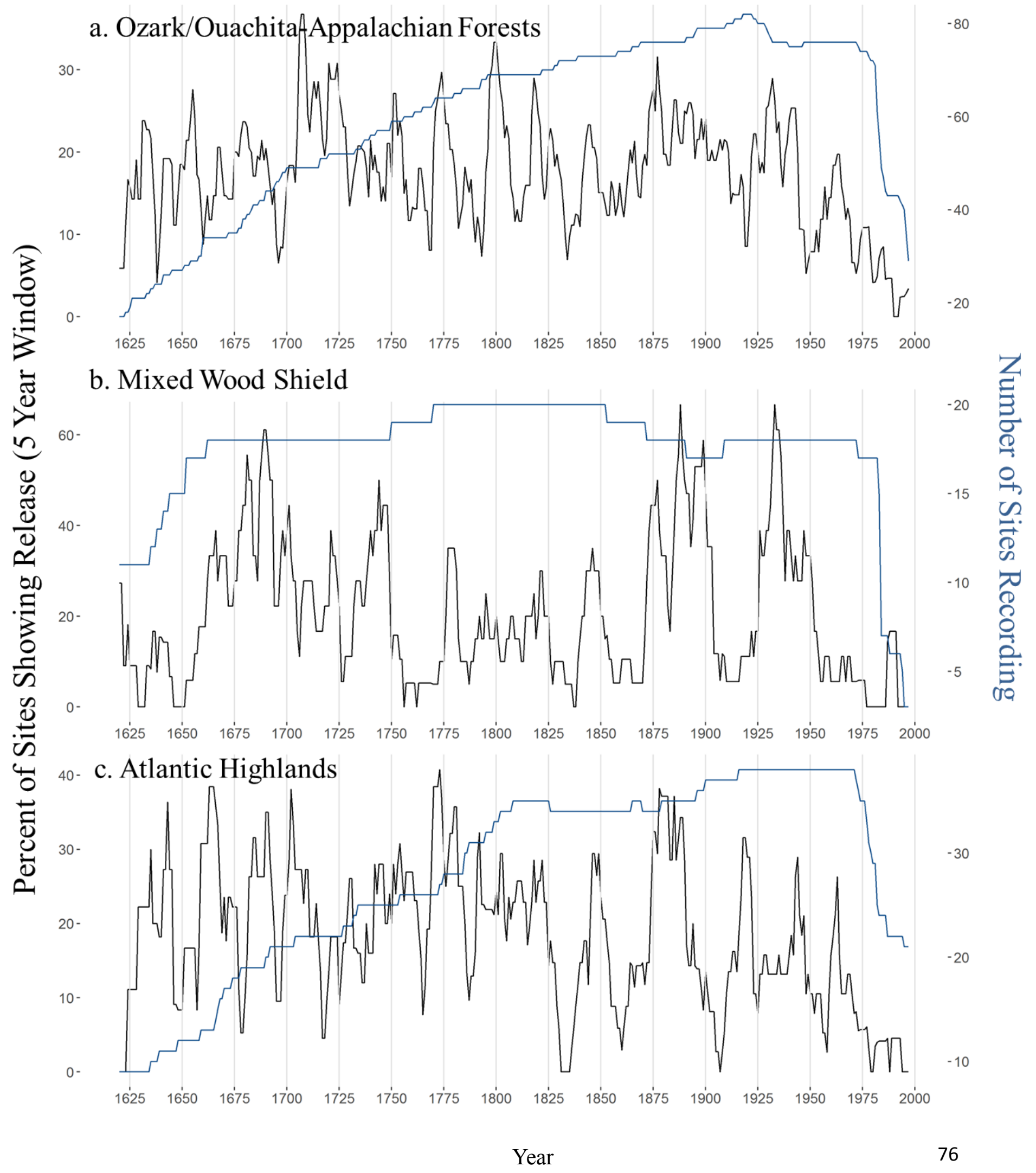




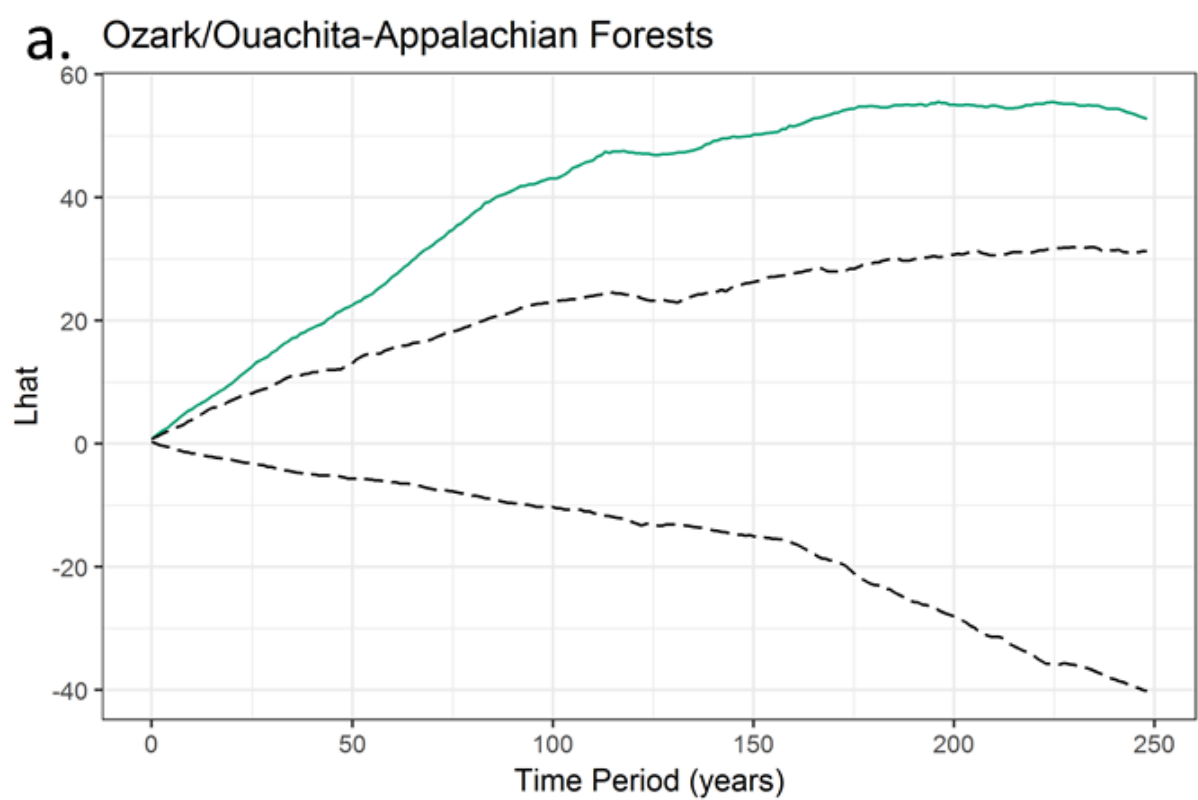

b. Mixed Wood Shield

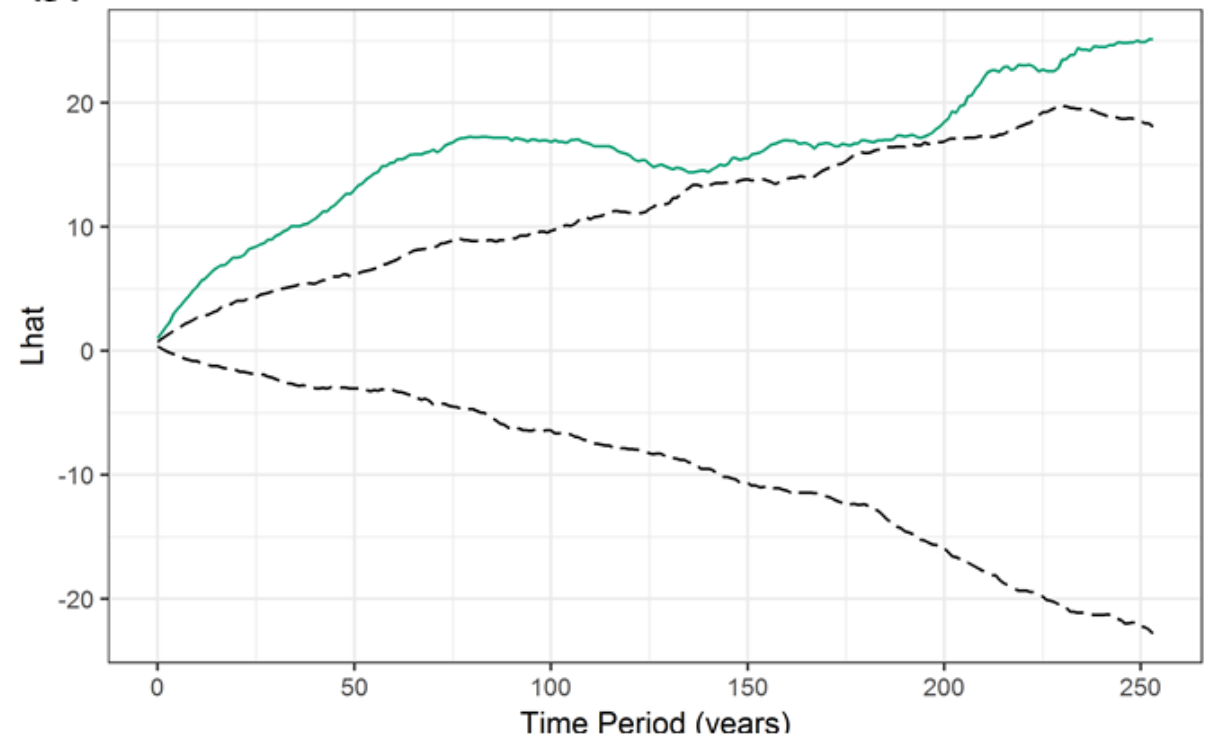

C. Atlantic Highlands

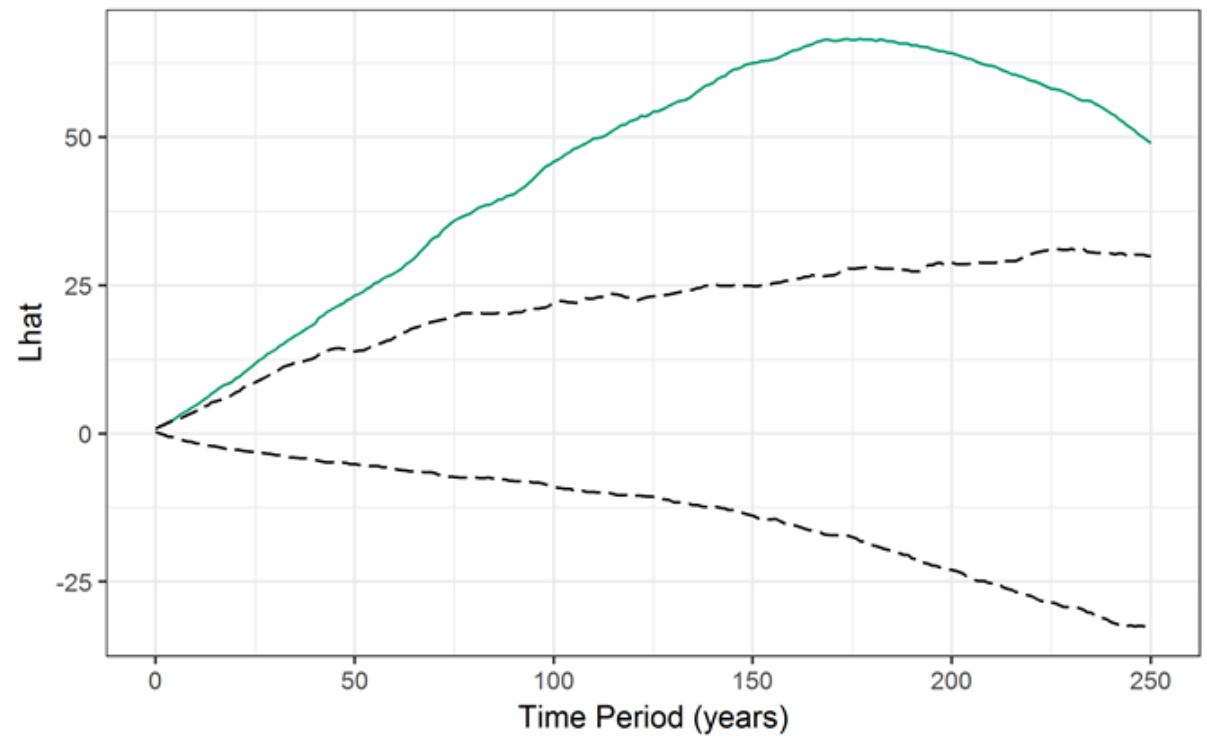

Figure 20. Results of modified Ripley's K method of analyzing synchrony. Results are shown for 3 ecoregions: a) Ozark/Ouachita-Appalachian Forests, b) Mixed Wood Shield, and c) Atlantic Highlands. Green lines show $L$ function (transformed $K$ function) calculated for disturbance dates from 15 sites within each ecoregion, for time periods from 0 years to 250 years. Dashed black lines indicate $99 \%$ confidence envelopes calculated from 1000 randomizations. 


\section{References}

Altman J, Fibich P, Dolezal J, and Aakala T. 2014. TRADER: a package for tree ring analysis of disturbance events in R. Dendrochronologia 32:107-112.

Anning AK. 2013. Prescribed fire and thinning effects on tree growth and carbon sequestration in mixed-oak forests, Ohio, USA. Ph.D. Dissertation. Ohio University.

Beverly JL and Martell DL. 2004. Modeling prescribed surface-fire regimes for Pinus strobus conservation. Conservation Biology 18:1541-1552.

Black BB and Abrams MD. 2003. Use of boundary-line growth patterns as a basis for Dendroecological release criteria. Ecological Applications 13:1733-1749.

Buell, M.F., Buell, H.F., and Small, J.A. 1954. Fire in the history of mettler's woods. Bulletin of the Torrey Botanical Club 81:253-255.

Bunn AG. 2008. A dendrochronology program library in R (dplR). Dendrochronologia 26:115-124. Retrieved from http://doi.org/10.1016/j.dendro.2008.01.002.

Chambers JQ, Fisher JI, Zeng H, Chapman EL, Baker DB, and Hurtt GC. 2007. Hurricane Katrina's carbon footprint on U.S. Gulf Coast forests. Science 318:1107.

Cho DS and Boerner REJ. 1991. Canopy disturbance patterns and regeneration of Quercus species in two Ohio old-growth forests. Vegetatio 93:8-18.

Cho DS and Boerner REJ. 1995. Dendrochronological analysis of the canopy history of two Ohio old-growth forests. Vegetatio 120:173-183.

Clarkson RB. 1964. Tumult on the Mountains: Lumbering in West Virginia-1770-1920. McClain Printing Company. Parsons, WV.

Commission for Environmental Cooperation. 1997. Ecological regions of North America: toward a common perspective. Commission for Environmental Cooperation, Montreal, Quebec, Canada. 71p. Map (scale 1:12,500,000). Revised 2006. Retrieved from https://www.epa.gov/eco-research/ecoregions-north-america.

Copenheaver CA, Seiler JR, Peterson JA, Evans AM, McVay JL, and White JH. 2014. Stadium Woods: A dendroecological analysis of an old-growth forest fragment on a university campus. Dendrochronologia 32:62-70.

D'Amato AW and Orwig DA. 2008. Stand and landscape-level disturbance dynamics in old growth forests in western Massachusetts. Ecological Monographs 78:507-522. 
Fraver S and White AS. 2005. Disturbance dynamics of old-growth Picea rubens forests of northern Maine. Journal of Vegetation Science 16:597-610.

Gavin DG. 2010. K1D: Multivariate Ripley's K-function for one-dimensional data-User's Manual. Version 1.2. University of Oregon, Eugene. Retrieved from http://geog.uoregon.edu/envchange/software.html.

Gavin DG, Hu FS, Lertzman K, and Corbett P. 2006. Weak climatic control of stand-scale fire history during the late Holocene. Ecology 87:1722-1732.

Goetz JB, Bond-Lamberty B, Law BE, Hicke JA, Huang C, Houghton RA, McNulty S, O’Halloran T, Harmon M, Meddens AJH, Pfeifer EM, Mildrexler D, and Kasischk ES. 2012. Observations and assessment of forest carbon dynamics following disturbance in North America. Journal of Geophysical Research 117:1-17.

Grissino-Mayer HD and Fritts HC. 1997. The International Tree-Ring Data Bank: an enhanced global database serving the global scientific community. The Holocene 7:235-238.

Hadley KS and Knapp PA. 2011. Detection of high-wind events using tree-ring data. Canadian Journal of Forest Research 41:1121-1129.

Hicks RR. 1998. Ecology and Management of Central Hardwood Forests. John Wiley and Sons, Inc. New York, NY.

Holmes RL. 1994. Dendrochronology Program Library - User's Manual. University of Arizona, Tucson.

Khakimulina T, Fraver S, and Drobyshev, I. 2016. Mixed-severity natural disturbance regime dominates in an old-growth Norway spruce forest of northwest Russia. Journal of Vegetation Science 27:400-413.

Lafon CW and Speer JH. 2002. Using dendrochronology to identify major ice storm events in oak forests of southwestern Virginia. Climate Research 20:41-54.

Lorimer C and Frelich LE. 1989. A methodology for estimating canopy disturbance frequency and intensity in dense temperate forests. Canadian Journal of Forestry 19:651-663.

Marusek JA. 2010. A Chronological Listing of Early Weather Events, $7^{\text {th }}$ edition. Retrieved from http://www.breadandbutterscience.com/Weather.pdf.

McCarthy J. 2001. Gap dynamics of forest trees: A review with particular attention to boreal forests. Environmental Reviews 9.1:1-59.

McEwan RW, Pederson N, Cooper A, Taylor J, Watts R., and Hruska A. 2014. Fire and 
gap dynamics over 300 years in an old-growth temperate forest. Applied Vegetation Science 17:312-322.

McMurry ER, Stambaugh MC, Guyette RP, and Dey DC. 2007. Fire scars reveal source of New England's 1780 Dark Day. International Journal of Wildland Fire 16:266-270.

Naidoo R and Lechowicz MJ. 2001. Effects of gypsy moth on radial growth of deciduous trees. Forest Science 47:338-348.

Nowacki GJ and Abrams MD. 1997. Radial-growth averaging criteria for reconstructing disturbance histories from presettlement-origin oaks. Ecological Monographs 67:225-249.

Oliver CD and Larson B.C. 1996. Forest Stand Dynamics. John Wiley \& Sons, Inc. New York, NY.

Oswalt SN and Smith BW, eds. 2014. U.S. Forest Resource Facts and Historical Trends. United States Department of Agriculture Forest Service. FS-1035. Retrieved from http://www.fs.fed.us/research/rpa.

Palmquist KA, Peet RK, and Weakley AS. 2014. Changes in plant species richness following reduced fire frequency and drought in one of the most species-rich savannas in North America. Journal of Vegetation Science 25:1426-1437.

Pederson N, Dyer JM, McEwan RW, Hessl AE, Mock CJ, Orwig DA, Rieder HE, and Cook BI. 2014. The legacy of episodic climatic events in shaping temperate broadleaf forests. Ecological Monographs 84: 599-620.

Pyne SJ, Andrews PL, and Laven RD. 1996. Introduction to Wildland Fire, $2^{\text {nd }}$ edition. John Wiley \& Sons, Inc. New York, NY.

R Core Team. 2016. R: A language and environment for statistical computing. R Foundation for Statistical Computing, Vienna, Austria. Retrieved from https://www.R-project.org/.

Rentch JS, Desta F, Miller GW. 2002. Climate, canopy disturbance, and radial growth averaging in a second-growth mixed-oak forest in West Virginia, USA. Canadian Journal of Forest Research 32:915-927.

Ripley BD. 1977. Modelling spatial patterns. Journal of the Royal Statistical Society B39:172-212.

Rodgers JC, Gamble DW, McCay DG, and Phipps S. 2006. Tropical cyclone signals within treering chronologies from Weeks Bay National Estuary and Research Reserve, Alabama. 
Journal of Coastal Research 22:1320-1329.

Runkle JR. 1982. Patterns of disturbance in some old-growth mesic forests of eastern North America. Ecology 63: 1533-1546.

Schleeweis K, Goward SN, Huang C, Masek JG, Moisen G, Kennedy RE, and Thomas NE. 2013. Regional dynamics of forest canopy change and underlying causal processes in the contiguous U.S. Journal of Geophysical Research: Biogeosciences 118:1035-1053.

Schuler, T.M. and McClain, W.R. 2003. Fire history of a ridge and valley oak forest. USDA Forest Service Northeastern Research Station, Research Paper NE-724.

Smolnik M, Hessl A, and Colbert JJ. 2006. Species-specific effects of a 1994 ice storm on radial tree growth in Delaware. Journal of the Torrey Botanical Society 133:577-584.

St. George S. 2014. An overview of tree-ring width records across the Northern Hemisphere. Quaternary Science Reviews 95:132-150.

Swetnam TW and Lynch AM. 1989. A tree-ring reconstruction of western spruce budworm history in the southern Rocky Mountains. Forest Science 35:962-986.

Trotsiuk V, Druckenbrod D, Martin-Benito D, Orwig D, Bishop D, Barker-Plotkin A, Fraver S, and Pederson N. In preparation. Testing the efficacy of tree-ring methods for detecting past canopy release events using experimental data and known events. Methods in Ecology and Evolution.

Van Bogaert R, Gauthier S, Drobyshev I, Jayen K, Greene DF, and Bergeron Y. 2015. Increased environmental stress may lead to reduced seedbank size in Picea mariana in boreal eastern North America. Ecosystems 18:1135-1150.

Wiegand T and Moloney KA. 2004. Rings, circles, and null-models for point pattern analysis in ecology. Oikos 104:209-229.

Zeng H, Chambers JQ, Negrón-Juárez RI, Hurtt GC, Baker DB, Powell MD, and Pacala SW. 2009. Impacts of tropical cyclones on U.S. forest tree mortality and carbon flux from 1851-2000. Proceedings of the National Academy of Sciences of the United States of America 106:7888-7892. 


\section{Supplemental Materials}

\section{A. Citations for data from the ITRDB used in this study}

Format of each citation is as follows: Record ID. Primary Investigator(s). Site Name.

AL001. ED COOK. SIPSEY WILDERNESS

AL002. JOHN KUSH, NEIL PEDERSON, RALPH MELDAHL. FLOMATON NATURAL AREA

AL003. ADAM BALE, MICHAEL STAMBAUGH, RICHARD GUYETTE, JOSEPH MARSCHALL. CHOCCOLOCCO MOUNTAIN

CANA005. AMES. NAIN A+B

CANA209. BRENDAN BUCKLEY, ROSANNE D'ARRIGO. EYEGLASS LAKE CANA210. BRENDAN BUCKLEY, ROSANNE D'ARRIGO. MEDUSA BAY CANA032. ED COOK. BOWATER-MERSEY, NOVA SCOTIA, STANDARD

CANA033. ED COOK. DIXON LAKE, ALGONQUIN PROV. PARK STANDARD CANA034. ED COOK. POT LAKE-NORTHWEST LAKE STANDARD

CANA035. ED COOK. REVIERE DU MOULIN - STANDARD

CANA037. ED COOK. TEMAGAMI LAKE

CANA313. ROSANNE D'ARRIGO, BRENDAN BUCKLEY, GORDON JACOBY.

ITTYHAUK BAY

CANA310. ROSANNE D'ARRIGO, BRENDAN BUCKLEY, GORDON JACOBY.

NAPAKTOK BAY SPRUCE/NAPAKTOK WOODS

CANA312. ROSANNE D'ARRIGO, BRENDAN BUCKLEY, GORDON JACOBY. PISTOLET BAY SPRUCE

CANA127. R.P. GUYETTE. DIVIDING LAKE

CANA148. R.P. GUYETTE, B. COLE. DIVIDING LAKE AQUATIC

CANA128. R.P. GUYETTE. HOBBS LAKE

CANA134. RICHARD GUYETTE, BILL COLE. SWAN LAKE ALGONQUIN PARK ONTARIO

CANA149. R.P. GUYETTE, B. COLE. WESTWARD LAKE, ONTARIO 
FL002. D.STAHLE, S. SIERZCHULA. LIVE OAK

FL003. D.STAHLE, M. CLEAVELAND. O'LENO STATE PARK

FL004. D.STAHLE, M. CLEAVELAND. OCALA NATIONAL FOREST

FL005. D.STAHLE, M. CLEAVELAND, S. SIERZCHULA. SUWANNEE RIVER

FL006. D.STAHLE, S. SIERZCHULA. WANNEE

GA001. HENRI D. GRISSINO-MAYER. ATHENS

GA005. NEIL PEDERSON, BRIAN PALIK, BOB MITCHELL. J.W. JONES ECOLOGICAL RESEARCH CENTER, COMBINED

GA006. NEIL PEDERSON, BRIAN PALIK, BOB MITCHELL. J.W. JONES ECOLOGICAL RESEARCH CENTER, DRY SITE

GA007. NEIL PEDERSON, BRIAN PALIK, BOB MITCHELL. J.W. JONES ECOLOGICAL RESEARCH CENTER, MESIC SITE

GA008. NEIL PEDERSON, BRIAN PALIK, BOB MITCHELL. J.W. JONES ECOLOGICAL RESEARCH CENTER, WET/MES.SITE

GA009. D. STAHLE, S. SIERZCHULA. MOODY TRACT

GA010. N. PEDERSON, B. CATRON, K. TACKETT. AMICALOLA

GA011. PEDERSON, BLOZAN, BRICE, CATRON, LELAND, SCHEFF, MALCOMB, TACKETT. FRICK CREEK

GA012. PEDERSON, BLOZAN, BRICE, CATRON, LELAND, SCHEFF, MALCOMB, TACKETT. CHATTAHOOCHEE NATIONAL FOREST

GA013. PEDERSON, BLOZAN, BRICE, CATRON, LELAND, SCHEFF, MALCOMB, TACKETT. BIG CANOE

GA014. PEDERSON, BLOZAN, BRICE, CATRON, LELAND, SCHEFF, MALCOMB, TACKETT. FRICK CREEK

GA015. T.A. KNIGHT. GREENWOOD PLANTATION

GA016. T.A. KNIGHT. LAVENDER MOUNTAIN

GA017. T.A. KNIGHT. SPREEWELL BLUFF

GA018. T.A. KNIGHT. MARSHALL FOREST

GA019. T.A. KNIGHT. RAMBULETTE MOUNTAIN

GA020. T.A. KNIGHT. PINE MOUNTAIN PMN

GA021. N. PEDERSON. PINE MOUNTAIN TMB 
GA022. T.A. KNIGHT, N. PEDERSON. PINE MOUNTAIN COMBINED

GA023. D. WALKER, C.A. COPENHEAVER. GEORGIA-HWA

IL001. DANIEL N. DUVICK. SANDWICH WHITE OAK

IL002. DANIEL N. DUVICK. SANDWICH WHITE OAK

IL006. E. ESTES. PINE HILLS - 4

IL007. ESTES. PINEY CREEK

IL008. DANIEL N. DUVICK. STARVED ROCK STATE PARK

IL009. DANIEL N. DUVICK. KANKAKEE RIVER STATE PARK

IL010. DANIEL N. DUVICK. LINCOLN'S NEW SALEM STATE PARK

IL011. DANIEL N. DUVICK. FOX RIDGE STATE PARK

IL012. DANIEL N. DUVICK. KICKAPOO STATE PARK

IL013. DANIEL N. DUVICK. FERNE CLYFFE STATE PARK

IL014. DANIEL N. DUVICK. GIANT CITY STATE PARK

IL015. SUSAN LOOMANS. DILLON BEND, MUDDY RIVER

IN001. ED COOK. PULASKI WOODS

IN002. JAMES H. SPEER, KEITH CLAY, GRAHAM BISHOP, MICHELLE CREECH. GREENE-SULLIVAN STATE FOREST

KY002. E. ESTES. MAMMOTH CAVE (ESTES)

KY003. ED COOK. LILLEY CORNETT TRACT

KY004. ED COOK. MAMMOTH CAVE

KY005. MICHAEL STAMBAUGH, RICHARD GUYETTE, JOSEPH MARSCHALL. LAND BETWEEN THE LAKES

KY006. MICHAEL STAMBAUGH, RICHARD GUYETTE, JOSEPH MARSCHALL. HATTON RIDGE

MA001. H.C. FRITTS, T.G. SICCAMA. LIVINGSTON

MA002. ED COOK. MOHAWK TRAIL

MA004. D.MILES. COFFIN HOUSE NEWBURY

MA008. D.MILES. FAIRBANKS HOUSE, DEDHAM

MA012. D.MILES. PIERCE HOUSE, DORCHESTER

MA016. AUGHENBAUGH, HARVEY, HAYES, KAYE, KERNAN, MARION, PETERSON, PIPKIN, RILEY. TEKOA MOUNTAIN 
MD008. JANE F HILL, BILL HILL. BEAR ISLAND

ME005. LAURA E. CONKEY. SUGARLOAF MOUNTAIN

ME010. LAURA E. CONKEY. ELEPHANT MOUNTAIN

ME015. LAURA E. CONKEY. TRAVELER MOUNTAIN

ME016. ED COOK. HANILIN RIDGE, MT. KATAHDIN

ME017. ED COOK. IRONBOUND ISLAND

ME018. ED COOK. IRONBOUND ISLAND, LONG CORES

ME019. ED COOK. MATAWAUMKEAG

ME020. ED COOK. NUMBER THREE POND

ME021. ED COOK. REED POND

ME022. ED COOK. SAG POND

ME023. ED COOK. SOPER BROOK, WEST BRANCH

ME024. ED COOK. WIZARD POND

ME028. A.E.S. HAGER, W.H. LIVINGSTON, A.S. WHITE. ST. FRANCIS

ME029. A.E.S. HAGER, W.H. LIVINGSTON, A.S. WHITE. WEST ENFIELD

ME031. A.E.S HAGER, W.H. LIVINGSTON, A.S. WHITE. BURNHAM

ME032. A.E.S HAGER, W.H. LIVINGSTON, A.S. WHITE. GRINDSTONE

ME033. G. ANDREW BARTHOLOMAY, ROBERT T. ECKERT. ACADIA NATIONAL PARK REGIONAL

ME034. G. ANDREW BARTHOLOMAY, ROBERT T. ECKERT. ACADIA NATIONAL PARK STAND 6

ME035. G. ANDREW BARTHOLOMAY, ROBERT T. ECKERT. ACADIA NATIONAL PARK STAND 8

ME036. HANNAH C. DRUMMOND, ALEXANDER K. STEWART. BRADFORD CAMPS

ME10. A.M. SWAIN. BASIN POND (B)

ME1. A.M. SWAIN. CATHEDRAL PINES

ME. A.M. SWAIN. BASIN POND (A)

MI001. DOUGLAS L. KOOP, HENRI D. GRISSINO-MAYER. HARTWICK PINES STATE PARK

MI004. ED COOK. ALGER COUNTY, MICHIGAN

MI005. ED COOK. CRANBROOK INSTITUTE 
MI006. ED COOK. LOON LAKE

MI007. ED COOK. PRESQUE ISLE RIVER

MI008. ED COOK. PRESQUE ISLE RIVER

MI009. ED COOK. SALT POINT

MI010. ED COOK. SILVER RIVER

MI021. M. STAMBAUGH, R. GUYETTE, J. MARSCHALL, R.-M. MUZIKA. PINE LAKE AND RIVER

MI022. M. STAMBAUGH, R. GUYETTE, J. MARSCHALL, R.-M. MUZIKA. RUSH LAKE

NC001. ED COOK. BALSAM GAP, MT. MITCHELL

NC002. ED COOK. CLINGMAN'S DOME

NC003. ED COOK. GRANDFATHER MOUNTAIN

NC004. ED COOK. JOYCE KILMER WILDERNESS

NC005. ED COOK. KELSEY TRACT

NC006. ED COOK. KELSEY TRACT

NC010. J. YOUNG, R. KEELAND, J. ALFORD. BOOGERMAN TRAIL

NC011. D. STAHLE, S. SIERZCHULA. JOYCE KILMER MEM FOREST

NC012. D. STAHLE, S. SIERZCHULA. JOYCE KILMER MEMORIAL FOREST

NC013. D. STAHLE, S. SIERZCHULA. JOYCE KILMER MEMORIAL FOREST

NC014. D. STAHLE, M. THERRELL. SHOT BEECH RIDGE

NC015. J. YOUNG, R. KEELAND. THOMAS DIVIDE TRAIL

NC017. JASON T. ORTEGREN. WEYMOUTH WOODS

NC019. ED COOK, SCOTT ST. GEORGE. BOYD TRACT

NC020. P. BAKER. BENT CREEK EXPERIMENTAL FOREST

NC021. P. BAKER. BENT CREEK EXPERIMENTAL FOREST

NC022. P. BAKER, N. PEDERSON. BENT CREEK EXPERIMENTAL FOREST

NC024. D. WALKER, C.A. COPENHEAVER. NORTH CAROLINA-HWA

NC1. A.C. BAREFOOT. HAMPTON HILLS

NC2. A.C. BAREFOOT. JEFFRIES SMOKEHOUSE

NC3. A.C. BAREFOOT. LEAD MINE, HAMPTON HILLS

NC4. A.C. BAREFOOT. KIT SPRINGS RANCH, NANTAHALA

NC6. A.C. BAREFOOT, W.L. HAFLEY. NEW HILL BEAVER TREE FARM 
NC7. A.C. BAREFOOT, W.L. HAFLEY. NEW HILL BEAVER TREE FARM

NC8. A.C. BAREFOOT, W.L. HAFLEY. NEW HELL BEAVER TREE FARM

NC9. A.C. BAREFOOT, W.L. HAFLEY, IAN GOURLAY. WEYMOUTH WOODS STATE PARK

NH001. H.C. FRITTS, T.G. SICCAMA. NANCY BROOK, NEW HAMPSHIRE

NH002. ED COOK. GIBB'S BROOK

NH003. ED COOK. NANCY BROOK

NH004. ED COOK. MOUNT WASHINGTON

NH005. PETER CLARK, STOCKTON MAXWELL. 2009 NADEF DENDROCLIMB

ATOLOGY GROUP. RATTLESNAKE MOUNTAIN AND TOWN POUND, RUMNEY

NJ001. ED COOK. HUTCHENSON FOREST WITH LONG CORES

NJO02. ED COOK. HUTCHENSON FOREST

NJ003. N. PEDERSON, E. MASHIG. GREENBROOK SANCTUARY

NJ004. N. PEDERSON, E. MASHIG. GREENBROOK SANCTUARY

NJ005. N. PEDERSON, K. VRANES. UTTERTOWN

NJ006. N. PEDERSON, E. COOK. UTTERTOWN

NJ007. N. PEDERSON, M. HOPTON, E. COOK. UTTERTOWN

NJ008. E. COOK, P. KRUSIC. GREATER HUTCHENSON FOREST REGION HISTORICAL OAK

NY001. ED COOK. ADIRONDACK MOUNTAIN RESERVE

NY002. ED COOK. DARK HOLLOW TRAIL

NY003. ED COOK. MOHONK LAKE

NY006. ED COOK. MOHONK LAKE - TALUS SLOPE

NY008. ED COOK. PACK FOREST

NY009. ED COOK. ROARING BROOK, KEENE VALLEY

NY010. ED COOK. ROARING BROOK, KEENE VALLEY

NY011. ED COOK. ROCK RIFT ROAD - MOHONK LAKE

NY012. ED COOK. SPRUCE GLEN

NY013. ED COOK. WILMINGTON NOTCH - ROARING BROOK

NY014. ED COOK. WINCH POND, ADIRONDACK MOUNTAINS 
NY017. N. PEDERSON, M. HOPTON, D. FRANK. GOOSE EGG RIDGE

NY018. N. PEDERSON, M. HOPTON, D. FRANK. GOOSE EGG RIDGE

NY019. N. PEDERSON. HUNTER ISLAND, BRONX

NY020. N. PEDERSON, T. NORTON. LAKE GEORGE

NY021. N. PEDERSON, E. MASHIG. LISHA KILL

NY022. N. PEDERSON, E. MASHIG. LISHA KILL

NY024. N. PEDERSON. MOHONK PRESERVE

NY025. PAUL KRUSIC, ED COOK. MOHONK LAKE 1996 UPDATE

NY026. N. PEDERSON. MOHONK PRESERVE

NY027. PAUL KRUSIC, ED COOK. MOHONK LAKE TALUS SLOPE UPDATE

NY028. PAUL KRUSIC, ED COOK. ROCK RIFT ROAD MOHONK LAKE UPDATE

NY029. PAUL KRUSIC, ED COOK. SPRUCE GLEN UPDATE

NY030. N. PEDERSON, D. DUKPA, K. ROCK. MONTGOMERY PLACE

NY031. N. PEDERSON, D. DUKPA, K. ROCK. MONTGOMERY PLACE

NY032. N. PEDERSON, D. DUKPA, K. ROCK. MONTGOMERY PLACE

NY033. N. PEDERSON, E. MASHIG, D. FRANK. PROSPECT MOUNTAIN

NY034. N. PEDERSON, E. MASHIG, D. FRANK. PROSPECT MOUNTAIN

NY035. N. PEDERSON, E. MASHIG, D. FRANK. PROSPECT MOUNTAIN

NY037. N. PEDERSON. OLD MAIDS WOODS

NY038. N. PEDERSON, P. KRUSIC, E. COOK. DARK HOLLOW TRAIL UPDATE

NY039. N. PEDERSON, F. BREGLIA, P. KRUSIC. MIDDLEBURGH

NY040. E. COOK, P. KRUSIC, N. PEDERSON. GREATER ALBANY REGION HISTORICAL OAK

NY042. E. COOK, P. KRUSIC. NORTHERN HUDSON VALLEY HISTORICAL

NY043. ALEXANDER K. STEWART, SADDIE R. SERVISS. CROOKED LAKE

NY044. CAROL GRIGGS, J. WATKINS, C. PEARSON, P. BREWER, S. MANNING.

MABEE FARM, ROTTERDAM JUNCTION

NY045. CAROL GRIGGS, TOMASZ WAZNY. FOUR STRUCTURES EAST OF LAKE ONTARIO

NY047. ELEANOR JONES, LUIS H.A. ARUJO, ALEXANDER K. STEWART. PLUMB BROOK 
OH001. ED COOK. ANDREW JOHNSON WOODS, OHIO

OH002. ED COOK. STEBBIN'S GULCH, HOLDEN ARB

OH003. ED COOK. DAVIS PURDUE - GLEN HELEN

OH005. MCCLENAHEN, HOUSTON. BUFFALO BEATS NORTH, CLAY LENS PRAIRIE SOIL

OH006. DARRIN L. RUBINO, BRIAN C. MCCARTHY. DYSART WOODS

PA001. ED COOK. ALAN SEEGER NATURAL AREA

PA003. ED COOK. DINGMAN'S FALLS STATE PARK

PA004. ED COOK. EAST BRANCH SWAMP

PA005. ED COOK. FERNCLIFFE NATURAL AREA

PA006. ED COOK. FIRE TOWER ROAD, COOK FOREST

PA007. ED COOK. HEMLOCKS NATURAL AREA

PA008. ED COOK. LONGFELLOW TRAIL

PA009. ED COOK. OTTER CREEK NATURAL AREA

PA010. ED COOK. RICKETT'S GLEN STATE PARK

PA011. ED COOK. SALT SPRINGS STATE PARK

PA012. ED COOK. SWEETROOT NATURAL AREA

PA013. ED COOK. TIONESTA NATURAL AREA

PA016. D. WALKER, C.A. COPENHEAVER. PENNSYLVANIA-HWA

PA. A.M. SWAIN. ELY LAKE

SC003. M.K. CLEAVELAND. CLEMSON FOREST

SC005. D.STAHLE, S. SIERZCHULA. FRANCIS BEIDLER SWAMP

TN005. DANIEL N. DUVICK. PINEY CREEK POCKET WILDERNESS

TN008. DANIEL N. DUVICK. NORRIS DAM STATE PARK

TN009. ED COOK. SAVAGE GULF

TN011. J. YOUNG, W. BLOZAN. LAUREL FALLS TRAIL

TN012. D. STAHLE, M. THERRELL. PORTERS CREEK

TN013. J. YOUNG, W. BLOZAN. GREENBRIER

TN014. J. YOUNG, R. KEELAND, E. NUNES. HENWALLOW FALLS

TN015. J. YOUNG, R. KEELAND, J. ALFORD. RAINBOW FALLS TRAIL

TN016. J. YOUNG, R. KEELAND, J. ALFORD. BOOGERMAN TRAIL TENNESSEE 
TN017. J. YOUNG, W. BLOZAN. GREENBRIAR

TN018. J. YOUNG, R. KEELAND, E. NUNES. HEN WALLOW FALLS

TN019. J. YOUNG, R. KEELAND, E. NUNES. HEN WALLOW FALLS [B]

TNO20. D. STAHLE, M. THERRELL. LYNN HOLLOW

TNO21. D.STAHLE, M. THERRELL. LYNN HOLLOW

TN022. D.STAHLE, M. THERRELL, W. BLOZAN. LYNN HOLLOW AND LOOK ROCK

TRAIL 2009 UPDATE

TN023. J. YOUNG. RAINBOW FALLS TRAIL

TN026. J. YOUNG, R. KEELAND, J. ALFORD. SNAKE DEN TRAIL

TN027. D. STAHLE, M. THERRELL. PORTER'S CREEK

TN029. NEIL PEDERSON, DAN GRIFFIN, JESS RIDDLE. SAVAGE GULF UPDATE

TN030. NEIL PEDERSON, KACIE TACKETT. 2007 NADEFW GROUP. FORGE CREEK

TN. DANIEL N. DUVICK. SCOTTS GAP

VA001. RICHARD L. PHIPPS. SPALDING (PRE-1913)

VA006. LARRY J. PUCKETT, WENDY CHITTENDEN. DALE CITY

VA007. LARRY J. PUCKETT, RICHARD L. PHIPPS. BURLING TRACT

VA008. LARRY J. PUCKETT, RICHARD L. PHIPPS. RAMSEYS DRAFT

VA009. ED COOK. BLUE RIDGE PARKWAY

VA010. ED COOK. HEMLOCK COVE-SUNSET FIELD

VA011. ED COOK. MOUNTAIN LAKE

VA012. ED COOK. MOUNT ROGERS, 3 SITES

VA013. ED COOK. MOUNTAIN LAKE

VA014. ED COOK. PINNACLE POINT - HAWKSBILL GAP

VA015. ED COOK. RAMSEYS DRAFT

VA016. ED COOK. WATCH DOG, MASSENHUTTEN MTN.

VA017. ED COOK. PATTY'S OAKS, BLUE RIDGE PARKWAY

VA018. DAVID M. LAWRENCE, ALISON M. SINCLAIR. MASSANUTTEN MTN, SOUTH OF HABRON GAP, VA

VA019. D.M. LAURENCE, FALL 1993 EVEC522 STUDENTS. CHARLOTTESVILLE - MT. JEFFERSON (OBSERVATORY HILL)

VA020. SUTHERLAND, GRISSINO-MAYER, WOODHOUSE. BRUSH MOUNTAIN, 
JEFFERSON NATIONAL FOREST

VA026. DRUCKENBROD, MANN, STAHLE, CLEAVELAND, THERRELL, SHUGART. MONTPELIER NATIONAL NATURAL LANDMARK FOREST

VA027. D.M. LAWRENCE, S.L. STEPHENSON, H.S. ADAMS. SWEET BRIAR COLLEGE OLD-GROWTH WHITE OAK

VA030. C.A. COPENHEAVER. ZOAR STATE FOREST (TERRACE)

VA031. C.A. COPENHEAVER. ZOAR STATE FOREST (FLOOD PLAIN)

VA032. D. WALKER, C.A. COPENHEAVER. VIRGINIA-HWA

VA033. C.A. COPENHEAVER. GAP MOUNTAIN

VA035. C.A. COPENHEAVER. STROUBLES CREEK

VA036. C.A. COPENHEAVER. BRUSH MOUNTAIN

VA037. C.A. COPENHEAVER. STADIUM WOODS

VT001. TOM SICCAMA. CAMELS HUMP C+A, VERMONT

VT002. ED COOK. GRANVILLE GULF

VT003. DANIEL G. GAVIN. BOLTON MOUNTAIN LOW

VT004. DANIEL G. GAVIN. BOLTON MOUNTAIN MID

VT005. DANIEL G. GAVIN. BOLTON MOUNTAIN MID

VT006. DANIEL G. GAVIN. BOLTON MOUNTAIN HIGH

VT007. DANIEL G. GAVIN. BOLTON MOUNTAIN LOW

VT008. DANIEL G. GAVIN. BOLTON MOUNTAIN HIGH

VT010. C. BAISAN. WEST BRATTLEBORO APARTMENTS HISTORICAL

WI002. WAYNE WENDLAND, ALBERT M. SWAIN. TROUT LAKE

WI004. ED COOK. BASS LAKE PENINSULA

WI005. ED COOK. DEVIL'S LAKE STATE PARK

WI008. STEVEN VOELKER. ST. CROIX RIVER

WI010. STEVEN VOELKER. BRULE RIVER

WI011. MICHAEL STAMBAUGH, RICHARD GUYETTE, JOSEPH MARSCHALL.

GRINDLE LAKE

WI012. MICHAEL STAMBAUGH, RICHARD GUYETTE, JOSEPH MARSCHALL.

WAUBEE LAKE

WI013. F.K. KAISER. TWO CREEKS 
WV001. ED COOK. GAUDIMEER SCENIC AREA

WV003. ADAMS, LAMARCHE, MUZIKA, STEPHENSON. FERNOW EXPERIMENTAL FOREST

WV004. R. STOCKTON MAXWELL, RAY R. HICKS, JR. NEW RIVER GORGE

WV006. T. SALADYGA, R.S. MAXWELL. PIPESTEM RESORT STATE PARK

WV007. T. SALADYGA, J. GELINAS, N. LAWRENCE. CABWAYLINGO STATE FOREST

WV008. D. WALKER, C.A. COPENHEAVER. WEST VIRGINIA-HWA

WV009. T. SALADYGA, C. RASO, T. HATFIELD. BABCOCK STATE PARK 


\title{
B. Example ring width file in Tucson Decadal Format
}

\author{
Example file: OH006. DARRIN L. RUBINO, BRIAN C. MCCARTHY. DYSART WOODS \\ Retrieved via: “ftp://ftp.ncdc.noaa.gov/pub/data/paleo/treering/measurements/northamerica/ \\ usa/oh006.rwl"
}

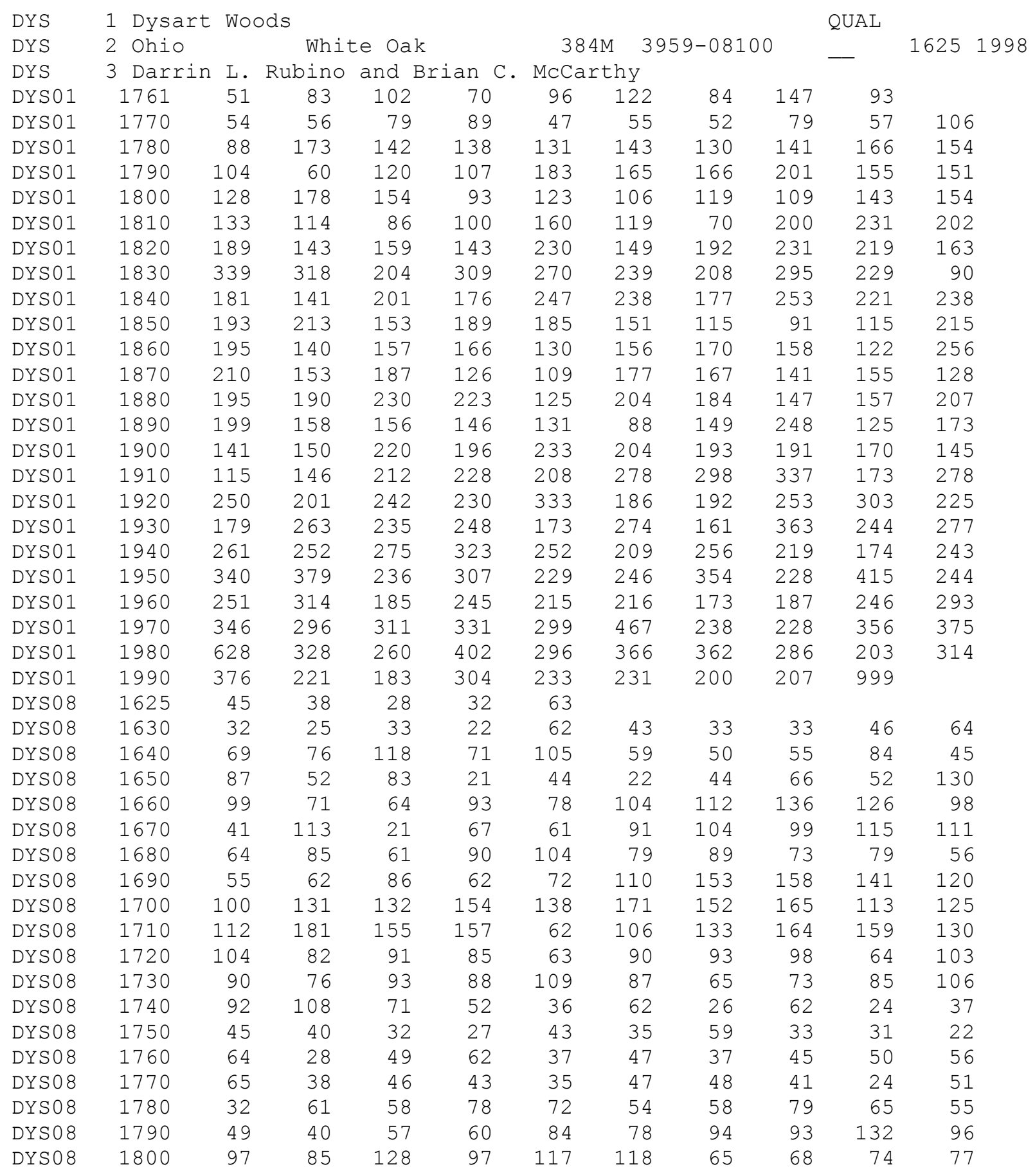




\begin{tabular}{|c|c|c|c|c|c|c|c|c|c|c|c|}
\hline DYSO 8 & 1810 & 77 & 90 & 90 & 75 & 99 & 86 & 58 & 115 & 58 & 40 \\
\hline DYS 08 & 1820 & 59 & 37 & 57 & 60 & 90 & 56 & 79 & 77 & 70 & 61 \\
\hline DYS 08 & 1830 & 88 & 100 & 104 & 127 & 124 & 187 & 130 & 128 & 105 & 76 \\
\hline DYSO 8 & 1840 & 107 & 92 & 111 & 101 & 94 & 100 & 83 & 112 & 98 & 99 \\
\hline DYS 08 & 1850 & 93 & 151 & 103 & 106 & 80 & 107 & 110 & 93 & 65 & 105 \\
\hline DYSO 8 & 1860 & 107 & 81 & 94 & 73 & 61 & 90 & 81 & 65 & 82 & 114 \\
\hline DYSO 8 & 1870 & 88 & 75 & 94 & 70 & 61 & 84 & 70 & 67 & 72 & 74 \\
\hline DYS 08 & 1880 & 93 & 86 & 120 & 125 & 111 & 136 & 139 & 131 & 158 & 195 \\
\hline DYSO 8 & 1890 & 165 & 152 & 170 & 151 & 135 & 116 & 174 & 159 & 178 & 216 \\
\hline DYSO 8 & 1900 & 147 & 116 & 101 & 99 & 92 & 104 & 93 & 80 & 87 & 84 \\
\hline DYS 08 & 1910 & 77 & 95 & 140 & 127 & 89 & 149 & 110 & 91 & 60 & 60 \\
\hline DYSO 8 & 1920 & 78 & 77 & 77 & 90 & 99 & 73 & 84 & 91 & 97 & 89 \\
\hline DYS 08 & 1930 & 82 & 107 & 95 & 103 & 115 & 154 & 120 & 155 & 138 & 129 \\
\hline DYS 08 & 1940 & 135 & 154 & 163 & 177 & 178 & 198 & 214 & 231 & 180 & 228 \\
\hline DYSO 8 & 1950 & 250 & 205 & 207 & 180 & 160 & 158 & 228 & 177 & 181 & 132 \\
\hline DYSO 8 & 1960 & 91 & 131 & 117 & 171 & 127 & 100 & 103 & 113 & 114 & 162 \\
\hline DYSO 8 & 1970 & 127 & 148 & 118 & 171 & 212 & 236 & 170 & 97 & 106 & 111 \\
\hline DYSO 8 & 1980 & 183 & 125 & 110 & 121 & 108 & 115 & 140 & 123 & 98 & 121 \\
\hline DYS 08 & 1990 & 143 & 114 & 81 & 160 & 143 & 123 & 85 & 104 & 999 & \\
\hline DYS 02 & 1777 & 144 & 87 & 112 & & & & & & & \\
\hline DYSO2 & 1780 & 142 & 197 & 192 & 158 & 144 & 181 & 144 & 195 & 201 & 213 \\
\hline DYS 02 & 1790 & 128 & 110 & 122 & 177 & 243 & 265 & 322 & 320 & 238 & 277 \\
\hline DYSO 2 & 1800 & 315 & 282 & 305 & 262 & 261 & 280 & 221 & 251 & 286 & 300 \\
\hline DYSO2 & 1810 & 222 & 293 & 284 & 278 & 338 & 290 & 129 & 270 & 312 & 227 \\
\hline DYS 02 & 1820 & 228 & 195 & 216 & 199 & 215 & 197 & 192 & 202 & 239 & 219 \\
\hline DYS 02 & 1830 & 285 & 308 & 254 & 267 & 320 & 232 & 252 & 251 & 203 & 148 \\
\hline DYSO2 & 1840 & 236 & 218 & 239 & 198 & 264 & 232 & 202 & 269 & 284 & 301 \\
\hline DYS 02 & 1850 & 217 & 227 & 191 & 176 & 214 & 207 & 194 & 219 & 251 & 314 \\
\hline DYSO2 & 1860 & 282 & 225 & 245 & 192 & 206 & 290 & 248 & 255 & 168 & 311 \\
\hline DYSO 2 & 1870 & 296 & 220 & 258 & 222 & 144 & 256 & 292 & 259 & 236 & 201 \\
\hline DYSO 2 & 1880 & 342 & 296 & 364 & 349 & 225 & 351 & 307 & 275 & 293 & 362 \\
\hline DYSO 2 & 1890 & 311 & 291 & 351 & 268 & 211 & 138 & 394 & 292 & 236 & 256 \\
\hline DYSO 2 & 1900 & 201 & 265 & 286 & 229 & 221 & 223 & 239 & 234 & 238 & 186 \\
\hline DYSO 2 & 1910 & 164 & 193 & 282 & 285 & 193 & 316 & 356 & 390 & 157 & 208 \\
\hline DYSO2 & 1920 & 208 & 167 & 181 & 153 & 149 & 143 & 150 & 237 & 223 & 168 \\
\hline DYS 02 & 1930 & 137 & 201 & 208 & 223 & 187 & 256 & 166 & 234 & 190 & 172 \\
\hline DYS 02 & 1940 & 162 & 161 & 146 & 172 & 155 & 168 & 194 & 180 & 138 & 168 \\
\hline DYSO2 & 1950 & 214 & 199 & 127 & 210 & 171 & 146 & 167 & 171 & 245 & 113 \\
\hline DYS 02 & 1960 & 143 & 171 & 140 & 156 & 174 & 173 & 115 & 116 & 125 & 162 \\
\hline DYSO 2 & 1970 & 130 & 122 & 88 & 138 & 115 & 163 & 96 & 108 & 133 & 113 \\
\hline DYSO2 & 1980 & 173 & 114 & 122 & 135 & 116 & 159 & 135 & 137 & 82 & 124 \\
\hline DYS 02 & 1990 & 107 & 120 & 119 & 196 & 145 & 190 & 127 & 154 & 999 & \\
\hline DYSO 3 & 1712 & 38 & 53 & 24 & 46 & 46 & 62 & 56 & 64 & & \\
\hline DYSO3 & 1720 & 51 & 41 & 28 & 27 & 33 & 36 & 80 & 111 & 140 & 139 \\
\hline DYSO 3 & 1730 & 136 & 176 & 162 & 116 & 144 & 94 & 99 & 128 & 130 & 143 \\
\hline DYSO 3 & 1740 & 178 & 214 & 175 & 111 & 102 & 190 & 115 & 171 & 155 & 144 \\
\hline DYSO 3 & 1750 & 126 & 157 & 115 & 127 & 178 & 105 & 201 & 176 & 181 & 90 \\
\hline DYSO 3 & 1760 & 172 & 134 & 117 & 103 & 108 & 115 & 154 & 131 & 166 & 133 \\
\hline DYSO 3 & 1770 & 117 & 128 & 157 & 136 & 100 & 152 & 197 & 215 & 125 & 176 \\
\hline DYSO 3 & 1780 & 122 & 165 & 153 & 143 & 142 & 86 & 104 & 119 & 104 & 82 \\
\hline DYSO 3 & 1790 & 51 & 37 & 50 & 46 & 69 & 64 & 80 & 72 & 66 & 60 \\
\hline DYSO 3 & 1800 & 85 & 80 & 87 & 60 & 76 & 94 & 59 & 108 & 105 & 111 \\
\hline DYSO 3 & 1810 & 93 & 106 & 112 & 64 & 90 & 74 & 49 & 114 & 105 & 83 \\
\hline DYSO 3 & 1820 & 81 & 62 & 90 & 74 & 133 & 113 & 120 & 91 & 159 & 105 \\
\hline DYSO 3 & 1830 & 176 & 131 & 139 & 169 & 129 & 205 & 167 & 163 & 131 & 71 \\
\hline DYSO 3 & 1840 & 160 & 123 & 166 & 140 & 52 & 65 & 46 & 58 & 46 & 45 \\
\hline DYSO 3 & 1850 & 37 & 47 & 37 & 45 & 44 & 37 & 33 & 19 & 19 & \\
\hline
\end{tabular}




\begin{tabular}{|c|c|c|c|c|c|c|c|c|c|c|c|}
\hline DYSO 3 & 1860 & 36 & 23 & 20 & 18 & 25 & 39 & 36 & 24 & 25 & 38 \\
\hline DYSO 3 & 1870 & 27 & 26 & 27 & 29 & 26 & 48 & 83 & 59 & 60 & 26 \\
\hline DYSO 3 & 1880 & 42 & 32 & 63 & 51 & 81 & 91 & 122 & 61 & 85 & 84 \\
\hline DYSO 3 & 1890 & 70 & 61 & 117 & 117 & 133 & 110 & 334 & 297 & 250 & 190 \\
\hline DYSO 3 & 1900 & 157 & 179 & 266 & 261 & 268 & 201 & 210 & 204 & 176 & 151 \\
\hline DYSO3 & 1910 & 179 & 140 & 232 & 215 & 142 & 206 & 269 & 233 & 174 & 168 \\
\hline DYSO 3 & 1920 & 186 & 180 & 179 & 230 & 286 & 174 & 189 & 264 & 245 & 199 \\
\hline DYSO 3 & 1930 & 160 & 191 & 219 & 230 & 191 & 271 & 183 & 301 & 304 & 222 \\
\hline DYSO3 & 1940 & 232 & 218 & 217 & 248 & 184 & 284 & 282 & 233 & 154 & 220 \\
\hline DYSO 3 & 1950 & 302 & 258 & 217 & 209 & 180 & 197 & 264 & 202 & 311 & 90 \\
\hline DYSO 3 & 1960 & 207 & 315 & 193 & 226 & 224 & 179 & 153 & 188 & 203 & 251 \\
\hline DYSO3 & 1970 & 203 & 198 & 150 & 221 & 236 & 270 & 167 & 66 & 197 & 152 \\
\hline DYSO 3 & 1980 & 226 & 188 & 167 & 204 & 227 & 320 & 240 & 229 & 196 & 302 \\
\hline DYSO 3 & 1990 & 263 & 159 & 190 & 281 & 272 & 327 & 250 & 197 & 999 & \\
\hline DYSO 4 & 1774 & 34 & 96 & 81 & 69 & 43 & 104 & & & & \\
\hline DYSO 4 & 1780 & 73 & 85 & 91 & 77 & 95 & 86 & 75 & 127 & 128 & 135 \\
\hline DYSO 4 & 1790 & 67 & 55 & 83 & 96 & 122 & 89 & 94 & 98 & 97 & \\
\hline DYSO 4 & 1800 & 82 & 90 & 105 & 81 & 96 & 132 & 90 & 144 & 156 & 155 \\
\hline DYSO 4 & 1810 & 126 & 123 & 116 & 132 & 186 & 203 & 149 & 232 & 252 & 182 \\
\hline DYSO 4 & 1820 & 186 & 125 & 148 & 168 & 198 & 179 & 174 & 213 & 208 & 161 \\
\hline DYSO 4 & 1830 & 218 & 207 & 151 & 171 & 183 & 161 & 175 & 184 & 133 & 82 \\
\hline DYSO 4 & 1840 & 169 & 141 & 141 & 124 & 115 & 121 & 74 & 126 & 150 & 134 \\
\hline DYSO 4 & 1850 & 172 & 184 & 165 & 153 & 115 & 98 & 82 & 96 & 113 & 220 \\
\hline DYSO 4 & 1860 & 160 & 131 & 137 & 139 & 141 & 243 & 172 & 152 & 114 & 203 \\
\hline DYSO 4 & 1870 & 200 & 100 & 172 & 131 & 83 & 173 & 174 & 156 & 153 & 134 \\
\hline DYSO 4 & 1880 & 151 & 169 & 179 & 163 & 154 & 151 & 145 & 121 & 128 & 191 \\
\hline DYSO 4 & 1890 & 157 & 166 & 165 & 149 & 157 & 97 & 212 & 277 & 183 & 174 \\
\hline DYSO 4 & 1900 & 220 & 210 & 267 & 278 & 248 & 222 & 271 & 230 & 287 & 194 \\
\hline DYSO 4 & 1910 & 195 & 210 & 280 & 266 & 219 & 281 & 288 & 262 & 179 & 209 \\
\hline DYSO 4 & 1920 & 232 & 216 & 229 & 236 & 253 & 224 & 191 & 279 & 262 & 205 \\
\hline DYSO 4 & 1930 & 172 & 192 & 219 & 242 & 181 & 240 & 168 & 303 & 237 & 215 \\
\hline DYSO 4 & 1940 & 193 & 213 & 239 & 222 & 219 & 232 & 234 & 197 & 204 & 218 \\
\hline DYSO 4 & 1950 & 221 & 246 & 218 & 234 & 191 & 163 & 245 & 216 & 234 & 183 \\
\hline DYSO 4 & 1960 & 196 & 276 & 196 & 234 & 205 & 233 & 160 & 154 & 212 & 200 \\
\hline DYSO 4 & 1970 & 273 & 188 & 148 & 190 & 215 & 207 & 200 & 153 & 207 & 167 \\
\hline DYSO 4 & 1980 & 211 & 136 & 159 & 197 & 148 & 174 & 161 & 155 & 140 & 162 \\
\hline DYS 04 & 1990 & 179 & 139 & 130 & 223 & 169 & 203 & 144 & 149 & 155 & 999 \\
\hline DYS 06 & 1811 & 46 & 42 & 62 & 43 & 48 & 50 & 55 & 54 & 98 & \\
\hline DYSO 6 & 1820 & 169 & 87 & 83 & 73 & 87 & 57 & 65 & 70 & 83 & 56 \\
\hline DYSO 6 & 1830 & 73 & 80 & 76 & 108 & 89 & 93 & 89 & 75 & 82 & 56 \\
\hline DYSO 6 & 1840 & 84 & 97 & 90 & 81 & 65 & 105 & 86 & 113 & 127 & 101 \\
\hline DYSO 6 & 1850 & 127 & 151 & 103 & 97 & 95 & 89 & 102 & 97 & 69 & 112 \\
\hline DYSO 6 & 1860 & 102 & 85 & 99 & 98 & 104 & 129 & 115 & 120 & 79 & 73 \\
\hline DYSO 6 & 1870 & 72 & 93 & 123 & 130 & 107 & 167 & 145 & 207 & 162 & 149 \\
\hline DYSO 6 & 1880 & 156 & 189 & 207 & 204 & 132 & 177 & 175 & 144 & 172 & 170 \\
\hline DYSO 6 & 1890 & 162 & 155 & 159 & 176 & 166 & 119 & 190 & 204 & 237 & 151 \\
\hline DYSO 6 & 1900 & 204 & 211 & 241 & 217 & 204 & 212 & 214 & 241 & 215 & 201 \\
\hline DYSO 6 & 1910 & 230 & 189 & 253 & 208 & 197 & 275 & 274 & 299 & 152 & 214 \\
\hline DYS 06 & 1920 & 246 & 213 & 208 & 216 & 252 & 165 & 164 & 205 & 252 & 198 \\
\hline DYS 06 & 1930 & 181 & 172 & 200 & 201 & 220 & 252 & 168 & 261 & 219 & 245 \\
\hline DYSO 6 & 1940 & 200 & 243 & 207 & 263 & 188 & 211 & 210 & 187 & 190 & 202 \\
\hline DYSO 6 & 1950 & 235 & 215 & 168 & 171 & 143 & 122 & 221 & 187 & 216 & 156 \\
\hline DYSO 6 & 1960 & 162 & 205 & 135 & 194 & 178 & 177 & 131 & 146 & 171 & 235 \\
\hline DYSO 6 & 1970 & 214 & 185 & 181 & 203 & 209 & 207 & 201 & 117 & 204 & 155 \\
\hline DYSO 6 & 1980 & 196 & 112 & 171 & 168 & 122 & 148 & 133 & 130 & 128 & 131 \\
\hline DYS 06 & 1990 & 146 & 123 & 142 & 189 & 181 & 181 & 159 & 136 & 167 & 999 \\
\hline DYS 07 & 1676 & 126 & 133 & 104 & 75 & & & & & & \\
\hline
\end{tabular}




\begin{tabular}{|c|c|c|c|c|c|c|c|c|c|c|c|}
\hline DYSO 07 & 1680 & 50 & 38 & 24 & 70 & 51 & 47 & 36 & 28 & 49 & 44 \\
\hline DYS 07 & 1690 & 22 & 52 & 56 & 31 & 79 & 60 & 84 & 64 & 51 & 19 \\
\hline DYS 07 & 1700 & 38 & 55 & 44 & 39 & 58 & 60 & 47 & 68 & 80 & 94 \\
\hline DYSO 7 & 1710 & 57 & 82 & 101 & 72 & 87 & 91 & 94 & 93 & 59 & 81 \\
\hline DYS 07 & 1720 & 42 & 54 & 58 & 35 & 54 & 71 & 106 & 82 & 89 & 88 \\
\hline DYS 07 & 1730 & 81 & 102 & 84 & 74 & 63 & 56 & 47 & 38 & 71 & 38 \\
\hline DYS 07 & 1740 & 44 & 34 & 33 & 23 & 20 & 49 & 16 & 41 & 25 & 9 \\
\hline DYS 07 & 1750 & 25 & 24 & 13 & 26 & 17 & 21 & 50 & 22 & 40 & 8 \\
\hline DYS 07 & 1760 & 52 & 37 & 55 & 37 & 58 & 51 & 51 & 45 & 93 & 9 \\
\hline DYS 07 & 1770 & 43 & 58 & 65 & 54 & 71 & 67 & 38 & 35 & 29 & 1 \\
\hline DYS 07 & 1780 & 54 & 63 & 29 & 59 & 112 & 76 & 54 & 39 & 38 & \\
\hline DYS 07 & 1790 & 30 & 25 & 33 & 52 & 86 & 95 & 144 & 107 & 72 & \\
\hline DYS 07 & 1800 & 93 & 87 & 60 & 47 & 38 & 35 & 32 & 60 & 69 & \\
\hline DYS 07 & 1810 & 60 & 64 & 96 & 72 & 121 & 85 & 70 & 107 & 235 & \\
\hline DYS 07 & 1820 & 92 & 64 & 85 & 103 & 138 & 171 & 117 & 132 & 115 & \\
\hline DYS 07 & 1830 & 144 & 194 & 101 & 181 & 191 & 153 & 103 & 77 & 55 & \\
\hline DYS 07 & 1840 & 76 & 46 & 82 & 67 & 61 & 100 & 62 & 124 & 159 & 120 \\
\hline DYS 07 & 1850 & 172 & 151 & 95 & 120 & 126 & 126 & 71 & 92 & 108 & 174 \\
\hline DYS 07 & 1860 & 158 & 161 & 153 & 114 & 112 & 176 & 154 & 164 & 136 & 243 \\
\hline DYS 07 & 1870 & 178 & 145 & 219 & 180 & 119 & 266 & 211 & 220 & 184 & 149 \\
\hline DYSO 7 & 1880 & 246 & 210 & 217 & 215 & 184 & 188 & 129 & 114 & 134 & 161 \\
\hline DYS 07 & 1890 & 191 & 162 & 182 & 192 & 173 & 109 & 239 & 245 & 308 & 144 \\
\hline DYS 07 & 1900 & 252 & 306 & 321 & 267 & 279 & 261 & 262 & 201 & 199 & 174 \\
\hline DYS 07 & 1910 & 196 & 245 & 248 & 331 & 233 & 343 & 257 & 279 & 161 & 179 \\
\hline DYS 07 & 1920 & 234 & 194 & 234 & 217 & 219 & 170 & 123 & 238 & 352 & 237 \\
\hline DYS 07 & 1930 & 164 & 246 & 249 & 259 & 205 & 264 & 158 & 367 & 241 & 247 \\
\hline DYSO 07 & 1940 & 224 & 277 & 290 & 362 & 274 & 236 & 220 & 199 & 134 & 171 \\
\hline DYS 07 & 1950 & 281 & 278 & 242 & 338 & 270 & 213 & 264 & 186 & 288 & 182 \\
\hline DYS 07 & 1960 & 181 & 187 & 125 & 132 & 164 & 132 & 115 & 141 & 137 & 16 \\
\hline DYS 07 & 1970 & 193 & 189 & 124 & 194 & 197 & 184 & 118 & 89 & 188 & 93 \\
\hline DYS 07 & 1980 & 278 & 125 & 131 & 176 & 90 & 155 & 175 & 163 & 98 & 160 \\
\hline DYS 07 & 1990 & 120 & 126 & 126 & 180 & 82 & 161 & 89 & 93 & 138 & 999 \\
\hline DYSO 5 & 1786 & 100 & 91 & 81 & 84 & & & & & & \\
\hline DYSO 05 & 1790 & 64 & 53 & 69 & 65 & 90 & 88 & 92 & 117 & 113 & \\
\hline DYSO 5 & 1800 & 93 & 121 & 114 & 90 & 117 & 88 & 74 & 72 & 73 & \\
\hline DYSO 5 & 1810 & 97 & 97 & 93 & 90 & 117 & 119 & 85 & 107 & 159 & 125 \\
\hline DYSO 05 & 1820 & 118 & 95 & 87 & 106 & 122 & 103 & 111 & 118 & 138 & \\
\hline DYSO 5 & 1830 & 144 & 135 & 131 & 152 & 151 & 137 & 121 & 132 & 149 & \\
\hline DYSO 5 & 1840 & 126 & 108 & 149 & 142 & 149 & 125 & 95 & 122 & 124 & 116 \\
\hline DYS 05 & 1850 & 115 & 152 & 135 & 135 & 128 & 110 & 111 & 91 & 103 & 20 \\
\hline DYSO 5 & 1860 & 198 & 176 & 184 & 138 & 135 & 163 & 175 & 123 & 114 & 19 \\
\hline DYS 05 & 1870 & 162 & 123 & 147 & 113 & 106 & 181 & 142 & 156 & 156 & 127 \\
\hline DYSO 5 & 1880 & 133 & 150 & 171 & 182 & 115 & 137 & 165 & 144 & 119 & 161 \\
\hline DYSO 5 & 1890 & 170 & 176 & 156 & 146 & 157 & 102 & 111 & 188 & 141 & 160 \\
\hline DYSO 5 & 1900 & 137 & 188 & 189 & 230 & 195 & 175 & 158 & 203 & 161 & \\
\hline DYSO 5 & 1910 & 106 & 127 & 151 & 188 & 113 & 191 & 243 & 214 & 170 & 16 \\
\hline DYSO 5 & 1920 & 245 & 183 & 199 & 161 & 183 & 150 & 121 & 193 & 209 & 15 \\
\hline DYSO 5 & 1930 & 131 & 121 & 158 & 145 & 121 & 206 & 160 & 209 & 231 & 18 \\
\hline DYSO 5 & 1940 & 192 & 169 & 219 & 238 & 169 & 191 & 160 & 176 & 146 & 136 \\
\hline DYSO 5 & 1950 & 171 & 170 & 146 & 156 & 108 & 125 & 165 & 158 & 126 & 125 \\
\hline DYS 05 & 1960 & 90 & 153 & 99 & 103 & 140 & 131 & 78 & 73 & 80 & \\
\hline DYSO 5 & 1970 & 88 & 100 & 57 & 95 & 87 & 87 & 80 & 66 & 98 & \\
\hline DYSO 5 & 1980 & 83 & 62 & 61 & 83 & 60 & 78 & 92 & 100 & 94 & 123 \\
\hline DYS 05 & 1990 & 123 & 96 & 101 & 140 & 108 & 126 & 102 & 90 & 131 & 99 \\
\hline DYSO 9 & 1659 & 160 & & & & & & & & & \\
\hline DYSO 9 & 1660 & 117 & 169 & 194 & 173 & 88 & 118 & 235 & 287 & 269 & \\
\hline DYSO 9 & 1670 & 151 & 127 & 192 & 287 & 266 & 277 & 246 & 239 & 270 & \\
\hline
\end{tabular}




\begin{tabular}{|c|c|c|c|c|c|c|c|c|c|c|}
\hline DYSO 9 & 1680 & 159 & 190 & 94 & 252 & 322 & 200 & 200 & 141 & 177 \\
\hline DYSO 9 & 1690 & 88 & 157 & 293 & 138 & 253 & 262 & 303 & 190 & 133 \\
\hline DYSO9 & 1700 & 91 & 181 & 123 & 96 & 108 & 119 & 92 & 144 & 171 \\
\hline DYSO9 & 1710 & 151 & 130 & 143 & 153 & 113 & 168 & 161 & 214 & 176 \\
\hline DYSO9 & 1720 & 136 & 93 & 67 & 82 & 47 & 88 & 111 & 83 & 64 \\
\hline DYSO9 & 1730 & 79 & 73 & 86 & 97 & 75 & 85 & 91 & 83 & 101 \\
\hline DYSO 9 & 1740 & 164 & 267 & 188 & 94 & 74 & 198 & 117 & 143 & 94 \\
\hline DYSO 9 & 1750 & 66 & 65 & 50 & 61 & 61 & 66 & 158 & 73 & 131 \\
\hline DYSO 9 & 1760 & 139 & 60 & 86 & 90 & 70 & 85 & 99 & 81 & 124 \\
\hline DYSO 9 & 1770 & 65 & 49 & 74 & 120 & 56 & 73 & 79 & 68 & 71 \\
\hline DYSO 9 & 1780 & 122 & 181 & 194 & 170 & 215 & 133 & 116 & 145 & 154 \\
\hline DYSO9 & 1790 & 67 & 53 & 93 & 76 & 146 & 133 & 157 & 168 & 155 \\
\hline DYSO 9 & 1800 & 205 & 220 & 188 & 124 & 214 & 150 & 110 & 158 & 164 \\
\hline DYSO 09 & 1810 & 183 & 147 & 122 & 112 & 228 & 126 & 92 & 273 & 421 \\
\hline DYSO9 & 1820 & 220 & 122 & 153 & 142 & 189 & 152 & 217 & 270 & 280 \\
\hline DYSO 9 & 1830 & 287 & 287 & 228 & 316 & 238 & 213 & 213 & 240 & 189 \\
\hline DYSO9 & 1840 & 204 & 131 & 214 & 190 & 257 & 214 & 182 & 203 & 224 \\
\hline DYSO 0 & 1850 & 176 & 180 & 172 & 187 & 175 & 167 & 102 & 93 & 118 \\
\hline DYSO 9 & 1860 & 186 & 151 & 170 & 153 & 135 & 174 & 171 & 112 & 109 \\
\hline DYSO 09 & 1870 & 173 & 117 & 161 & 117 & 123 & 220 & 183 & 235 & 151 \\
\hline DYSO9 & 1880 & 175 & 212 & 229 & 214 & 125 & 189 & 175 & 140 & 113 \\
\hline DYSO 9 & 1890 & 171 & 145 & 155 & 125 & 123 & 80 & 177 & 218 & 140 \\
\hline DYSO 9 & 1900 & 113 & 169 & 197 & 187 & 172 & 150 & 164 & 160 & 196 \\
\hline DYSO 9 & 1910 & 104 & 139 & 195 & 181 & 181 & 277 & 303 & 272 & 144 \\
\hline DYS 09 & 1920 & 178 & 160 & 164 & 159 & 244 & 155 & 161 & 195 & 234 \\
\hline DYSO 09 & 1930 & 131 & 186 & 163 & 183 & 148 & 213 & 135 & 253 & 182 \\
\hline DYSO 9 & 1940 & 164 & 168 & 182 & 211 & 174 & 154 & 155 & 190 & 148 \\
\hline DYSO 9 & 1950 & 246 & 244 & 181 & 224 & 190 & 201 & 317 & 272 & 342 \\
\hline DYSO 9 & 1960 & 196 & 244 & 201 & 213 & 252 & 191 & 138 & 169 & 260 \\
\hline DYSO 9 & 1970 & 234 & 200 & 150 & 221 & 226 & 312 & 150 & 147 & 278 \\
\hline DYSO 09 & 1980 & 468 & 252 & 214 & 324 & 261 & 377 & 242 & 293 & 194 \\
\hline DYSO9 & 1990 & 320 & 189 & 243 & 324 & 205 & 190 & 228 & 201 & 48 \\
\hline
\end{tabular}




\section{Temporal Synchrony Analysis with Different Moving Window Sizes}

1) Ozark-Appalachian Forest Sites

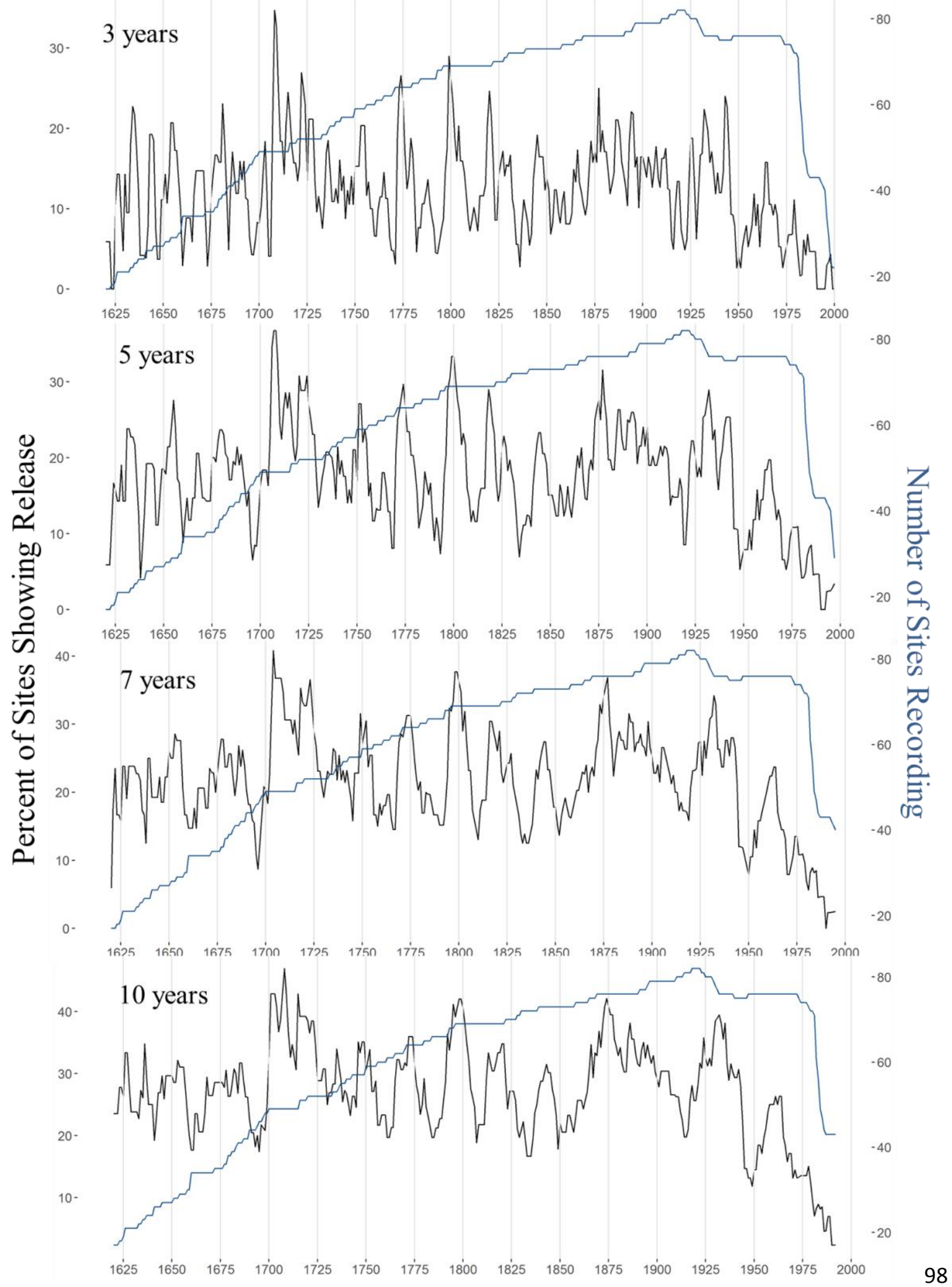




\section{2) Mixed Wood Shield Sites}

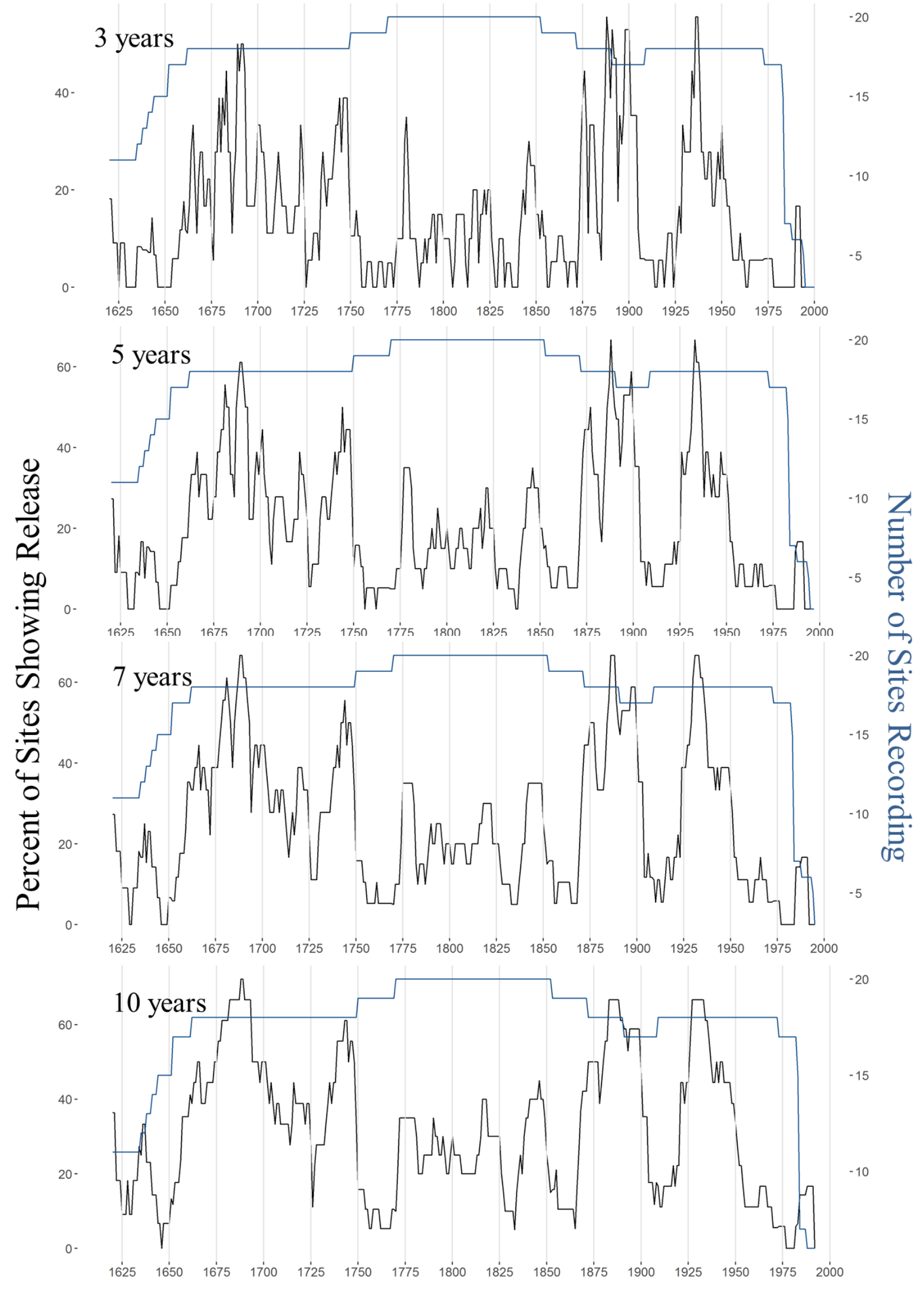




\section{3) Atlantic Highlands Sites}

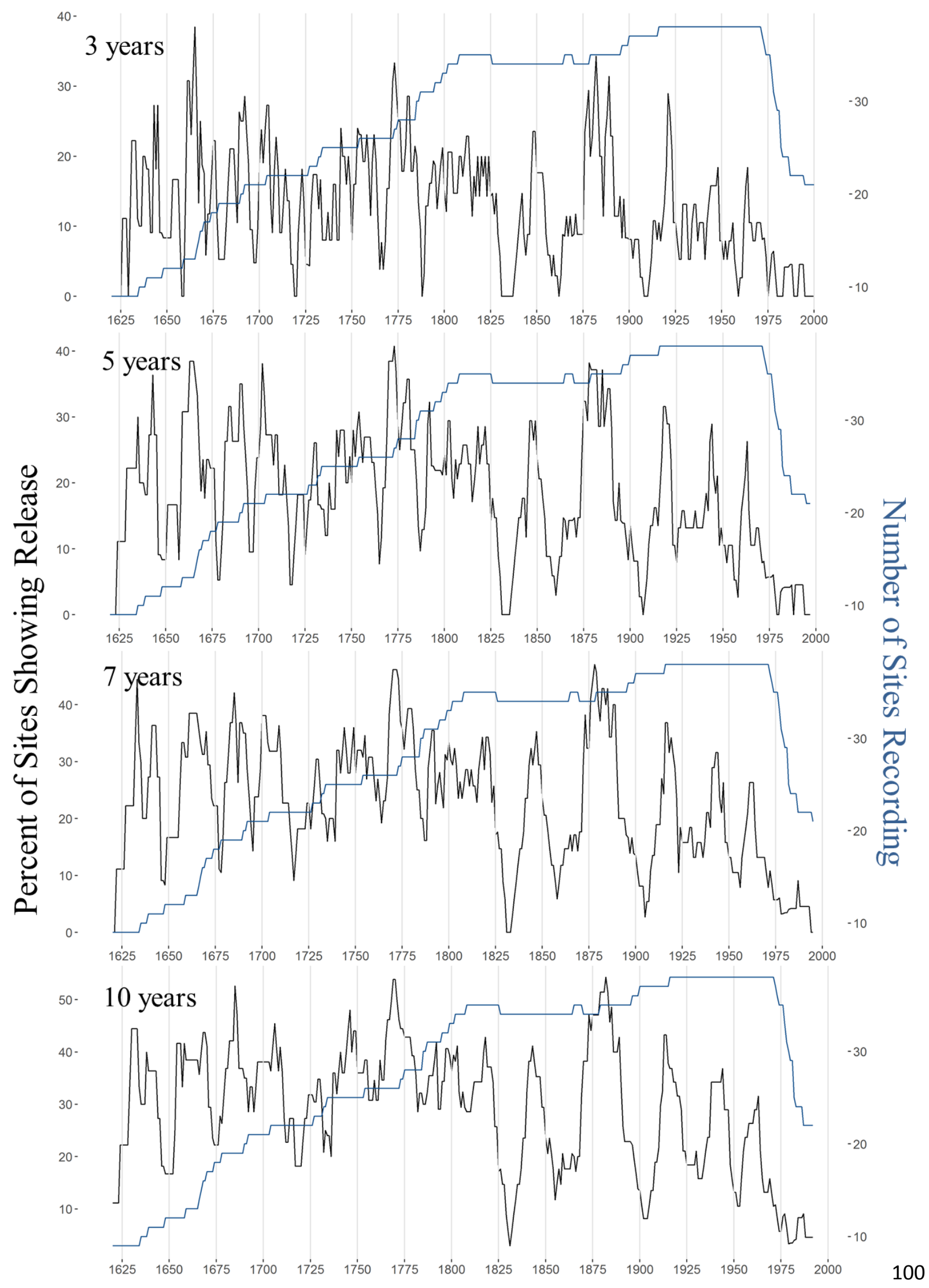


D. $\boldsymbol{R}$ Code Used for Disturbance Analysis. Comments and additional packages needed are as noted.

setwd(") \#Make sure to set your working directory before starting, as a11 downloaded files \# and output files will be saved to that folder

1ibrary(httr) \# used for download function cal1s GET(), content(), etc.

1ibrary (dplR)

library (TRADER)

library(tidyr)

library(dplyr)

library(tibble)

1ibrary(reshape2)

\#\#\#\# GENERATE 'filelist_selection' \#\#\#\#\#

\# This bit of code can be used whenever to generate a vector of sites of interest \#\# -- 'filetist_selection'

\#\# Especially useful if you don't already have a file with this included. Otherwise, it is \#\# unnecessary. Alternatively, you can generate this vector however you see fit.

ur1 <- "ftp://ftp.ncdc.noaa.gov/pub/data/pa1eo/treering/measurements/northamerica/usa/" \#for rw1 files

allfiles <- GET(ur1) \# equivalent of curl() function

getcontent <- content(a11Files, "text")

\# separate \& parse individual .rw1 files

fileList <- unlist(strsplit(getContent, "-rw-rw-r--|1rwxrwxrwx"))

filelist <- unlist(strsplit(fileList, "->"))

filelist <- gsub("^(.\{36\})", "", filelist)

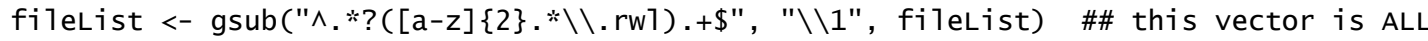
\# possible downloadable files from current ITRDB database (in the \# US, unless you change 'url')

\# SELECT state(s) of interest to download, create a vector of files \#\#other eastern states:

\# pa|me|vt|nh|ma|ct|ri|ny|pa|nj|de|md|oh|va|mi|in|tn|nc|ga|al|ms|wi|i1|sc filelist_Indexofselection <- grep("ky|wv", filelist) \# Insert states of interest here filelist_selection <- fileList[fileList_Indexofselection[1:1ength(fileList_Indexofselection)]]

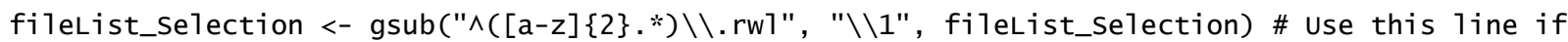
\# you want the vector to be just simple site names, not.rwl file names

\#\#\#\#\#\#\#\#\#\#\#\#\#\#\#\#\#\#\#\#\#\#\#\#\#\#\#\#\#\#\#\#\#\#\#\#\#\#\#\#\#\#\#\#\#\#\#\#\#\#\#\#\#\#\#\#\#\#\#\#\#\#\#\#\#\#\#\#\#\#\#\#\#\#\#\#\#

\#\#\#\# DOWNLOAD .RWL FILES \#\#\#\#\#

\# The following code downloads just the rwl files 1isted in 'filelist_selection'

\# If rwl files AND metadata need to be downloaded, use the code snippet starting at 1 ine 52 ur1 <- "ftp://ftp.ncdc.noaa.gov/pub/data/paleo/treering/measurements/northamerica/usa/"

for(i in 1:length(filelist_selection)) \{

$\operatorname{trycatch}(\{$

individualFilename <- paste0("N://R_Files/A11_ITRDB/", fileList_selection[i])

\# change filepath

download.file(paste0(url, filelist_selection[i],".rwl"), destfile=individualfileName) 

\}

\}, error=function(e)\{cat("ERROR :",conditionMessage (e), "\n")\})

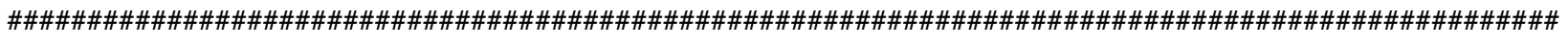

\#\#\#\# DOWNLOAD RWL AND METADATA FILES \#\#\#\#\#

\# This code wi11 download a11 rwl files and metadata files, and put the information into a flat

\# file

outputDf <- data.frame(NULL)

url <- "ftp://ftp.ncdc.noaa.gov/pub/data/paleo/treering/measurements/northamerica/usa/"

ur12 <- "ftp://ftp.ncdc.noaa.gov/pub/data/paleo/treering/measurements/correlation-stats/"

for(i in 1:1ength(filelist_selection)) \{

\# download selected files and associated metadata, read into dplr

\# the trycatch function allows the loop to keep running after encountering

\# an error. The problem file is skipped, and an error message printed

$\operatorname{trycatch}(\{$

\#.rw1 file details

individua1Filename <- paste0("N://R_Files/A11_ITRDB/", fileList_Selection[i],".rw1")

\# change filepath

down1oad.file(paste0(ur1, filelist_selection[i],".rw1"), destfile=individualFileName)

rawFile <- read.rw1 (paste0(fileList_Selection[i],".rw1"))

noRownames <- rownames_to_column(rawFile, var = "Years")

rawFilemelt <- melt(noRownames, id.vars = "Years", variable.name = "CoreID", na.rm = TRUE, value. name = "Ringwidths", factorsAsstrings $=$ TRUE)

\# Melt raw file to create flat file

\# extract metadata details using readLines and grep

metaFile <- paste0(fileList_selection[i],".txt")

download.file(paste0(ur12, fileList_Selection[i],".txt"), destfi1e=metafi1e)

metadata <- readLines (paste0(fileList_Selection[i],".txt"))

name <- metadata[grep("Site name", metadata)]

1ocation <- metadata[grep("Site 1ocation", metadata)]

species <- metadata[grep("Species information", metadata)]

latitude <- metadata[grep("Latitude", metadata)]

1ongitude <- metadata[grep("Longitude", metadata)]

startYr <- metadata[grep("Beginning year", metadata)]

endYr <- metadata[grep("Ending year", metadata)]

numDatedseries <- metadata[grep("Number dated series", metadata)]

siteID <- paste0("siteID : ",filelist_selection[i])

\# clean up, organize, and save all data in flat file

metadat <- c(siteID, name, location, species, 1atitude, 1ongitude, startYr, endYr, numDatedseries)

metadat <- as.data.frame (metadat, stringsAsFactors = FALSE)

metadat <- $\operatorname{separate}($ data $=$ metadat, $\operatorname{col}=$ metadat, into = c("variable", "value"), sep = ":",

convert $=$ TRUE)

metadat\$variable <- gsub("[[:blank:]]", "", metadat\$variable)

metadataTransform <- spread(metadat, variable, value)

metadataTransform $[1,3]<-$ gsub(" $(\wedge .+) \mathrm{N} "$, "\\1", metadataTransform $[1,3])$

\#fixing Lat (getting rid of "N")

metadataTransform $[1,4]<-$ gsub(" $(\wedge .+) W^{\prime}$, , "-\1", metadataTransform $\left.[1,4]\right)$

\#fixing long (getting rid of " $W "$ )

metadataTransform $[1,4]<-\operatorname{gsub}("[[$ :blank: $]]$ ", "", metadataTransform[1,4]) 


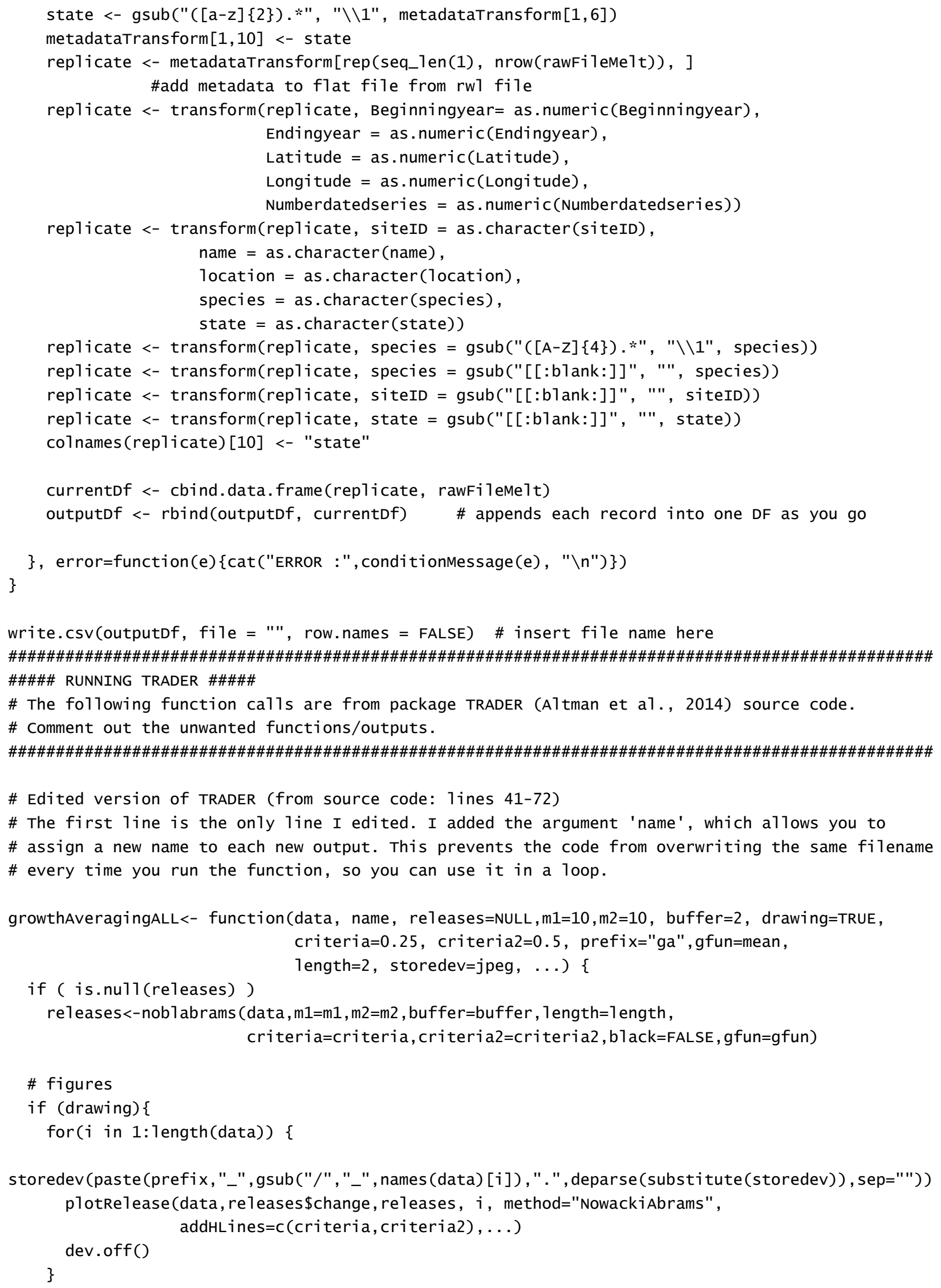




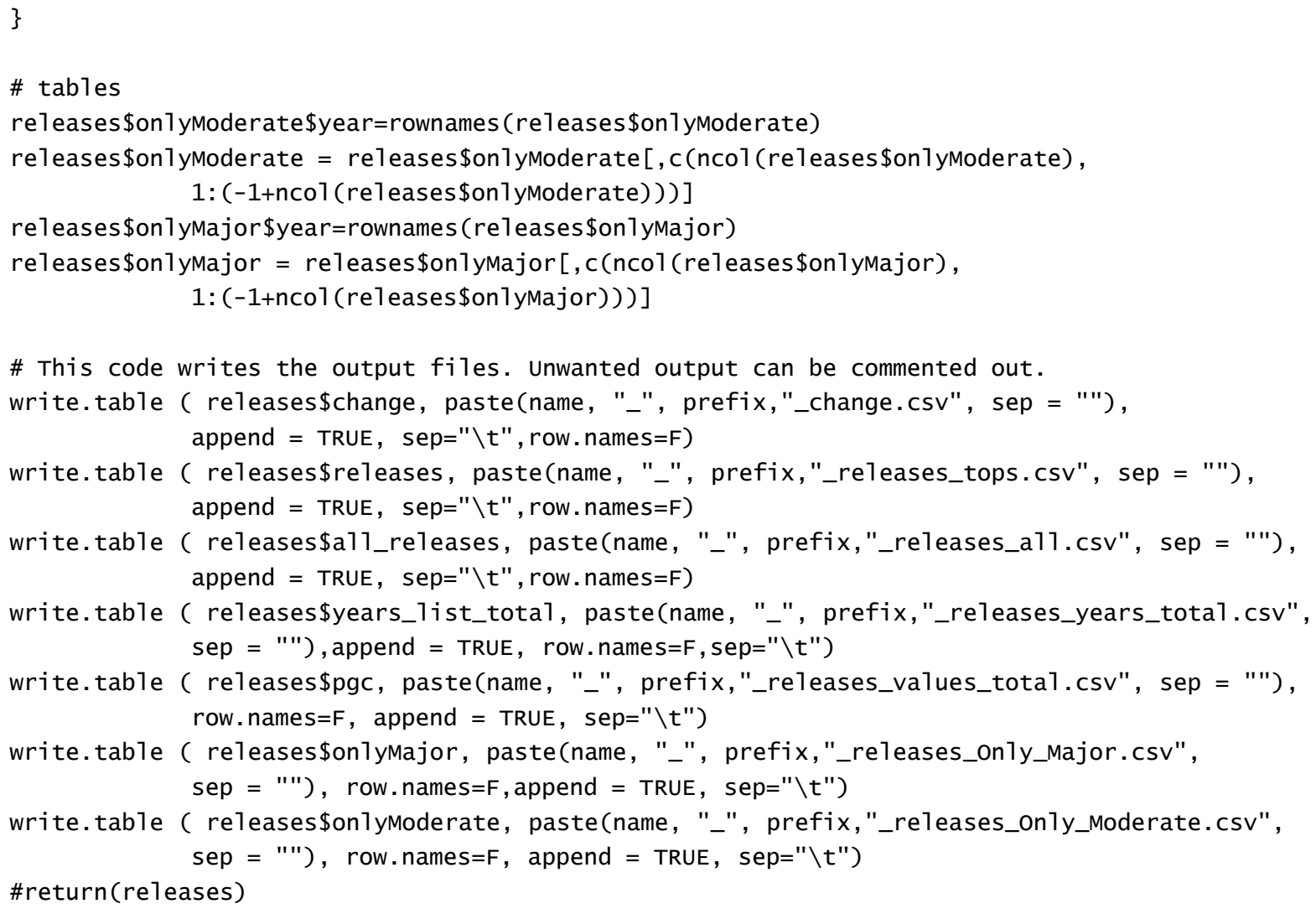




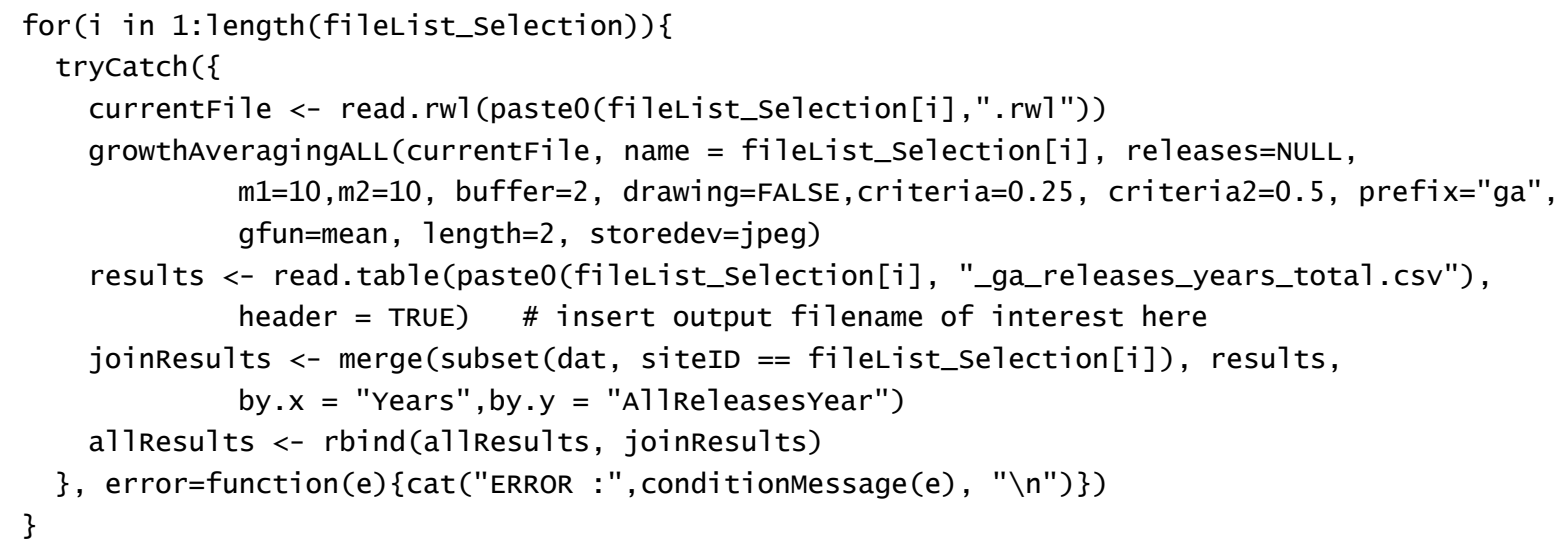




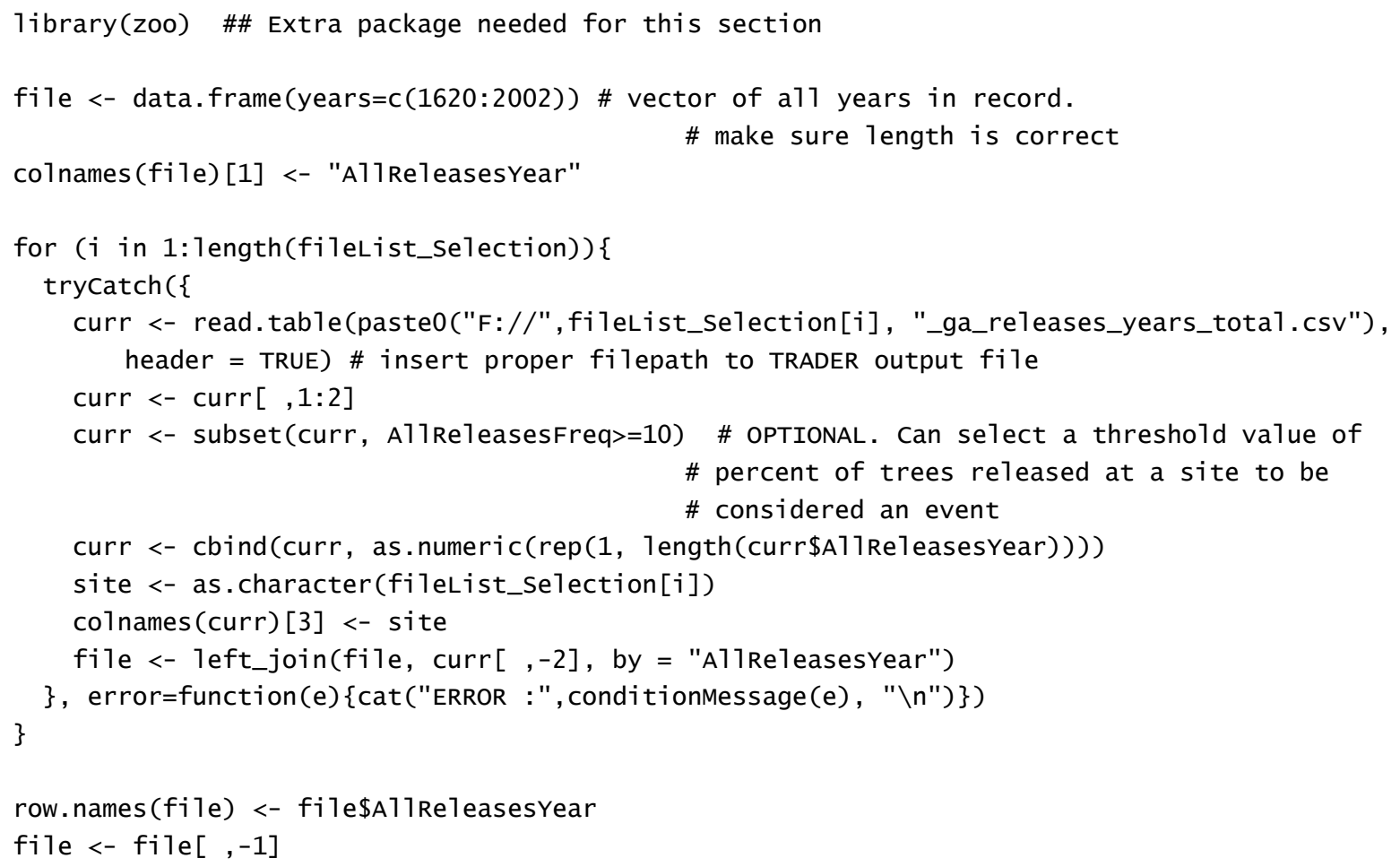


\#Calculate percent of sites showing release

MovingCount $\$$ PercRe $1<-$ MovingCount\$MovingSum/MovingCount $\$$ NumSitesRec $* 100$

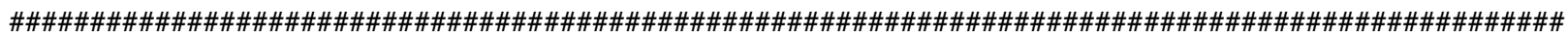

\#\#\#\#\# GENERATE PADDED DATAFRAME FOR K1D \#\#\#\#\#

\# These functions take a list of vectors of different lengths

\#\# and turn them into a data frame padded with NAS

\# (retrieved from: http://stackoverflow.com/questions/7196450/create-a-data-frame-of\#unequal-1engths)

na.pad <- function $(x, 1 e n)\{$

$x[1: 1$ en $]$

\}

makePaddedDataFrame <- function $(1, \ldots)\{$

maxlen <- $\max (\operatorname{sapply}(1,1$ ength))

data. frame (1apply (1, na.pad, 1en=max1en), ...)

\}

\# I used the above two functions to create a file in the correct format for

\# K1D (Gavin, 2010). That is, a file with each column composed of years

\# showing a release at a given site, one column for each site

\# Since al1 sites will have a different set of release years, the columns

\# wi11 be of different length...

\# This code uses TRADER output files ending in "_releases_years_total.csv"

rk $<-1$ ist ()

for ( $i$ in 1:1ength(filelist_selection)) \{

$\operatorname{trycatch}(\{$

curr <- read.table(paste0("F://",filelist_selection[i], "_ga_releases_years_total.csv"), header = TRUE) \# insert proper filepath to TRADER output file

curr $<-\operatorname{curr}[, 1: 2]$

curr <- subset(curr, AllReleasesfreq>=10) \# OPTIONAL. Can select a threshold value of

\# percent of trees released at a site to be considered an event

site <- as.character(fileList_selection[i])

curr <- c(site, $\operatorname{curr}[, 1])$

$\mathrm{rk}[[i]]<-$ curr

\} , error=function (e)\{cat("ERROR :", $\operatorname{conditionMessage}(e), " \backslash n ")\})$

\}

\#This portion takes the list created above and converts it into a data frame

rk <- rk[!sapply(rk,is.nu11)] \# removes any members of the 1ist that are nu11

\# (sites that had no releases over the threshold)

df <- makePaddedDataFrame(rk) \#\# use functions defined above (1ine 288-295)

df <- sapply(df, as.character)

$\operatorname{colnames}(d f)<-d f[1$,

df[is.na(df)] <- "" \#\# change NAs to "" blanks, so that K1D doesn't get confused

\# write to a .txt --insert correct filepath

write.table(df, "dataFork1D.txt", sep = "\t", eol = "\n", na = "", row. names = FALSE)

\# In order to actually run K1D, you will first have to open this txt file in excel

\# and add the correct first row (see Gavin [2010] for detai1s) 